\author{
UNIVERSIDADE DE SÃO PAULO \\ FACULDADE DE ECONOMIA, ADMINISTRAÇÃO E CONTABILIDADE \\ DEPARTAMENTO DE ECONOMIA \\ PROGRAMA DE PÓS-GRADUAÇÃO EM ECONOMIA
}

Sobre os Determinantes das Taxas de Juros dos

\title{
Títulos Soberanos
}

Um estudo em painel para os países emergentes

Victor Magalhães Cezarini

Orientador: Prof. Dra. Fabiana Fontes Rocha

São Paulo

2016 
Prof. Dr. Marco Antonio Zago

Reitor da Universidade de São Paulo

Prof. Dr. Adalberto Américo Fischmann

Diretor da Faculdade de Economia, Administração e Contabilidade

Prof. Dr. Hélio Nogueira da Cruz

Chefe do Departamento de Economia

Prof. Dr. Márcio Issao Nakane

Coordenador do Programa de Pós-Graduação em Economia 


\title{
Sobre os Determinantes das Taxas de Juros dos
}

\author{
Títulos Soberanos \\ Um estudo em Painel para os Países Emergentes
}

Dissertação apresentada ao Programa de Pós-Graduação em Economia do Departamento de Economia da Faculdade de Economia, Administração e Contabilidade da Universidade de São Paulo, como requisito parcial para a obtenção do título de Mestre em Ciências.

Orientador: Prof. Dra. Fabiana Fontes Rocha

Versão Corrigida

versão original disponível na Biblioteca da Faculdade de Economia, Administração e Contabilidade

São Paulo 
FICHA CATALOGRÁFICA

Elaborada pela Seção de Processamento Técnico do SBD/FEA/USP

Cezarini, Victor Magalhães

Sobre os determinantes das taxas de juros dos títulos soberanos: um estudo em painel para os países emergentes / Victor Magalhães Cezarini. - São Paulo, 2016.

$135 \mathrm{p}$

Dissertação (Mestrado) - Universidade de São Paulo, 2016.

Orientador: Fabiana Fontes Rocha.

1. Taxa de juros 2. Política fiscal 3. Fundamentos internos 4. Fatores externos I. Universidade de São Paulo. Faculdade de Economia, Administração e Contabilidade. II. Título.

CDD -332.8 
À minha família 



\section{Agradecimentos}

A lista de pessoas a quem devo agradecer é longa. O tempo necessário para a conclusão deste trabalho não foi de apenas um ano e meio, mas sim de mais de 26 anos. Durante todo esse período foram diversas pessoas que me ajudaram e contribuíram na minha trajetória.

A minha família teve um papel de suma importância. Meu pai Rogério e minha mãe Sandra foram verdadeiros guias na minha vida e sempre me apoiaram nas minhas escolhas, sem eles, certamente, eu não teria chegado aonde cheguei. Meus irmãos Priscila e Marcelo sempre foram grandes companheiros, sempre me ajudaram e me apoiaram, guardo grande admiração pelos dois. Meus avós, tias e tios, primas e primos sempre estiveram do meu lado e sempre me ajudaram. Eu tive muita sorte de nascer na família em que nasci.

Gostaria também de agradecer à minha namorada Denise, que me ajudou nos momentos difíceis, sempre foi amiga e companheira, e colaborou com o desenvolvimento deste trabalho.

Gostaria de agradecer a todos meus amigos, principalmente aos belorizontinos que mudaram para São Paulo, tornando a minha vida nessa nova cidade muito mais fácil, alegre e divertida. E aos colegas de mestrado da FEA, pessoas incríveis que vieram de toda parte do Brasil para fazer um curso sério, árduo e desafiador, são pessoas que tive o orgulho de conhecer e que jamais serão esquecidas. Em especial a meu grande amigo Paulo, que me ajudou na revisão deste trabalho e contribuiu com importantes ideias.

Gostaria de agradecer a toda a equipe de colaboradores e professores da FEA. O curso de mestrado que fiz foi excelente e isso se deve a dedicação e a capacidade técnica de todos os responsáveis. Gostaria de agradecer em especial a minha orientadora Fabiana Rocha e aos professores Siegfried Bender e Bruno Giovannetti que colaboraram com críticas construtivas na minha qualificação e ajudaram a transformar para melhor este trabalho.

Por fim, agradeço à Fundação de Amparo a Pesquisa do Estado de São Paulo (FAPESP) pelo apoio financeiro durante boa parte do período de pesquisa (referente 
ao processo 2015/10358-5). Ressalto que as opiniões, hipóteses, e conclusões expressas neste material são de responsabilidade do autor e não necessariamente refletem a visão da FAPESP. 
"Se (reduzir os juros) fosse uma questão administrativa, uma decisão do Banco Central, eu juro que teria feito." 



\section{Resumo}

O objetivo desse trabalho é analisar a influência que fundamentos internos e fatores externos exercem sobre a taxa de juros nominal dos títulos soberanos de longo prazo nos países emergentes. A base de dados engloba 13 países ao longo de 33 trimestres entre 2006 e 2014. A metodologia utilizada aborda as técnicas econométricas mais recentes para tratar dados macroeconômicos. O modelo estimado é o Pooled Mean Group desenvolvido por Pesaran, Shin e Smith (1999). O modelo consegue separar as variáveis que afetam o nível de equilíbrio da taxa de juros das que exercem efeito apenas no curto prazo. Na melhor especificação apresentada, os resultados indicam que as variáveis que causam flutuações de curto prazo na taxa de juros dos países emergentes são a taxa de juros livre de risco $(+0,3)$, a taxa de curto prazo $(+0,4)$ e o déficit do governo americano $(+0,1)$. Já as variáveis que afetam o nível de equilíbrio são a taxa de juros livre de risco $(+0,5)$, a aversão ao risco dos investidores $(+0,1)$, o saldo em conta corrente $(-0,3)$, a inflação $(+0,1)$, a abertura econômica $(-0,04)$ e a dívida bruta (efeito positivo não linear). Por fim, ao analisar exclusivamente o caso brasileiro, nosso modelo indica que se o país tivesse mantido os fundamentos internos em linha com a média dos outros emergentes desde o final de 2006, o Brasil iria chegar ao final de 2014 com uma taxa de juros nominal de longo prazo de $6,1 \%, 6$ p.p. abaixo do valor efetivamente observado que foi de $12,1 \%$.

Palavras-chaves: Taxa de Juros, Política Fiscal, Fundamentos Internos, Fatores Externos, Raiz Unitária em Painel, Cointegração em Painel. 


\section{Abstract}

The aim of this study is to analyze the influence that internal fundamentals and external factors have on long-term sovereign bond yields in emerging markets. The database covers 13 countries over 33 quarters between 2006 and 2014. The methodology addresses the latest techniques to deal with macro panels, such as panel unit root and panel cointegration tests. The estimated model is the Pooled Mean Group developed by Pesaran, Shin e Smith (1999). This model can separate the variables that affect the interest rate equilibrium from the ones that only have an effect in the short-run. In the best specification presented, the results indicates that in the short-run the variables that affects the interest rates in emerging markets are the risk free interest rate $(+0.3)$, the short term interest rate $(+0.4)$ and the American government deficit $(+0.1)$. The variables that affects the equilibrium level are the risk free interest rate $(+0.5)$, risk aversion $(+0.1)$, current account balance $(-0.3)$, inflation $(+0.1)$, trade openness (-0.04) and gross debt (non-linear positive effect). Finally, by examining only the Brazilian case, our model indicates that if the country had maintained the internal fundamentals in line with the average of other emerging markets since the end of 2006, Brazil would reach the end of 2014 with a long-term interest rate of $6.1 \%, 6$ p.p. below the actual value of $12.1 \%$.

Key-words: Sovereign Bond Yields, Fiscal Policy, Internal Fundamentals, External Factors, Panel Unit Root, Panel Cointegration. 


\section{Lista de ilustrações}

Figura 1 - Dívida Bruta . . . . . . . . . . . . . . . . 39

Figura 2 - Superávit Nominal . . . . . . . . . . . . . . . . 40

Figura 3 - Abertura Econômica . . . . . . . . . . . . . . . . . . 41

Figura 4 - Saldo em Conta Corrente . . . . . . . . . . . . . . . . 41

Figura 5 - Crescimento do PIB . . . . . . . . . . . . 42

Figura 6 - Inflação . . . . . . . . . . . . . . . . . . . . . . 42

Figura 7 - Taxa de Juros Brasileira . . . . . . . . . . . . . . . . . 43

Figura 8 - Taxa de Juros de Longo Prazo . . . . . . . . . . . . . . . . . . . 44

Figura 9 - Juros e Fundamentos Internos (1) . . . . . . . . . . . . . 45

Figura 10 - Juros e Fundamentos Internos $(2) \ldots \ldots$. . . . . . . . . . . . 46

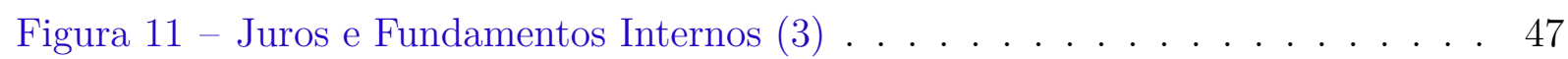

Figura 12 - Taxas de Juros e Aversão ao Risco . . . . . . . . . . . . . . . . . . . . 49

Figura 13 - Valores Previstos vs Observados $1 \ldots \ldots$. . . . . . . . . 70

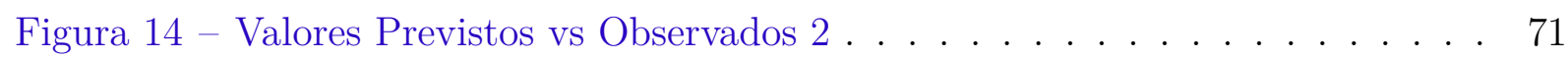

Figura 15 - Valores Previstos vs Observados $3 \ldots \ldots$. . . . . . . . . . . . 72

Figura 16 - Valores Previstos vs Observados $4 \ldots \ldots$. . . . . . . . . . . 73

Figura 17 - Valores Previstos vs Observados $5 \ldots \ldots$. . . . . . . . . . . . 74

Figura 18 - Brasil Comparativo - Juros Nominal de Longo Prazo . . . . . . . . . . 77

Figura 19 - Brasil Comparativo - Inflação . . . . . . . . . . . . . . . . . . 77

Figura 20 - Brasil Comparativo - Saldo em Conta Corrente . . . . . . . . . . . . . 78

Figura 21 - Brasil Comparativo - Abertura Econômica . . . . . . . . . . . . . 78

Figura 22 - Brasil Comparativo - Dívida Bruta . . . . . . . . . . . . . . . 79

Figura 23 - Brasil Estimado - Juros Nominal de Longo Prazo . . . . . . . . . . . . 80 


\section{Lista de tabelas}

Tabela 1 - Superávit Nominal como porcentagem do PIB $(\%) \ldots \ldots$. . . . . . 18

Tabela 2 - Taxa de Juros dos Títulos Soberanos com vencimento em 10 anos (\%) 19

Tabela 3 - Variável Dependente: Taxa de Juros Real ou Nominal . . . . . . . . . . 29

Tabela 4 - Variável Dependente: Taxa de Juros Real . . . . . . . . . . . . . . 30

Tabela 5 - Variável Dependente: Taxa de Juros Nominal . . . . . . . . . . . . . 30

Tabela 6 - Correlação entre a taxa de juros interna e o spread da dívida externa $2006 \mathrm{Q} 4$ a $2014 \mathrm{Q} 4 \ldots \ldots \ldots \ldots \ldots$

Tabela 7 - Variável Dependente: Spread da Dívida Externa . . . . . . . . . . . . 34

Tabela 8 - Teste de Dependência Cross Section . . . . . . . . . . . 56

Tabela 9 - Testes de Raiz Unitária Segunda Geração . . . . . . . . . . . . . . 58

Tabela 10 - Testes de Raiz Unitária Primeira Geração . . . . . . . . . . . . . . . 58

Tabela 11 - Resultados Estimados - Pooled Mean Group . . . . . . . . . . . . . . 63

Tabela 12 - Testes de Cointegração de Westerlund . . . . . . . . . . . . . . . 63

Tabela 13 - Resultados Estimados - Pooled Mean Group . . . . . . . . . . . . . . . 66

Tabela 14 - Testes de Cointegração de Westerlund . . . . . . . . . . . . . . . . 66

Tabela 15 - Resultados Estimados - Pooled Mean Group . . . . . . . . . . . . . . 68

Tabela 16 - Testes de Cointegração de Westerlund . . . . . . . . . . . . . . . 68

Tabela 17 - Testes de Raiz Unitária Univarido Augmented Dickey Fuller (Parte 1)

P-Valor .......................... 106

Tabela 18 - Testes de Raiz Unitária Univarido Augmented Dickey Fuller (Parte 2)

P-Valor ........................... 107

Tabela 19 - Testes de Raiz Unitária Univarido Augmented Dickey Fuller (Parte 3)

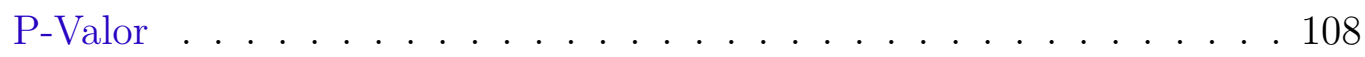

Tabela 20 - Resultados Prévios - Apenas Fundamentos Internos (1) . . . . . . . 110

Tabela 21 - Resultados Prévios - Apenas Fundamentos Internos (2) . . . . . . . 110

Tabela 22 - Resultados Prévios - Fatores Externos: Aversão ao Risco e Políticas

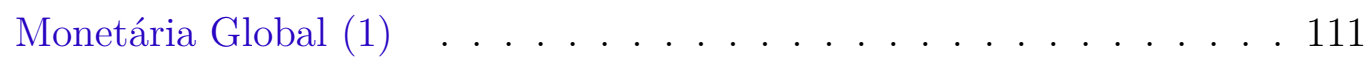


Tabela 23 - Resultados Prévios - Fatores Externos: Aversão ao Risco e Políticas Monetária Global (2) . . . . . . . . . . . . . . . . . 112

Tabela 24 - Resultados Prévios - Fatores Externos: Aversão ao Risco, Políticas Monetária e Fiscal Globais (1) . . . . . . . . . . . . . . . . . . 112

Tabela 25 - Resultados Prévios - Fatores Externos: Aversão ao Risco, Políticas Monetária e Fiscal Globais (2) . . . . . . . . . . . . . 113

Tabela 26 - Resultados por País - Apenas Fundamentos Internos . . . . . . . . . . 115

Tabela 27 - Resultados por País - Apenas Fundamentos Internos (continuação) . 116

Tabela 28 - Resultados por País - Fatores Externos: Aversão ao Risco e Política Monetária Global . . . . . . . . . . . . . . . . . 117

Tabela 29 - Resultados por País - Fatores Externos: Aversão ao Risco e Política Monetária Global (continuação) ..........118

Tabela 30 - Resultados por País - Fatores Externos: Aversão ao Risco e Política Monetária Global (continuação) . . . . . . . . . . . . . . . . . 119

Tabela 31 - Resultados por País - Fatores Externos: Aversão ao Risco, Políticas Monetária e Fiscal Globais . . . . . . . . . . . . . . . . . 120

Tabela 33 - Resultados por País- Fatores Externos: Aversão ao Risco, Políticas Monetária e Fiscal Globais (continuação)

Tabela 35 - Resultados por País - Fatores Externos: Aversão ao Risco, Políticas Monetária e Fiscal Globais (continuação) . . . . . . . . . . . . . . . 122

Tabela 37 - Resultados Estimados - Pooled Mean Group . . . . . . . . . . . . . . . 123

Tabela 38 - Resultados Estimados - Pooled Mean Group . . . . . . . . . . . . . . . 123

Tabela 39 - Taxas de Juros de Longo Prazo . . . . . . . . . . . . . . . . . . . 126

Tabela 40 - Dívida Bruta . . . . . . . . . . . . . . . . . 127

Tabela 41 - Superávit Nominal . . . . . . . . . . . . . . . . . . 128

Tabela 42 - Saldo em Conta Corrente . . . . . . . . . . . . . . . . . . . 129

Tabela 43 - Taxa de Juros de Curto Prazo . . . . . . . . . . . . . . . . . . . . . 130

Tabela 44 - Inflação . . . . . . . . . . . . . . . . . . . . . . . . . . . 131

Tabela 45 - Exportações . . . . . . . . . . . . . . . . . . . . . . . 132 
Tabela 46 - Importações . . . . . . . . . . . . . . . . . . . . . . . 133

Tabela 47 - PIB Nominal . . . . . . . . . . . . . . . . 134

Tabela 48 - PIB Real . . . . . . . . . . . . . . . . . . . . 135

Tabela 49 - Fatores Externos . . . . . . . . . . . . . . . . 135 


\section{Sumário}

Lista de ilustrações . . . . . . . . . . . . . . . . . . 10

Lista de tabelas . . . . . . . . . . . . . . . 11

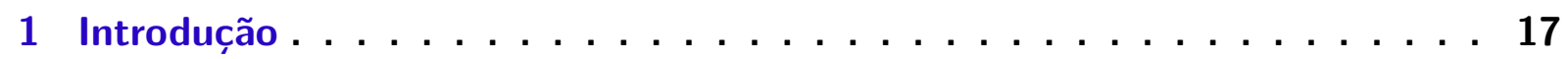

2 Literatura . . . . . . . . . . . . . . . 23

3 Dados . . . . . . . . . . . . . . . . . . 37

3.1 Descrição dos Dados . . . . . . . . . . . . . . . . . . . . 37

3.2 Estatísticas Descritivas . . . . . . . . . . . . . . . . 39

4 Metodologia . . . . . . . . . . . . . . . . 51

5 Resultados . . . . . . . . . . . . . . . . . . . 55

5.1 Teste de Dependência Cross Section . . . . . . . . . . . . . . . . 55

5.2 Testes de Raiz Unitária . . . . . . . . . . . . . . . . . . . . 57

5.3 Cointegração e Estimação dos Modelos … . . . . . . . . . . . 60

5.3 .1 Apenas Fundamentos Internos . . . . . . . . . . . . . 63

5.3.2 Fatores Externos: Aversão ao Risco e Política Monetária Global . . 65

5.3.3 Fatores Externos: Aversão ao Risco, Políticas Monetária e Fiscal

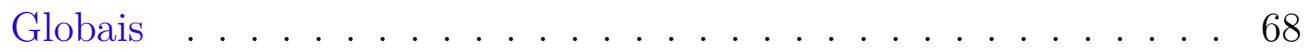

6 o Caso Brasileiro . . . . . . . . . . . . . . . 77

7 Conclusão . . . . . . . . . . . . . . . . . . . 83

Referências . . . . . . . . . . . . . . . . . 85

8 Apêndice A . . . . . . . . . . . . . . 89

8.1 Teste de Dependência Cross Section . . . . . . . . . . . . . . . . . 89

8.2 Testes de Raiz Unitária em Painel . . . . . . . . . . . . . . . . . . 90

8.2.1 Testes de Primeira Geração _ . . . . . . . . . . . . . . 90

8.2.2 Testes de Segunda Geração . . . . . . . . . . . . . . . . . . 94

8.3 Pooled Mean Group . . . . . . . . . . . . . . . . . . . . . 99

8.4 Testes de Cointegração . . . . . . . . . . . . . . . . . . . . . . . . . 101

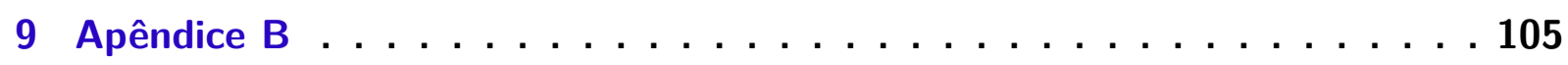


10 Apêndice C . . . . . . . . . . . . . . . . . . . . 109

11 Apêndice D . . . . . . . . . . . . . . . . . . 115

12 Apêndice E . . . . . . . . . . . . . . . . . . . 123

13 Apêndice $F \ldots \ldots \ldots \ldots$ 


\section{Introdução}

Compreender o papel que a política fiscal exerce sobre a taxa de juros dos títulos soberanos é um tema de extrema importância no campo econômico. A primeira década do século XXI foi marcada por uma elevada liquidez nos mercados mundiais e substancial crescimento dos mercados emergentes, tal situação econômica permitiu a muitos governos aumentarem suas despesas sem comprometer a situação fiscal. O cenário começou a mudar com a crise financeira de 2008. Nos anos seguintes à crise, o crescimento da economia mundial reduziu-se significativamente e os países que não se adaptaram mais rapidamente a essa nova situação viram suas receitas estagnarem enquanto suas despesas continuavam a crescer, criando um buraco fiscal e levantando dúvidas em relação a sustentabilidade de suas finanças.

A teoria sugere que uma situação fiscal mais frágil, com maiores dívidas e maiores déficits, deveria exercer pressão positiva no nível taxas de juros. Leal (2011) descreve de forma bastante clara três canais pelos quais esse efeito pode ocorrer:

O primeiro canal ocorre via o efeito crowding out, no qual o aumento do consumo do governo exerce pressão sobre os recursos disponíveis na economia e diminui a disponibilidade de recursos disponíveis ao setor privado. Se esse aumento da demanda do governo não for compensado por um aumento da poupança do setor privado ocorrerá um desequilíbrio entre a poupança total e o investimento, pressionando para cima as taxas de juros. Caso o aumento do consumo do governo seja compensado em igual magnitude pelo aumento da poupança privada, ocorre o efeito chamado de Equivalência Ricardiana. Para que isso ocorra é necessário que os agentes econômicos sejam racionais e forward looking. Qualquer déficit público é visto como um imposto a ser cobrado no futuro, portanto, os agentes reduziriam seu consumo presente aumentando sua poupança, já se preparando para o pagamento do futuro imposto. Supondo que a Equivalência Ricardiana seja válida, as taxas de juros não devem apresentar aumento com a elevação dos gastos públicos.

O segundo canal se refere ao risco de default na dívida pública. Dívida e déficits fiscais elevados podem indicar uma trajetória insustentável das finanças do governo. Se 
este for o caso, os agentes podem ficar relutantes em comprar títulos públicos exigindo um prêmio maior devido ao aumento no risco de calote, o que resulta em uma maior taxa de juros necessária para financiar a dívida pública. Contudo, se o governo consegue aumentar a dívida e/ou o déficit e ao mesmo tempo convencer o mercado de que os futuros resultados fiscais serão positivos e suficientes para manter a dívida em uma trajetória sustentável, a piora fiscal momentânea pode não resultar em aumento dos juros.

O terceiro canal é similar ao segundo e se refere ao risco de monetização da dívida pública. Governos que apresentam elevados níveis de endividamento e não conseguem colocar as finanças em uma trajetória sustentável podem ficar tentados a recorrer a políticas inflacionárias para diminuir o valor real da dívida. Se este for o caso, e os agentes enxergarem que a piora fiscal será acompanhada de um aumento da inflação futura, será exigido uma maior taxa nominal de juros para financiar o governo.

Portanto, dado que a teoria não nos permite obter uma única e assertiva resposta, é interessante avaliar empiricamente se a piora na situação fiscal nos últimos anos refletiram em maior taxa de juros ou não. Como mostra a tabela 1, alguns países emergentes após a crise financeira internacional apresentaram piora significativa em suas finanças, enquanto outros conseguiram manter estável sua situação fiscal.

Tabela 1 - Superávit Nominal como porcentagem do PIB (\%)

\begin{tabular}{lccc}
\hline \hline & $2006-2008$ & $2009-2011$ & $2012-2014$ \\
\hline \hline Brazil & -2.58 & -2.76 & -3.03 \\
Bulgaria & 2.61 & -3.30 & -1.63 \\
Chile & 7.46 & -0.61 & -0.27 \\
Hungary & -5.55 & -4.01 & -3.14 \\
Malaysia & -4.12 & -5.36 & -4.28 \\
Russia & 6.05 & -2.73 & -0.36 \\
South Korea & 2.70 & -0.11 & 0.82 \\
\hline \hline
\end{tabular}

O comportamento da taxa de juros dos títulos soberanos com vencimento de dez anos é descrito na tabela 2. A relação entre o déficit fiscal e os juros não aparenta ser muito clara com base na análise dessas duas tabelas. Alguns países apresentaram piora fiscal e aumento nos juros, enquanto outros apresentaram redução em suas taxas de juros mesmo com o aumento do déficit, o que indica que outros fatores devem ser levados em 
conta para melhor compreender o comportamento dessa variável.

Tabela 2 - Taxa de Juros dos Títulos Soberanos com vencimento em 10 anos (\%)

\begin{tabular}{lccc}
\hline \hline & $2006-2008$ & $2009-2011$ & $2012-2014$ \\
\hline \hline Brazil & 12.94 & 12.41 & 11.17 \\
Bulgaria & 5.16 & 6.26 & 3.82 \\
Chile & 6.44 & 6.01 & 5.17 \\
Hungary & 7.45 & 8.01 & 6.21 \\
Malaysia & 3.90 & 3.98 & 3.75 \\
Russia & 6.76 & 8.85 & 8.23 \\
South Korea & 5.40 & 4.71 & 3.30 \\
\hline \hline
\end{tabular}

O juro representa o preço do dinheiro no tempo. Uma taxa de juros menor aumenta o valor das rendas futuras, enquanto uma taxa de juros maior diminui o valor dos recebimentos futuros. Uma economia que possui juros menores torna o investimento mais atrativo e aumenta as oportunidades de crescimento. Portanto, é de extrema importância compreender quais são os determinantes da taxa de juros e quais políticas podem ser realizadas com o intuito de reduzi-la.

A literatura sobre como a política fiscal afeta a taxa de juros é extensa. Um dos trabalhos pioneiros é Evans (1985), no qual se realiza um estudo sobre o comportamento da taxa de juros americana em períodos de piora substancial das finanças públicas.

Em relação aos trabalhos mais recentes, talvez o mais importante seja Ardagna, Caselli e Lane (2007), neste estudo se analisa o comportamento da taxa de juros em diversos países. Os autores concluem que vários fundamentos internos do próprio país exercem efeito sobre sua taxa de juros, como déficit nominal, dívida pública, inflação e crescimento do PIB. Porém, fatores externos ao país também exercem influência, como o nível de endividamento mundial e crescimento da economia mundial. Esses resultados mostram que os governos podem adotar políticas corretas para reduzir sua taxa de juros, contudo, a redução também dependerá de fatores externos que em geral não podem ser controlados.

A discussão sobre fatores externos versus fundamentos internos não é tão explorada nessa literatura. Mesmo após Ardagna, Caselli e Lane (2007) diversos estudos importantes 
praticamente ignoram essa questão, como, por exemplo, Baldacci e Kumar (2010). Além disso, mais raros ainda são os estudos que tentam analisar o impacto que os fatores externos exercem sobre as taxas de juros nos países emergentes.

A importância que o fatores externos exercem sobre as economias emergentes é bastante explorada em uma literatura semelhante, que se refere ao spread da dívida externa. Embora seja um tópico diferente, a contribuição dessa literatura não deve ser ignorada para o nosso propósito.

O presente trabalho possui três objetivos: (i) Verificar quais foram os principais determinantes das taxas de juros dos títulos soberanos de longo prazo nos países emergentes nos anos de 2006 a 2014, compreendendo e comparando o papel dos fundamentos internos em relação aos fatores externos, (ii) analisar de forma individual o caso brasileiro para verificar por que o país possui uma taxa de juros tão mais elevada que a média mundial, e (iii) introduzir uma nova metodologia econométrica que foi pouco utilizada até a presente data, bem como mostrar as falhas nas metodologias utilizadas nos trabalhos anteriores.

O problema dos altos juros brasileiros provoca calorosos debates entre os economistas. Embora alguns estudos tenham sido feitos sobre o tema, como Arida, Bacha e Lara-Resende (2004), Franco et al. (2011), Segura-Ubiergo (2012) e Gonçalves, Holland e Spacov (2007) a questão permanece em aberto. Portanto, é oportuno abordarmos novamente esse tema com o objetivo de trazer respostas mais claras para essa obscura questão.

Consideramos que este trabalho traz boas contribuições para a literatura, visto que praticamente nenhum estudo feito até hoje (a que tivemos acesso) conseguiu reunir dados de taxas de juros de longo prazo para países emergentes em base tão ampla. Além disso, essa dissertação irá abordar as técnicas econométricas mais avançadas que se referem aos testes de raiz unitária em painel e cointegraçao em painel, realizando todos os passos necessários para trabalhar com Time-Series Cross Section Data (TSCS), passos estes que muitas vezes são negligenciados na literatura.

Esta dissertação está dividida em seis capítulos além dessa introdução, o capítulo 2 
realiza uma ampla revisão da literatura, o 3 descreve a base de dados que será utilizada, o 4 descreve a metodologia utilizada, o 5 reporta os principais resultados obtidos no estudo, o 6 analisa de forma individual o caso brasileiro, verificando se o modelo utilizado consegue explicar a elevada taxa de juros do país e, por fim, o 7 conclui esta dissertação. 



\section{Literatura}

A literatura sobre como a política fiscal afeta a taxa de juros é bastante extensa e pode ser dividida em dois grandes grupos. O primeiro consiste em análises single country e o segundo em análises de painel de países. O primeiro grupo de estudos é mais antigo e um dos primeiros trabalhos sobre o tema foi Evans (1985). Quanto ao segundo grupo, a maior parte dos trabalhos foram realizados apenas na década de 2000, embora um dos pioneiros tenha sido Orr, Edey e Kennedy (1995). A relativa demora em análises sobre efeitos da política fiscal nas taxas de juros envolvendo painel de países deve-se principalmente à dificuldade em obtenção de dados.

O trabalho de Evans (1985) é provavelmente o primeiro a analisar o efeito que o déficit público exerce sobre a taxa de juros. Em um estudo para a economia americana ele analisa os três períodos onde houve um forte aumento do déficit: a Guerra Civil, a Primeira Guerra Mundial e a Segunda Guerra Mundial. Em todos estes períodos Evans mostra que apesar de uma forte deterioração nas finanças do governo, a taxa de juros se manteve estável, indicando ausência de correlação entre déficit e juros.

Outro estudo pioneiro no tema foi Wachtel e Young (1987) em que os autores analisaram o impacto do déficit nos juros por meio da metodologia de estudo de eventos. Utilizando dados da economia americana, foi avaliado se houve uma variação significativa na taxa de juros quando se divulgavam novas projeções para o déficit do governo. Seus resultados indicam que quando novas previsões sobre as finanças públicas são divulgadas as taxas de juros aumentam se essa previsão indica um déficit maior que o anteriormente previsto e diminuem se as novas previsões indicam um déficit menor que o anteriormente previsto.

No estudo de Canzoneri, Cumby e Diba (2002) os autores ressaltam a importância de trabalhar com a taxa de juros de longo prazo ao invés da de curto prazo. Esta última é muito mais vulnerável às políticas dos Bancos Centrais e pode ser manipulada mais facilmente, levando a não refletir o valor de equilíbrio dado pelos fundamentos da economia. No estudo os autores não trabalham com a taxa de juros em si, mas com a diferença entre 
os juros pagos por um Treasury Bill de cinco anos (e também de dez anos) em relação aos juros pagos por um de três meses. Os resultados indicam que quanto maior é o déficit orçamentário maior a diferença entre a taxa de juros dos títulos de longo prazo com relação aos de curto prazo. Seus resultados também indicam que a estimativa de déficit possui influência até mais significativa do que o próprio déficit realizado.

Em um resumo da literatura feito por Gale (2003) utilizando apenas estudos single country, o autor mostra que a literatura até então apresentava resultados inconclusivos. Dos 58 estudos feitos até a data, 28 apresentavam efeitos predominantemente positivos do déficit na taxa de juros, 19 apresentavam efeitos predominantemente negativo e 11 apresentavam resultados mistos. Conclusões semelhantes também foram obtidas em outros resumos mais antigos como Barth (1989) e Elmendorf e Mankiw (1999). Contudo, Gale (2003) mostra que ao selecionar apenas estudos que envolviam expectativas futuras de déficits dos 17 feitos até a época, 12 achavam efeito positivo, 4 achavam efeitos mistos e apenas 1 achava efeito negativo, mostrando resultados bem mais conclusivos do que os estudos que envolviam apenas o déficit corrente. De fato, Feldstein (1986) já tinha observado que "É errado relacionar a taxa de juros com o déficit fiscal corrente sem levar em consideração os déficits futuros esperados. É importante notar que praticamente nenhuma das análises feitas até então a respeito do efeito dos déficits sobre as taxas de juros incluíram uma medida de déficit futuro esperado." 1

Estudos em painel sobre o efeito da política fiscal na taxa de juros de longo prazo começam com Orr, Edey e Kennedy (1995). Neste trabalho os autores estimam um modelo de correção de erros em painel utilizando dados de 17 países desenvolvidos entre os anos de 1981 a 1994. Concluem que o aumento de um ponto percentual do déficit sobre o PIB eleva a taxa de juros real em 0,12\%. Os autores, ao utilizarem o modelo de correção de erros, conseguem separar os determinantes da taxa de juros real no longo prazo dos determinantes no curto prazo $^{2}$. No longo prazo, se mostram significativos a taxa de retorno

1 "It is wrong to relate the rate of interest to the concurrent budget deficit without taking into account the anticipated future deficits. It is significant that almost none of the past empirical analyses of the effect of deficits on interest rates makes any attempt to include a measure of expected future deficits."

2 Determinantes de curto prazo se referem a variáveis que provocam oscilações na variável dependente por um breve período de tempo, mas não altera seu nível de equilíbrio. Determinantes de longo prazo 
média do capital, o déficit fiscal, o saldo em conta corrente e a diferença entre a inflação corrente e a média dos últimos períodos. Já no curto prazo, os principais determinantes são a taxa de juros de curto prazo, o câmbio real, a inflação corrente e uma métrica de taxa de juros livre de risco. Ao incluir a taxa de juros de curto prazo como variável explicativa os autores conseguem controlar os efeitos da política monetária. É interessante observar que essa variável só entra como determinante no curto prazo, mostrando que o Banco Central pode afetar a taxa no curto prazo, embora, esta tende a voltar para seu valor de equilíbrio no longo prazo, o qual é dado pelos fundamentos.

Em Kinoshita (2006) examina-se o efeito que os gastos e a dívida do governo exercem sobre a taxa de juros real dos títulos soberanos com vencimento em 10 anos. O autor na verdade trabalha com a taxa média dos últimos cinco anos ao invés do valor corrente para eliminar a dinâmica de curto prazo. Utilizando dados anuais de 17 países desenvolvidos entre os anos de 1981 a 1994 o autor realiza uma estimação de efeito fixo e encontra evidências de que a dívida e os gastos do governo exercem efeito positivo e significativo na taxa de juros.

Um dos principais trabalhos na literatura é Ardagna, Caselli e Lane (2007), no qual os autores utilizaram dados anuais de 16 países desenvolvidos entre 1960 a 2002 para verificar o impacto que a política fiscal exerce sobre as taxa de juros nominal dos títulos soberanos de longo prazo. Este é certamente um estudo econometricamente mais completo que os anteriores, visto que os autores se preocuparam em analisar se as séries possuem raiz unitária e se possuem são cointegradas ou não. O estudo de Kinoshita (2006), por exemplo, poderia ser fortemente contestado visto que não verifica se há problema de regressão espúria. Para verificar se as séries são estacionárias Ardagna, Caselli e Lane (2007) utilizam o teste de raiz unitária em painel proposto em Im, Pesaran e Shin (2003). Como os resultados apontam não estacionariedade das séries eles verificam se essas são cointegradas utilizando o teste de cointegração em painel proposto por Pedroni (1999). Somente após realizar essas duas etapas realizam uma estimação via Dynamic OLS e também reportam os resultados de efeito fixo para fins de robustez. 
Ardagna, Caselli e Lane (2007) obtêm diversos resultados importantes, entre eles: (i) a dívida possui efeito não linear sobre os juros, sendo que seu efeito é não significativo ou até mesmo negativo até atingir cerca de 60\% do PIB, acima disso seu efeito passa a ser positivo, (ii) o déficit fiscal exerce efeito positivo nos juros e a magnitude de seu efeito é maior para os países que possuem dívida acima de $60 \%$ do PIB, (iii) não só os fundamentos internos de cada país são importantes na determinação da sua taxa de juros interna, fatores globais como dívida e déficits mundiais também são relevantes. No mais, os autores também reportam que inflação, a taxa de juros de curto prazo e o crescimento do PIB possuem efeito positivo e significante na taxa de longo prazo.

Leal (2011) realiza um estudo em painel para 25 países da OCDE, seus resultados indicam que déficits fiscais possuem efeito significativo e positivo sobre a taxa de juros e a dívida pública não possui efeito significativo, porém, quanto maior a dívida, maior o efeito do déficit sobre a taxa de juros. Além disso, o autor inova ao utilizar expectativas de déficits como variáveis explicativas, constituindo assim um dos poucos trabalhos em painel que utiliza expectativas além dos valores correntes. Os resultados, porém, mostram que as expectativas dos déficits possuem efeito não significante sobre a taxa de juros. Leal conclui seu trabalho dizendo que tais resultados provavelmente são causados pelo pouco número de observações. ${ }^{3}$

Em Poghosyan (2014) também se analisa se as séries são estacionárias utilizando testes de raiz unitária em painel da primeira geração ${ }^{4}$. Posteriormente, estimam o modelo Pooled Mean Group desenvolvido por Pesaran, Shin e Smith (1999), que permite diferenciar as variáveis determinantes no longo prazo das determinantes no curto prazo. O autor conclui que crescimento do PIB e dívida exercem efeito positivo e significativo na taxa de juros real no longo prazo, enquanto no curto prazo as variáveis significativas são taxa de juros de curto prazo (positivo), a própria dívida (positivo) e inflação (negativo). Os autores não utilizam nenhuma variável global para controlar por fatores externos.

Os trabalhos mais recentes de Dell'Erba e Sola (2013) e Afonso e Rault (2015)

3 Dados sobre expectativas dos déficits fiscais dos países da OCDE só estavam disponíveis a partir de 1996, apenas 13 observações para cada país.

4 A diferença entre os testes da primeira e segunda geração será explicado no capítulo 4. 
analisam a estacionariedade das séries utilizando testes de raiz unitária em painel da segunda geração. Em ambos, entre as variáveis explicativas incluem-se dívida, déficit fiscal e inflação. Afonso e Rault (2015) incluem ainda o saldo em conta corrente, a taxa de câmbio real e uma medida de liquidez, enquanto, Dell'Erba e Sola (2013) incluem a mais somente o crescimento do PIB e a taxa de juros de curto prazo. Ambos estudos controlam por fatores externos e utilizam a média cross section das variáveis explicativas e/ou da variável dependente para representar esses fatores. Em Dell'Erba e Sola (2013) a variável dependente é a taxa de juros nominal dos títulos soberanos de longo prazo. Seus resultados indicam que o déficit possui efeito positivo e dívida possui efeito não significante quando não se inclui os fatores externos, quando estes são incluídos a dívida passa a exercer efeito positivo enquanto o déficit passa a ser não significante. Em Afonso e Rault (2015) a variável dependente é a taxa de juros real dos títulos de longo prazo. Seus resultados indicam que o déficit fiscal possui efeito significativo e positivo, enquanto a dívida possui efeito significativo e negativo, em linha com os primeiros resultados obtidos em Ardagna, Caselli e Lane (2007) quando não se controlava pela não linearidade da dívida.

Todos estudos citados anteriormente tratam apenas de países desenvolvidos. De fato, é difícil achar nessa literatura estudos envolvendo apenas países emergentes. A maior dificuldade está em achar dados para estes países, uma vez que muitos não possuem títulos de vencimento de longo prazo, o que inviabiliza a análise. Alguns estudos, contudo, utilizam países desenvolvidos e emergentes, como por exemplo, Aisen e Hauner (2008), no qual se analisa mais de 60 países entre os anos de 1970 e 2006. O maior problema é que o autor utiliza taxas de juros de longo prazo para os países desenvolvidos e taxas de curto prazo para os países emergentes, sendo algumas destas a própria taxa meta definida pelo Banco Central, que pode estar sujeita a ações discricionárias dos governos que não são contempladas em nenhuma variável explicativa, como já evidenciado em Canzoneri, Cumby e Diba (2002). De qualquer forma, vale ressaltar que seus resultados mostram que o efeito do déficit sobre os juros é significante e positivo, enquanto a dívida não apresenta resultado significativo. Os autores utilizam a taxa de juros do Tesouro americano para controlar por fatores externos e obtém que seu coeficiente é significativo e positivo. 
Alper e Forni (2011) também utilizam países desenvolvidos e países emergentes em sua análise. Para os países desenvolvidos utilizam como variável dependente a taxa de juros dos títulos soberanos de longo prazo, porém, para os países emergentes ao invés de utilizar a taxa de juros da dívida interna, utilizam a taxa de juros da dívida externa que é aproximada pela soma da taxa de juros do Tesouro americano com o índice EMBI calculado pelo banco J.P. Morgan. Portanto, Alper e Forni (2011) não abordam, exatamente, a análise do comportamento da taxa de juros interna dos países emergentes, que é o objetivo dessa dissertação. De toda maneira, os resultados obtidos no estudo indicam que a dívida possui efeito não linear nos juros, sendo seu efeito positivo e significante somente para valores mais elevados. Quanto aos fatores externos utilizam uma métrica de taxa de juros livre de risco, indicadores fiscais globais e uma medida de aversão ao risco dos investidores dada pelo VIX (Volatilidade implícita do S\&P 500 calculada pela Chicago Board Options Exchange). Todas as três variáveis exercem efeito positivo sobre os juros dos países emergentes.

Baldacci e Kumar (2010) analisam 31 países, desenvolvidos e emergentes, entre os anos de 1980 a 2008. Os autores estimam um modelo de efeito fixo e chegam aos resultados de que o déficit afeta de forma positiva a taxa de juros e a dívida possui efeito não linear sobre o mesmo. Além disso, quanto maior a dívida e/ou maior a dependência de financiamento externo maior é a magnitude em que o déficit afeta os juros. Os únicos problemas nesse trabalho é que os autores não incluem uma variável para controlar pelos fatores externos e também não analisam a questão da estacionariedade das séries.

Um trabalho que parece estar a parte da literatura é Segura-Ubiergo (2012), este não cita e também não é citado pelos trabalhos anteriormente descritos. Segura-Ubiergo (2012) trabalha com dados anuais de 15 países emergentes entre os anos de 1980 e 2009, sua variável dependente é a taxa de juros meta determinada pelo Banco Central. O autor estima um modelo de correção de erros em painel e conclui que o déficit fiscal exerce efeito positivo e significativo nos juros tanto no longo como no curto prazo. O saldo em conta corrente possui efeito negativo no longo prazo e a volatilidade da inflação possui efeito positivo no curto prazo. Segura-Ubiergo também utiliza a taxa de juros do Tesouro americano para controlar pelos fatores externos, obtém o resultado de que essa variável 
possui efeito positivo tanto no longo como no curto prazo. Por fim, este é o primeiro estudo a incluir entre as variáveis explicativas a taxa de poupança nacional, obtendo o resultado de que seu coeficiente é negativo, porém, pouco significante.

O único estudo a que tivemos acesso que trabalha apenas com países emergentes e utiliza a taxa de juros de longo prazo como variável dependente foi Perović (2015). Neste trabalho o autor analisa dados anuais de 10 países emergentes do leste europeu entre 2001 e 2013, utiliza um estimador de efeito fixo e apresenta diversos resultados, entre eles (i) Dívida, déficit fiscal e a taxa de juros de curto prazo possuem efeito positivo nos juros de longo prazo, (ii) crescimento do PIB exerce efeito negativo, (iii) a medida de aversão ao risco dada pelo yield dos High Yield Bonds americanos se mostra significante e positivo e (iv) em épocas de crise aumenta a magnitude do efeito da dívida e do déficit sobre os juros.

Assim como Gale (2003) que apresenta uma tabela resumindo os principais resultados obtidos em análises single country, nas tabelas 3, 4 e 5 resumimos os principais resultados obtidos em estudos envolvendo painel de países. As tabelas incluem as principais variáveis explicativas utilizadas e os sinais dos coeficientes obtidos.

Tabela 3 - Variável Dependente: Taxa de Juros Real ou Nominal

\begin{tabular}{lcccc}
\hline \hline & $\begin{array}{c}\text { Positivo e } \\
\text { Signficante }\end{array}$ & $\begin{array}{c}\text { Inconclusivo ou } \\
\text { NãoSignificante }\end{array}$ & $\begin{array}{c}\text { Negativo e } \\
\text { Significante }\end{array}$ & Total \\
\hline FUND. INTERNOS & & & & \\
JurosCurtoPrazo & 9 & 2 & 0 & 11 \\
DéficitFiscal $^{\text {Dívida }}$ & 10 & 1 & 0 & 11 \\
SaldoCCorrente $^{4}$ & 8 & 4 & 1 & 13 \\
Inflação $_{\text {CrescPIB }}$ & 7 & 1 & 6 & 7 \\
FAT. EXTERNOS & 2 & 2 & 4 & 13 \\
PolitFiscalMundial & & 5 & 4 & 11 \\
TaxaLivreRisco $^{6}$ & 4 & 1 & 0 & 4 \\
Aversão.Risco $^{7}$ & 2 & 1 & 2 & 7 \\
\hline \hline
\end{tabular}


Tabela 4 - Variável Dependente: Taxa de Juros Real

\begin{tabular}{|c|c|c|c|c|}
\hline & $\begin{array}{l}\text { Positivo e } \\
\text { Signficante }\end{array}$ & $\begin{array}{l}\text { Inconclusivo ou } \\
\text { NãoSignificante }\end{array}$ & $\begin{array}{l}\text { Negativo e } \\
\text { Significante }\end{array}$ & Total \\
\hline \multicolumn{5}{|l|}{ FUND. INTERNOS } \\
\hline JurosCurtoPrazo & 4 & 2 & 0 & 6 \\
\hline DéficitFiscal & 4 & 1 & 0 & 5 \\
\hline Dívida ${ }^{4}$ & 5 & 2 & 1 & 8 \\
\hline SaldoCCorrente & 0 & 1 & 5 & 6 \\
\hline Inflação & 3 & 0 & 4 & 7 \\
\hline CrescPIB & 1 & 3 & 2 & 6 \\
\hline \multicolumn{5}{|l|}{ FAT. EXTERNOS } \\
\hline PolíticaFiscalMundial ${ }^{5}$ & 2 & 0 & 0 & 2 \\
\hline TaxaLivreRisco ${ }^{6}$ & 2 & 0 & 2 & 4 \\
\hline Aversão.Risco ${ }^{7}$ & 1 & 1 & 0 & 2 \\
\hline
\end{tabular}

Tabela 5 - Variável Dependente: Taxa de Juros Nominal

\begin{tabular}{lcccc}
\hline \hline & $\begin{array}{c}\text { Positivo e } \\
\text { Signficante }\end{array}$ & $\begin{array}{c}\text { Inconclusivo ou } \\
\text { NãoSignificante }\end{array}$ & $\begin{array}{c}\text { Negativo e } \\
\text { Significante }\end{array}$ & Total \\
\hline FUND. INTERNOS & & & & \\
JurosCurtoPrazo & 5 & 0 & 0 & 5 \\
DéficitFiscal $^{\text {Dívida }}{ }^{4}$ & 6 & 0 & 0 & 6 \\
SaldoCCorrente $^{\text {Inflação }}$ & 3 & 2 & 0 & 5 \\
CrescPIB $^{\text {FAT. EXTERNOS }}$ & 0 & 0 & 1 & 1 \\
PolíticaFiscalMundial $^{5}$ & 1 & 2 & 0 & 6 \\
TaxaLivreRisco $^{6}$ & 1 & 2 & 2 & 5 \\
Aversão.Risco $^{7}$ & 2 & 1 & 0 & 2 \\
\hline \hline
\end{tabular}

4 Em relação aos estudos que levam em conta a não linearidade da dívida consideramos positivo e significante aqueles que têm como resultado o fato de que a partir de um determinado valor o aumento da dívida leva a um aumento dos juros. Sendo isso válido tanto para aqueles estudos que utilizaram dummies para representar um certo threshold, quanto para aqueles que obtiveram um coeficiente positivo para a variável dívida ao quadrado e negativo para a variável dívida na forma linear. No mais, vale ressaltar que em Baldacci e Kumar (2010) foi obtido um coeficiente positivo para dívida na forma linear e negativo para dívida ao quadrado, consideramos esse resultado inconclusivo, embora os autores reportem que esse resultado indica efeito positivo da dívida nos juros.

5 Essa variável representa basicamente a dívida e/ou déficit médio dos países da amostra (Ardagna, Caselli e Lane (2007)) ou de uma economia principal (Perović (2015) trabalha com uma base de dados de 10 países emergentes do leste europeu e utiliza como variáveis a dívida e déficit da Alemanha para representar a política fiscal mundial). Um coeficiente positivo significa que uma política fiscal mais frouxa afeta positivamente a taxa de juros.

6 Assim como política fiscal mundial, a taxa livre de risco é em geral representada pela média das taxas dos países da amostra (Ardagna, Caselli e Lane (2007)) ou de uma economia principal (Segura-Ubiergo (2012) utiliza a taxa de juros do Tesouro americano).

7 Em geral duas variáveis são utilizadas como métrica de aversão ao risco dos investidores internacionais, o yield dos High Yield Bonds americanos e a volatilidade implícita do S\&P 500 (VIX) 
Como mostram as tabelas, os indicadores de política fiscal, déficit e dívida apresentam resultados bastante conclusivos e em linha com o que a teoria sugere. Diferentemente dos estudos single country que não utilizavam déficits esperados, os estudos em painel mostram resultados bem mais consistentes, mesmo quando são utilizados valores correntes das variáveis explicativas. Pode-se inferir do resumo acima que uma política fiscal mais frouxa leva inevitavelmente a um aumento da taxa de juros. A melhora do saldo em conta corrente possui efeito negativo nos juros, o que está em linha com a teoria, visto que quando o saldo em conta corrente é negativo há um excesso de investimento em relação a poupança interna o que pressiona para cima a taxa de juros (o país tem de absorver poupança externa para equilibrar suas contas). No que se refere ao crescimento do PIB os resultados ainda são inconclusivos. Por um lado, maior crescimento gera maior receita e diminui a dívida em relação ao PIB, levando a condições melhores de sustentabilidade financeira e exigindo menor taxa de juros para financiamento. Por outro lado, maior crescimento aumenta a demanda por recursos na economia o que pressiona os juros para cima. A inflação exerce pressão positiva nos juros nominais, contudo, seu efeito sobre os juros reais é dúbio. Se por um lado o aumento da inflação exige juros maiores para manter a estabilidade dos preços, por outro lado um aumento repentino na inflação (supondo juros nominais constantes) leva à queda dos juros reais.

Não são muitos estudos que utilizam fatores externos entre as variáveis explicativas, mas, de qualquer forma, as evidências até hoje indicam que: (i) uma política fiscal mais frouxa nas principais economias do mundo levam a um aumento generalizado nas taxas de juros internas de grande parte dos países, (ii) um aumento da aversão ao risco por parte dos investidores internacionais pressiona para cima a taxa de juros, principalmente dos países emergentes $^{8}$, e (iii) a taxa de juros livre de risco não mostra resultados conclusivos, o que não é um resultado tão inesperado, como será visto nos próximos parágrafos.

Embora a literatura sobre efeitos da política fiscal nas taxas de juros de títulos

8 Os dois estudos em que aversão ao risco se mostrou significativo utilizavam base de dados de países emergentes (Perović (2015) e Alper e Forni (2011) na estimação para países emergentes) e o estudo em que mostrou não significativo utilizava dados de países desenvolvidos (Alper e Forni (2011) na estimação para países desenvolvidos). 
soberanos tenha incluído fatores externos como variáveis explicativas somente a partir de Ardagna, Caselli e Lane (2007), uma literatura paralela e semelhante já tinha chamado atenção para o papel das variáveis externas na determinação dos preços internos. Esta tem como tema principal a análise dos determinantes do spread da dívida externa e pelo menos desde Eichengreen e Mody (1998) se analisa o impacto que os fatores externos exercem no spread de determinado país.

A vantagem de se adentrar na literatura sobre a determinação do spread deve-se a dois fatores: (i) a semelhança teórica e empírica com a taxa de juros interna e (ii) a abundância de estudos sobre o tema utilizando países emergentes, ao contrário da literatura sobre taxas internas de juros.

O spread da dívida externa é a diferença entre a taxa de juros dos títulos de determinado país denominados em dólar e a taxa de juros do Tesouro americano (em geral é representado pelo índice EMBI calculado pelo banco J.P. Morgan) e está intimamente ligado com a taxa de juros interna, como ressalta Megale (2005) "A importância do risco (spread) para a economia de um país está relacionada ao fato de que, em um ambiente de alta mobilidade de capital, ele acaba sendo um importante balizador da taxa interna de juros. Ou seja, quanto a maior o risco (spread) de um país, maior deverá ser a taxa de juros praticada por suas autoridades monetárias". De fato, a teoria da paridade descoberta da taxa de juros estabelece que:

$$
i_{d}=d e\left(i^{*}+p\right)
$$

Onde $i_{d}$ é a taxa de juros de determinado país em moeda doméstica, $i^{*}$ é a taxa de juros internacional (livre de risco) medida em moeda externa, de é a desvalorização cambial (em nível) e $p$ representa o prêmio de risco associado ao país. Se este mesmo país 
emite um título denominado em moeda externa, então:

$$
\begin{array}{r}
i_{e}=i^{*}+p \\
s=i_{e}-i^{*}=p
\end{array}
$$

Onde $s$ é o spread da dívida externa e $i_{e}$ é a taxa de juros de determinado país em moeda externa. Portanto,

$$
i_{d}=d e\left(i^{*}+s\right)
$$

Logo, o spread da dívida externa deve apresentar uma forte relação com a taxa de juros interna. A tabela 6 mostra, para alguns países, a correlação entre a taxa de juros interna e o spread, e a correlação entre a taxa de juros interna e a taxa de juros externa (aproximada pela soma do spread com a taxa livre de risco).

Tabela 6 - Correlação entre a taxa de juros interna e o spread da dívida externa - 2006Q4 a $2014 \mathrm{Q} 4$

\begin{tabular}{lcc}
\hline \hline & $\begin{array}{c}\text { Correl }^{9} \\
i_{d}-s\end{array}$ & $\begin{array}{c}\text { Correl } \\
i_{d}-s+i^{*}\end{array}$ \\
\hline Brasil & 0.59 & 0.77 \\
Bulgaria & 0.82 & 0.88 \\
Chile & -0.01 & 0.50 \\
China & -0.01 & 0.20 \\
Colombia & 0.54 & 0.86 \\
Hungria & 0.44 & 0.79 \\
Malasia & 0.01 & 0.35 \\
Mexico & 0.31 & 0.92 \\
Polonia & 0.38 & 0.82 \\
Russia & 0.79 & 0.57 \\
South Africa & 0.20 & 0.47 \\
\hline \hline
\end{tabular}

Mesmo sem levar em consideração o efeito da desvalorização cambial ${ }^{10}$, a correlação entre a taxa de juros interna e o spread da dívida externa mostra-se elevada para grande parte dos países, superando 90\% em alguns casos. Portanto, é de se esperar que as variáveis relevantes na determinação do spread sejam semelhantes às que determinam a taxa de juros. Como ressaltado anteriormente, a taxa de juros livre de risco não apresentou resultados 
conclusivos em relação a seu efeito sobre a taxa de juros, de fato, diversos estudos sobre a determinação do spread também não acham resultados conclusivos sobre o papel da taxa livre de risco.

A tabela abaixo mostra um resumo dos resultados encontrados em diversos estudos sobre a determinação do spread, sendo todos eles realizados com painel de países e incluindo somente países emergentes.

Tabela 7 - Variável Dependente: Spread da Dívida Externa

\begin{tabular}{lcccc}
\hline \hline & $\begin{array}{c}\text { Positivo e } \\
\text { Signficante }\end{array}$ & $\begin{array}{c}\text { Inconclusivo ou } \\
\text { NãoSignificante }\end{array}$ & $\begin{array}{c}\text { Negativo e } \\
\text { Significante }\end{array}$ & Total $^{11}$ \\
\hline FUND. INTERNOS & & & & \\
DéficitFiscal & 3 & 0 & 0 & 5 \\
Dívida Externa & 3 & 0 & 3 & 3 \\
Abertura Econômica & 0 & 2 & 1 & 3 \\
SaldoCCorrente & 0 & 2 & 0 & 3 \\
Inflação & 2 & 0 & 2 & 2 \\
CrescPIB & 0 & & & \\
\hline FAT. EXTERNOS & 1 & 4 & 0 & 5 \\
TaxaLivreRisco & 4 & 2 & 0 & 6 \\
Aversão.Risco & 4 &
\end{tabular}

As variáveis utilizadas como determinantes do spread são similares às das taxas de juros e seus respectivos coeficientes apontam em direção semelhante. Vale ressaltar os principais resultados: uma política fiscal mais frouxa exerce efeito positivo, o aumento da aversão ao risco também, a taxa de juros livre de risco não apresenta resultados conclusivos e crescimento do PIB e abertura econômico exercem efeito negativo.

Por fim, ressaltamos que essa dissertação visa complementar a literatura sobre os

$9 \quad$ A taxa de juros doméstica utilizada foi a taxa dos títulos soberanos com vencimento em 10 anos (Fonte: OCDE, FMI e Datastream), para o spread da dívida externa foi utilizado o EMBI (Fonte: JP Morgan). Vale ressaltar que o prazo de vencimento dos títulos utilizados no cálculo do índice não é divulgado.

10 Optamos por não calcular a correlação levando em conta a desvalorização cambial, porque não é divulgado o prazo dos títulos utilizados no cálculo do EMBI. Qualquer cálculo de desvalorização da taxa de câmbio seria feito utilizando um período de tempo completamente arbitrário.

11 Para a elaboração da tabela foram utilizados os estudos Megale (2005), Baldacci, Gupta e Mati (2008),Miyajima, Mohanty e Chan (2015), Petrova, Papaioannou e Bellas (2010), Alexopoulou, Bunda e Ferrando (2010) e Dailami, Masson e Padou (2008). Optamos por não inserir na tabela os estudos que incluem o rating soberano como variável explicativa, como Kamin e Kleist (1999) e Jaramillo e Tejada (2011). Como ressalta Cantor e Packer (1996), o rating já inclui informações sobre as variáveis macros e sua inclusão oculta o efeito das outras variáveis sobre o spread. Estudos que utilizam apenas índices como variáveis explicativas também não foram incluídos, por exemplo Csonto e Ivaschenko (2013) e Comelli (2012) 
determinantes da taxa de juros. Embora, em geral, esta se concentre no papel da política fiscal como principal determinante, abordaremos não só o papel da política fiscal como também de outros fundamentos internos e fatores externos. Visto que a maior parte da literatura trabalha apenas com países desenvolvidos e os estudos que trabalham com países emergentes na maioria das vezes apresentam algum problema nos dados, acreditamos que esse trabalho venha a contribuir de forma significativa para a literatura ao preencher essa lacuna existente. Consideramos útil e proveitosa para o nosso propósito a literatura complementar sobre a determinação do spread da dívida externa, visto que ela utiliza base de dados e metodologias semelhantes e já se aprofundou de forma mais ampla na influência que os fatores externos exercem sobre os mercados emergentes. Esperamos, portanto, estender esse conhecimento para a questão relativa à taxa de juros interna. 



\section{Dados}

\subsection{Descrição dos Dados}

Este trabalho utiliza dados trimestrais do quarto trimestre de 2006 ao quarto trimestre de 2014. Os países que compõe a amostra são Africa do Sul, Brasil, Bulgária, Chile, China, Colômbia, Coreia do Sul, Hungria, Malásia, México, Polônia, Republica Tcheca e Rússia. Os países e o período de tempo foram selecionados com base na disponibilidade de dados. Optamos por não incluir nenhum país desenvolvido na amostra, de forma que a base de dados seja composta de países mais facilmente comparáveis entre si. Apesar de muitos considerarem a Coreia do Sul já como um país desenvolvido, optamos por inclui-la mesmo assim, pois apesar do país asiático ter experimento elevadas taxas de crescimento nos últimos anos e já ter superado países como Portugal em índices como PIB per capta, seu nível de riqueza ainda não é tão elevado, sendo inferior ao dos países mais pobres da Zona do Euro, como Grécia e Portugal ${ }^{1}$. O aumento do nível de renda pode ocorrer de forma rápida e acelerada em período de anos ou algumas décadas, contudo, o crescimento da riqueza total depende de muitas décadas de crescimento econômico ou até mesmo séculos, e nesse quesito consideramos que a Coreia do Sul ainda não atingiu os patamares dos países desenvolvidos.

Este é o primeiro trabalho nessa literatura (a que tivemos acesso) que conseguiu obter dados sobre taxa de juros de longo prazo para países emergentes em base trimestral. As taxas de juros obtidas são refentes a títulos soberanos com prazo de vencimento de dez anos, as fontes utilizadas foram a OCDE, Thomson Reuters, Data Stream e Bancos Centrais.

Com relação às variáveis explicativas dividimos estas em dois grupos. O primeiro grupo reúne variáveis referentes a fundamentos internos, dívida bruta, déficit nominal, saldo em conta corrente (essas três representadas como \% do PIB), crescimento do PIB,

$1 \quad$ De acordo com o FMI o PIB per capita da Coreia do Sul no ano de 2014 foi de US\$ 35 mil superior ao de Portugal (US\$2 27 mil) e equivalente a $65 \%$ do PIB per capita americano. Contudo, de acordo com a OCDE o nível de riqueza por adulto na Coreia do Sul foi de US\$ 79 mil, inferior a Grécia e Portugal (US\$ 103 mil e US\$ 89 mil, respectivamente) e equivalente a apenas $26 \%$ do nível americano. 
taxa de juros de curto prazo, inflação e abertura econômica (exportações mais importações como \% do PIB). O segundo grupo reúne variáveis referentes a fatores externos, taxa de juros livre de risco, aversão ao risco dos investidores internacionais e política fiscal mundial. A taxa de juros livre de risco é representada pela taxa de juros dos títulos do Tesouro americano com prazo de vencimento de dez anos, a aversão ao risco é representada pelo yield dos High Yield Bonds americanos ${ }^{2}$ e a política fiscal mundial é representada pela dívida e déficit do governo dos Estados Unidos. As fontes utilizadas foram FMI, Oxford Economics, Bloomberg, Banco Mundial, Datastream, Eurostat e Bancos Centrais e Ministérios da Economia dos diversos países. Devido a dificuldade de obtenção desses dados, reportamos no Apêndice F a fonte exata de cada variável e o link de onde foi obtida.

Optamos por selecionar exatamente essas variáveis devido a três motivos principais. Primeiro, referente a razões teóricas, todas essas variáveis possuem motivos para afetar a taxa de juros, o que será descrito no capítulo 5. Segundo, referente a razões empíricas, a revisão da literatura feita no capítulo 2 mostra que essas são as mais utilizadas em estudos feitos para explicar a taxa de juros. A variável abertura econômica não tinha sido utilizado para esse propósito até então, contudo, sua elevada influência sobre o spread da dívida externa torna interessante verificar se essa variável também tem efeito sobre a taxa de juros interna. Terceiro, por motivos de disponibilidade de dados.

Por fim, vale ressaltar que durante este estudo vamos trabalhar apenas com os valores correntes das variáveis explicativas. Embora estejamos cientes das vantagens e da importância que existe em trabalhar com níveis esperados de dívidas e déficits, como ressaltado em Gale (2003), a indisponibilidade de dados nos impede de trabalhar com expectativas. Portanto, deixamos para trabalhos futuros a inclusão de variáveis esperadas em estudos envolvendo países emergentes.

$2 \quad$ Ver Megale (2005) 


\subsection{Estatísticas Descritivas}

A dívida americana sofreu um forte crescimento após a crise financeira internacional. Com o receio de se obter as mesmas consequências que aconteceram após a crise de 1929, o governo dos Estados Unidos optou por salvar os bancos privados e impedir uma forte contração da oferta de moeda. Esse ato deixou o sistema financeiro relativamente sólido as custas de uma piora significativa nas finanças do governo. O efeito nas economias emergentes foi de certa forma semelhante: muitos países observaram um crescimento substancial em seu endividamento, contudo, alguns conseguiram atravessar a crise sem apresentar piora relevante na situação fiscal. Os gráficos abaixo ilustram a situação.

Figura 1 - Dívida Bruta

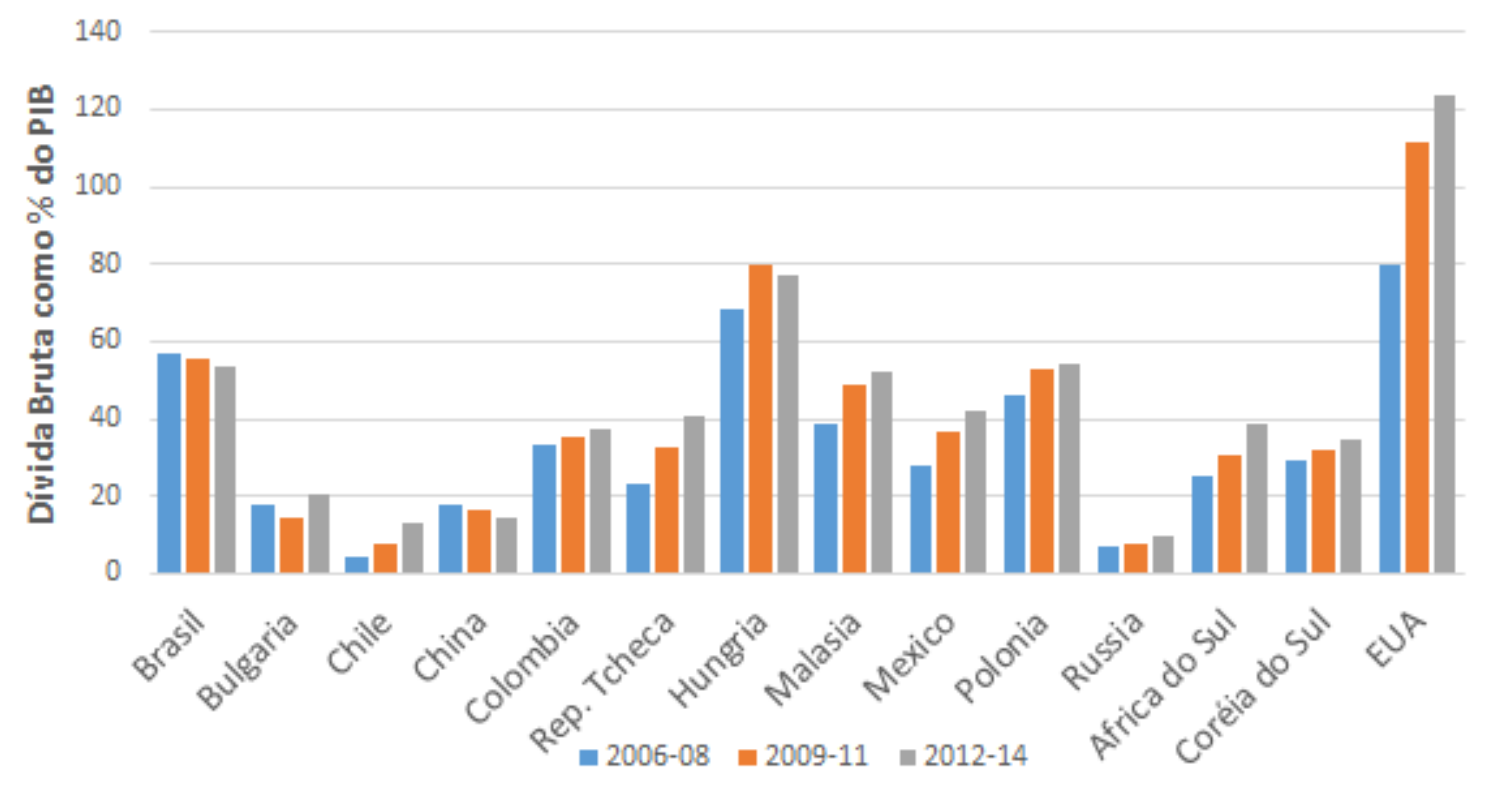

Apenas Brasil e China conseguiram apresentar uma trajetória de redução da dívida ao longo dos anos, contudo, a redução da dívida brasileira ocorreu sob um cenário econômico marcado por diversos incentivos governamentais não sustentáveis ${ }^{3}$, o que acabou resultando em uma explosão da dívida pública no ano pós-eleição, atingindo $68 \%$ do PIB em 2015.

Apesar do aumento no endividamento, alguns países conseguiram mostrar sustenta-

$3 \quad$ Ver Mesquita et al. (2014) 
Figura 2 - Superávit Nominal

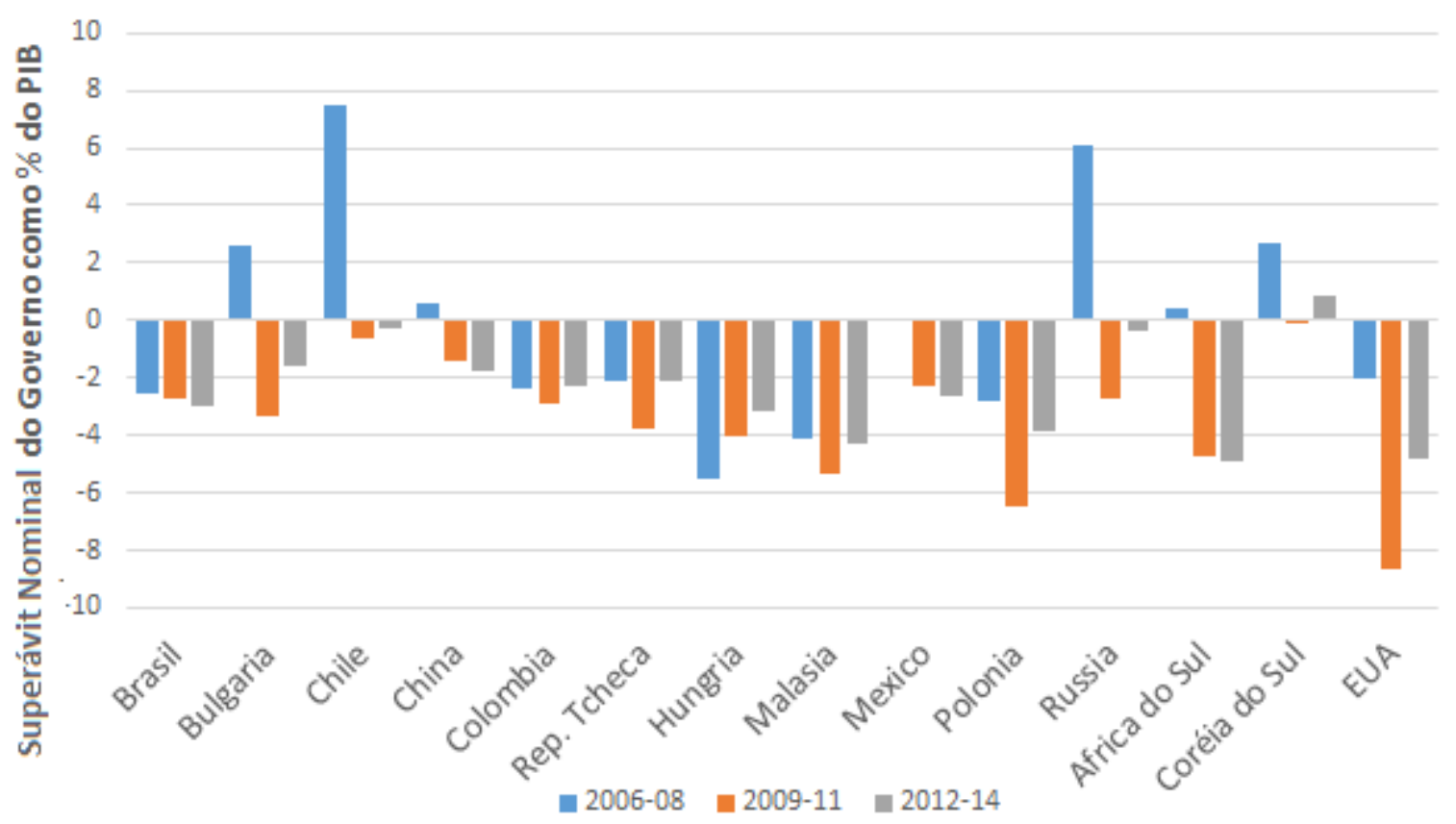

bilidade em suas finanças, como a Coreia do Sul que obteve um orçamento médio positivo ao longo dos anos de 2012 e 2014 e o Chile que apresentou um déficit médio de apenas 0,3\% no mesmo período.

Embora dívida e déficit tenham sido utilizados na literatura como principais determinante da taxa de juros, outros fundamentos internos também devem exercer considerável influência sobre essa variável. As razões para tal serão descritas no capítulo 5, mas é oportuno no momento comparar os fundamentos internos entre os países. Os gráficos abaixo ilustram a situação.

Dentre os principais pontos vale ressaltar a baixa abertura da economia brasileira, a soma das exportações e importações totalizaram 25\% do PIB no triênio 2012-14, muito abaixo da Colômbia (38\%), a segunda economia menos aberta da amostra.

Outro ponto a ser ressaltado é a ampla queda do crescimento da economia mundial, que ocorreu de forma bastante difundida entre os países, não apenas concentrada em alguma nação específica. Entre todos os países da amostra praticamente nenhum conseguiu voltar a apresentar taxas de crescimento nos níveis pré-crise. A única exceção foi o México 
Figura 3 - Abertura Econômica

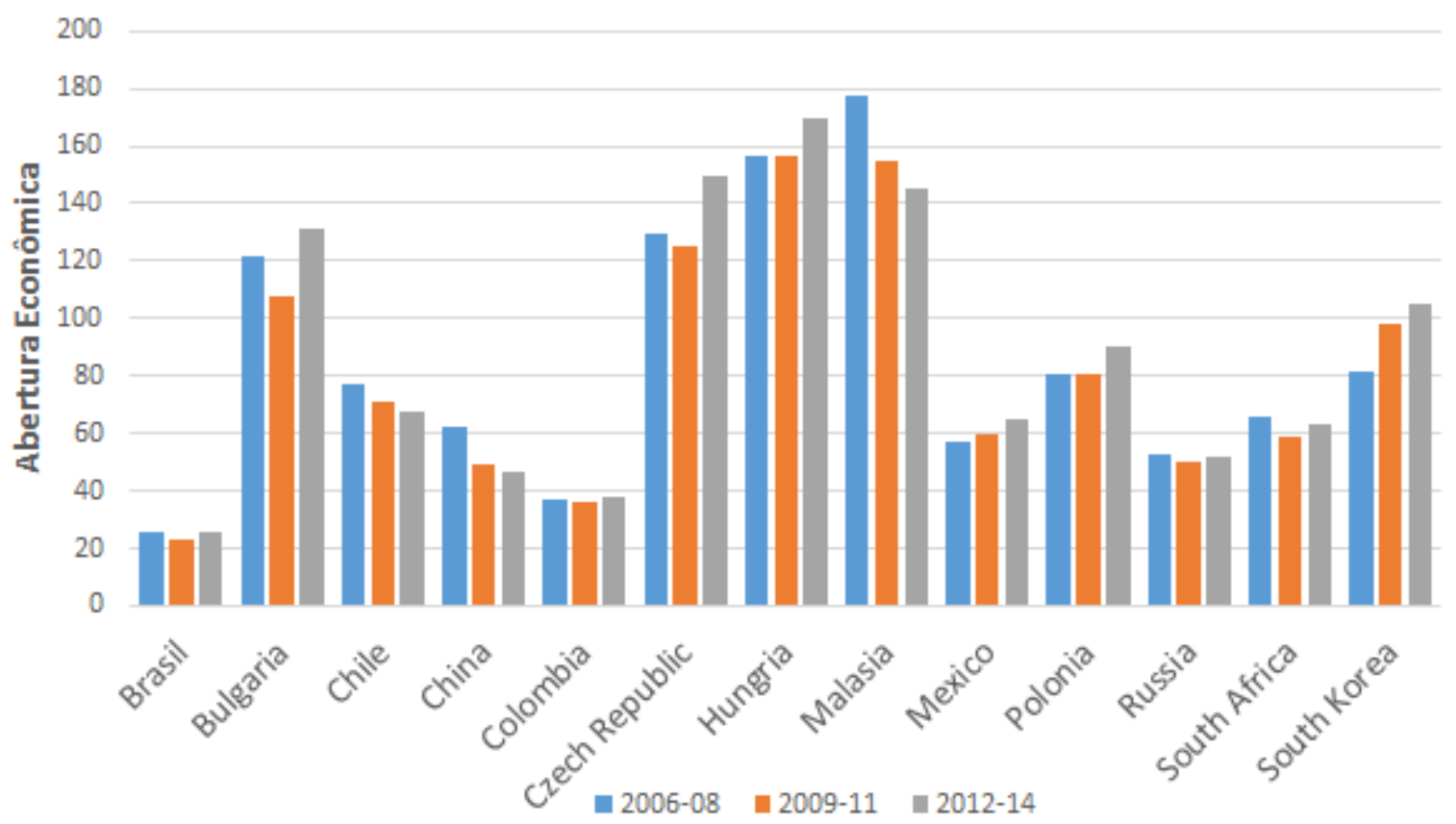

Figura 4 - Saldo em Conta Corrente

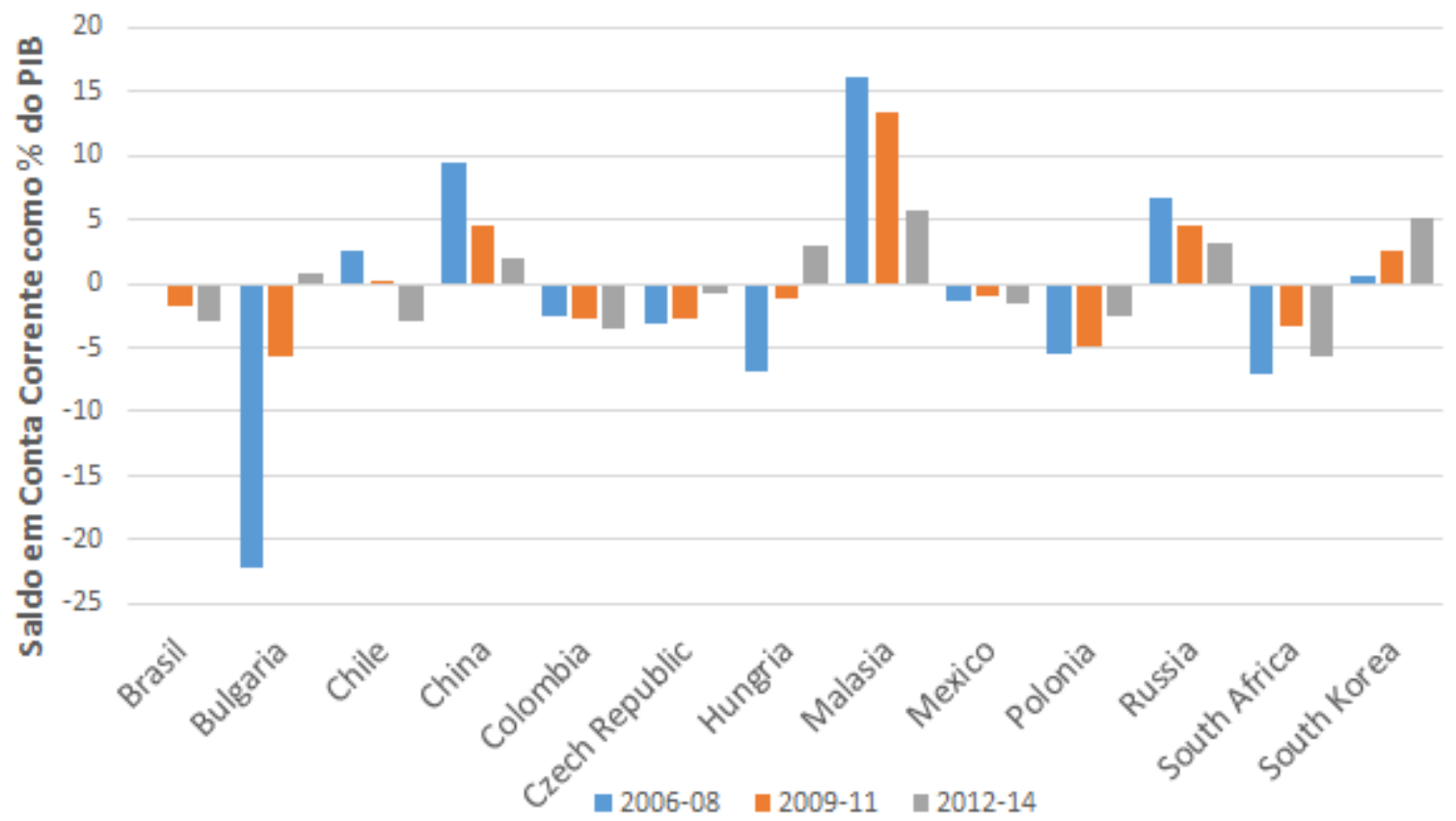


Figura 5 - Crescimento do PIB

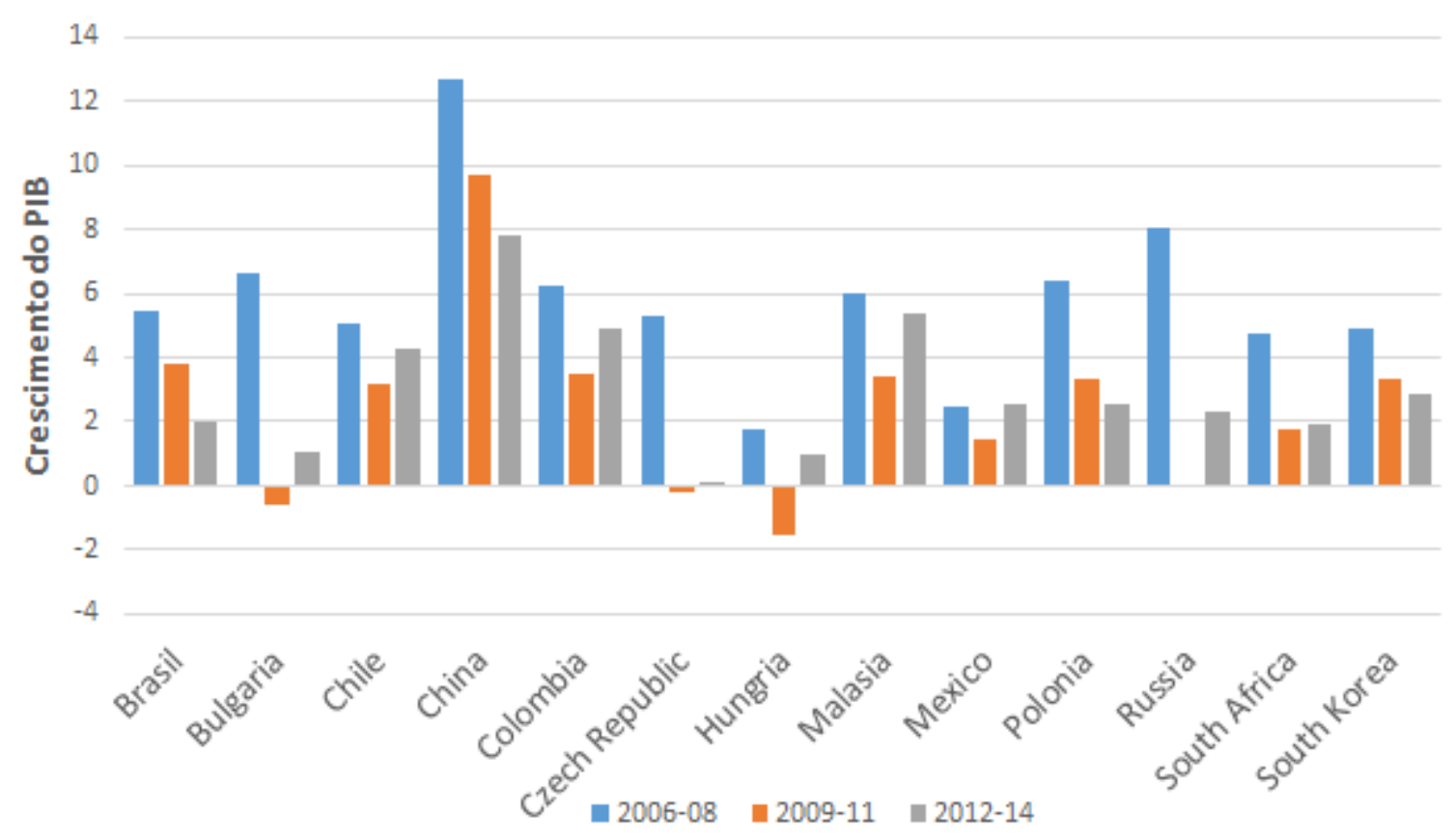

Figura 6 - Inflação

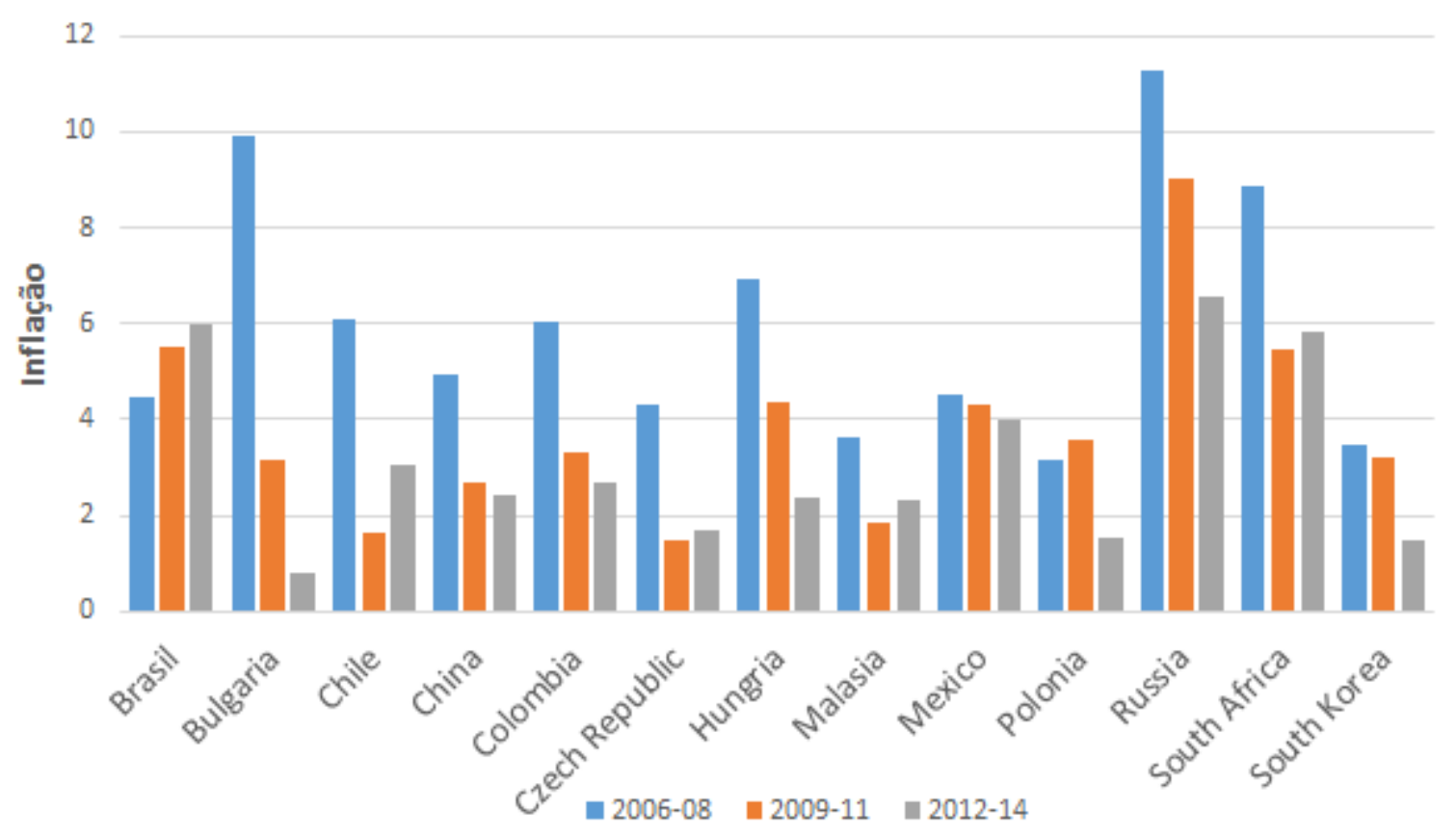


que já não vinha crescendo de forma tão intensa antes da crise e no triênio 2012-14 apresentou crescimento médio de 2,52\% ao ano, levemente acima dos 2,48\% apresentado antes de 2009.

Vale ainda ressaltar o comportamento da inflação brasileira, que se mostrou bastante singular, enquanto houve uma tendência de queda na variação dos preços em quase todos os países analisados, o Brasil foi o único que apresentou constante aumento da inflação ao longo do período. As razões são diversas, entre elas se destacam o aumento do crédito público e a redução forçada da taxa de juros. ${ }^{4}$

Mesmo com a redução forçada da taxa meta definida pelo Banco Central, a taxa dos títulos de longo prazo não acompanhou essa redução e o Brasil continuou apresentando a maior taxa de juros da amostra, em todos os períodos analisados:

Figura 7 - Taxa de Juros Brasileira

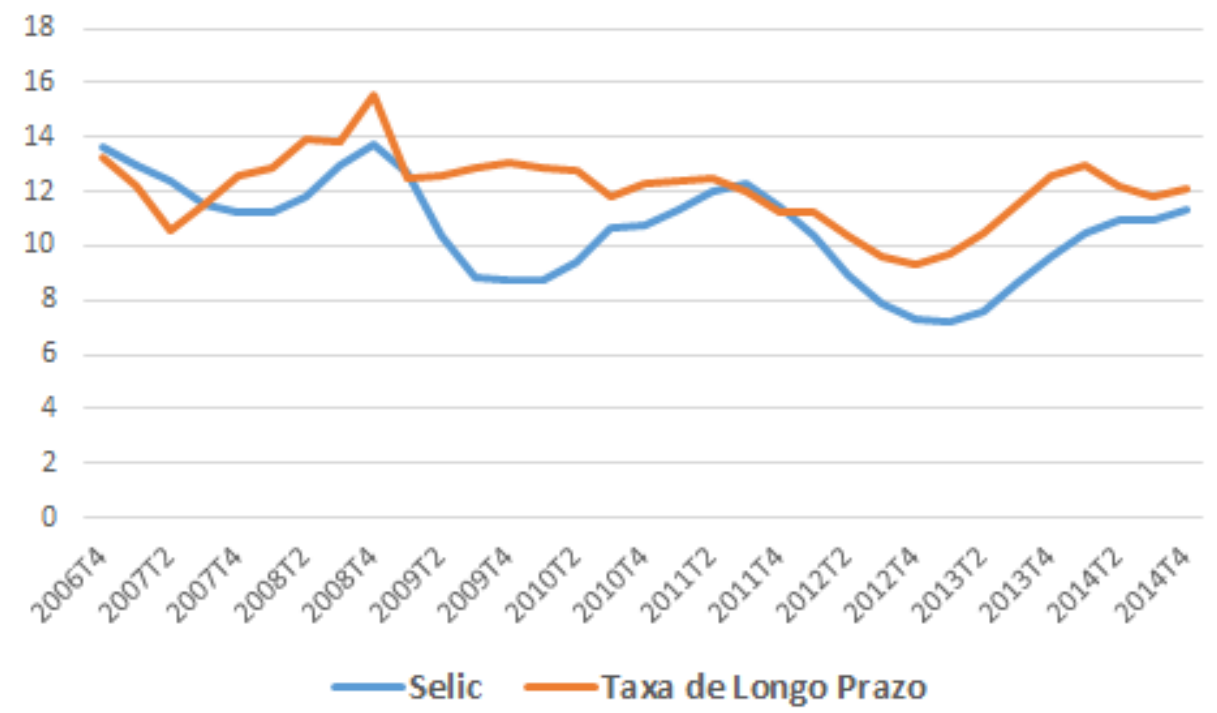

$\overline{4}$ Ver Goncalves (2015) e Mesquita et al. (2014). 
Figura 8 - Taxa de Juros de Longo Prazo

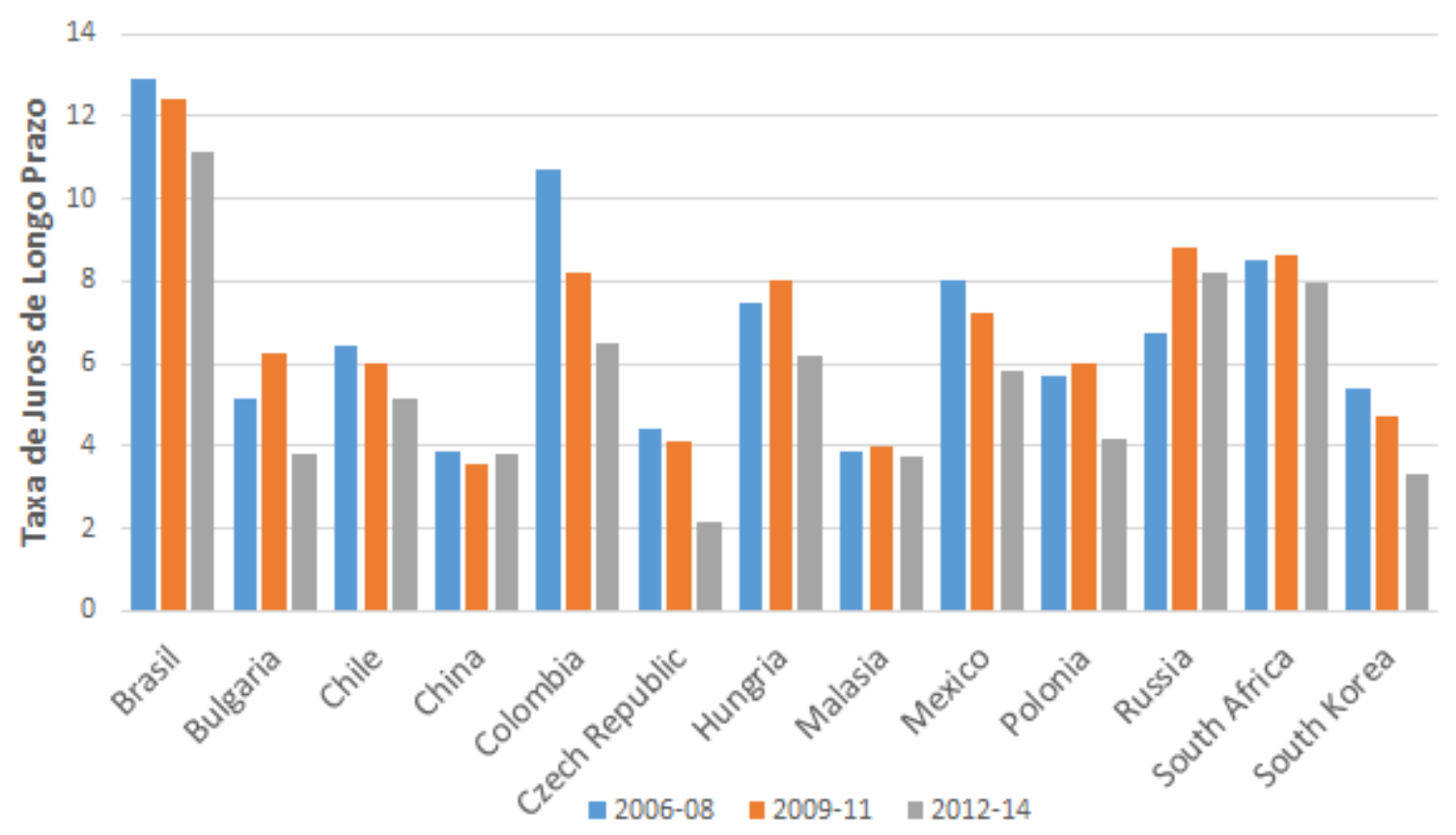


A elevada taxa de juros brasileira permanece sendo um fenômeno a ser explicado, como ressaltado na capítulo 1, diversos estudos já foram feitos sobre o tema, porém, ainda não há um consenso sobre as principais causas. De fato, nenhum indicador sozinho consegue explicar a elevada taxa de juros no Brasil, em todos os gráficos nosso país permanece acima da linha de regressão. Os gráficos mostram em relação a taxa de juros nominal, mas o cenário é praticamente o mesmo se utilizada a taxa de juros real.

Figura 9 - Juros e Fundamentos Internos (1)

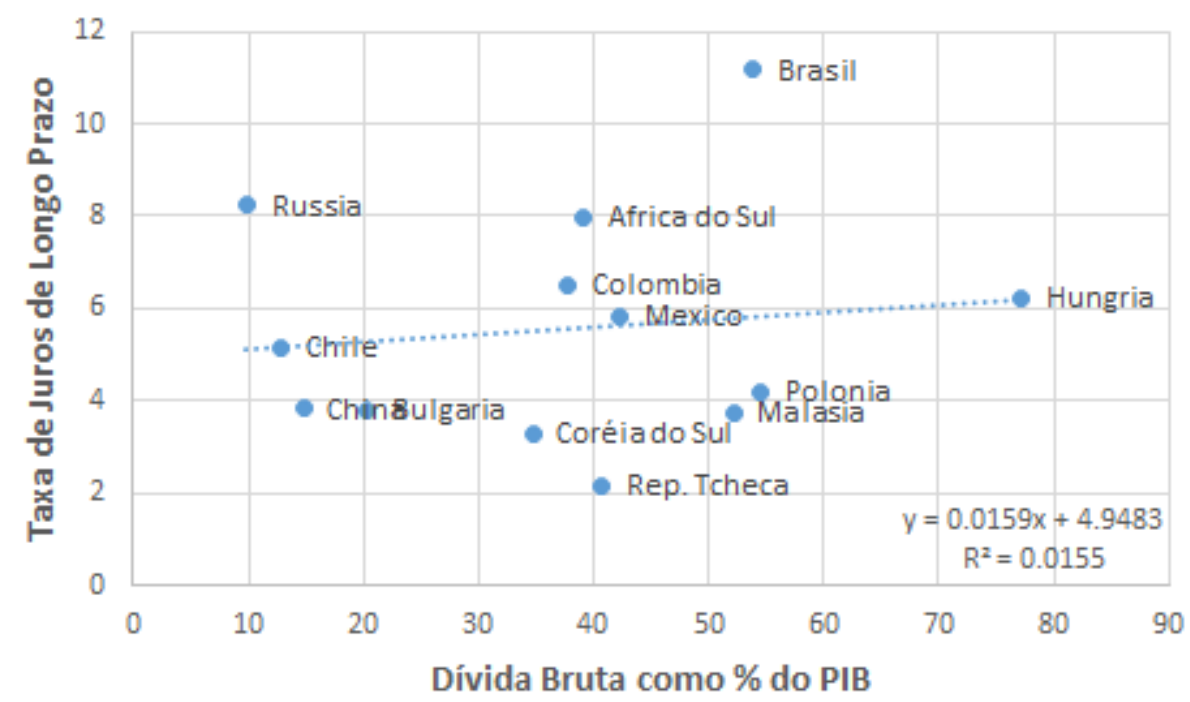


Figura 10 - Juros e Fundamentos Internos (2)
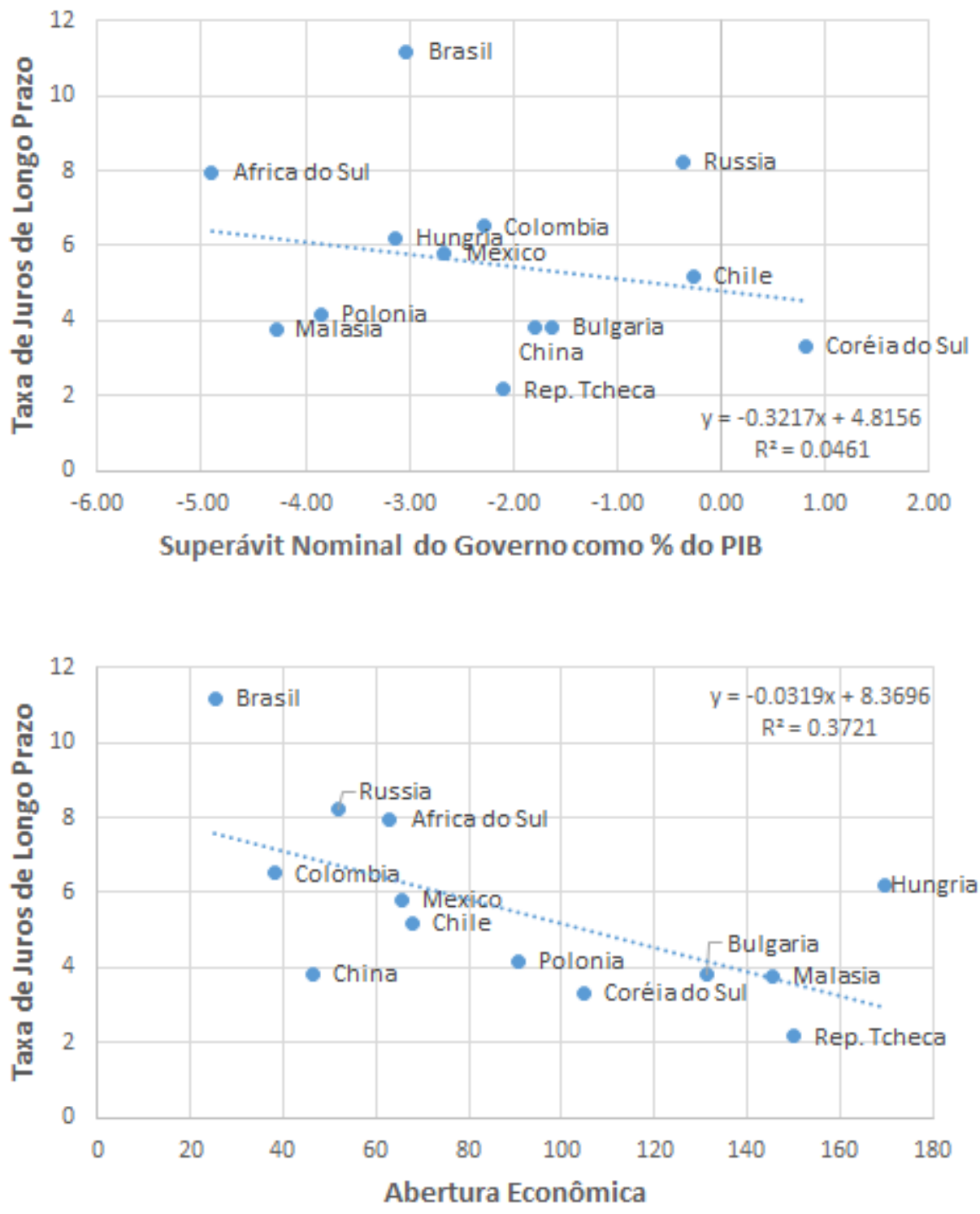
Figura 11 - Juros e Fundamentos Internos (3)
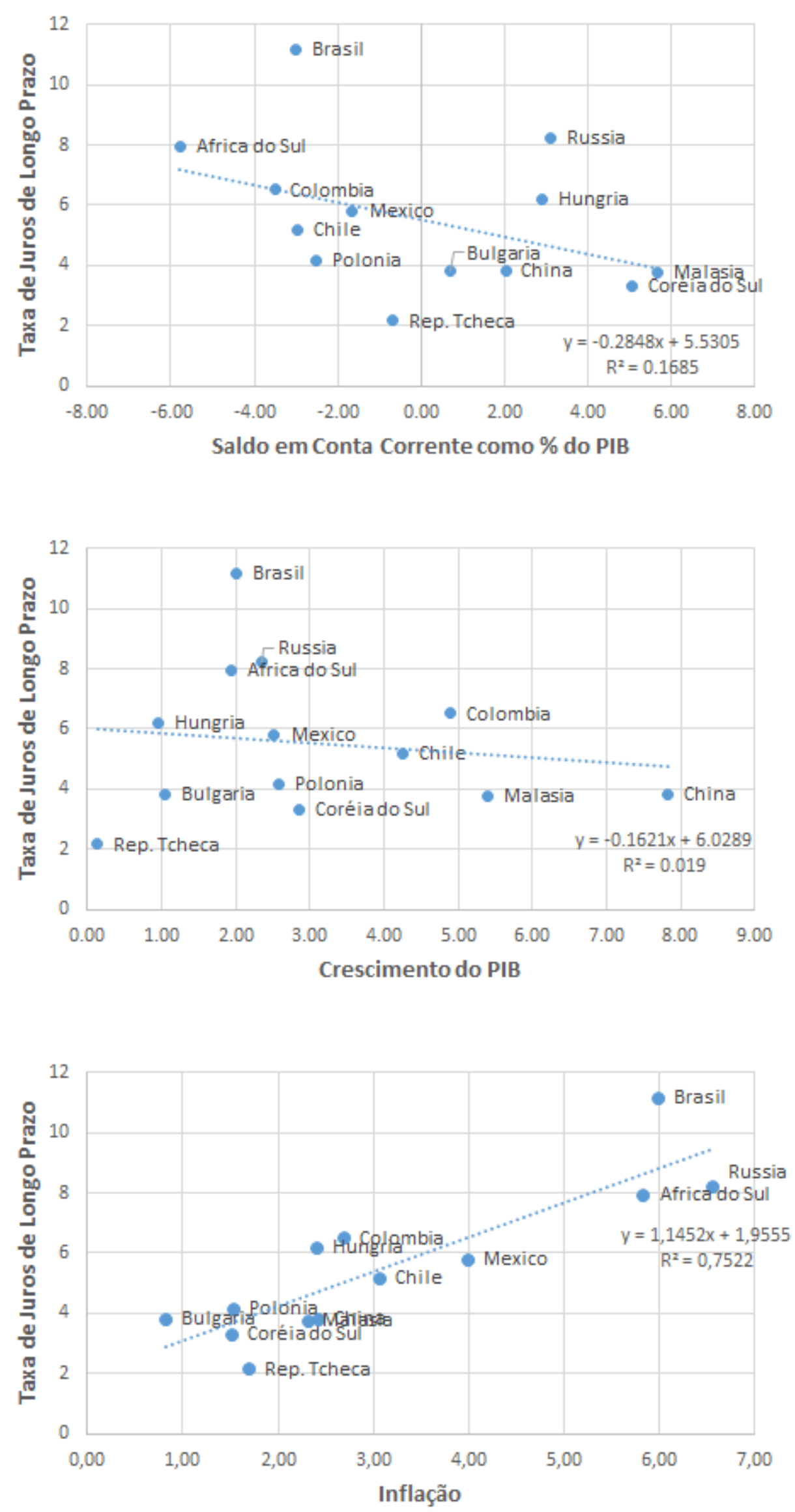
Portanto, fica a dúvida se uma combinação desses indicadores consegue de alguma forma explicar o nível da taxa de juros brasileira ou se existem outros fatores que puxam para cima o juros do Brasil e não estão contemplados nessas variáveis. Essa questão será respondida na capítulo 6 .

Vale ressaltar ainda o papel que os fatores externos exercem sobre a taxa de juros dos mercados emergentes. A redução da taxa de juros americana implica maior liquidez nos mercados mundiais, o que favorece a entrada de recursos em países de menor renda pressionando para baixo a taxa de juros da dívida soberana. Contudo, é importante ressaltar que em um cenário de forte aversão ao risco, mesmo que haja elevada liquidez nos mercados, os investidores podem ficar relutantes em investir em países mais arriscados, fazendo com que a menor taxa de juros dos Estados Unidos não reflita em maior fluxo de capitais para as economias emergentes. Esse ponto é muito bem explorado em Megale (2005) e o autor sugere utilizar o yield dos High Yield Bonds americanos como medida para a aversão ao risco. De fato, a correlação entre o yield dos HYB e a taxa de juros média entre os países emergentes é elevada (80\%) e a correlação com a taxa de juros do Tesouro americano também é relevante (57\%). 
Figura 12 - Taxas de Juros e Aversão ao Risco

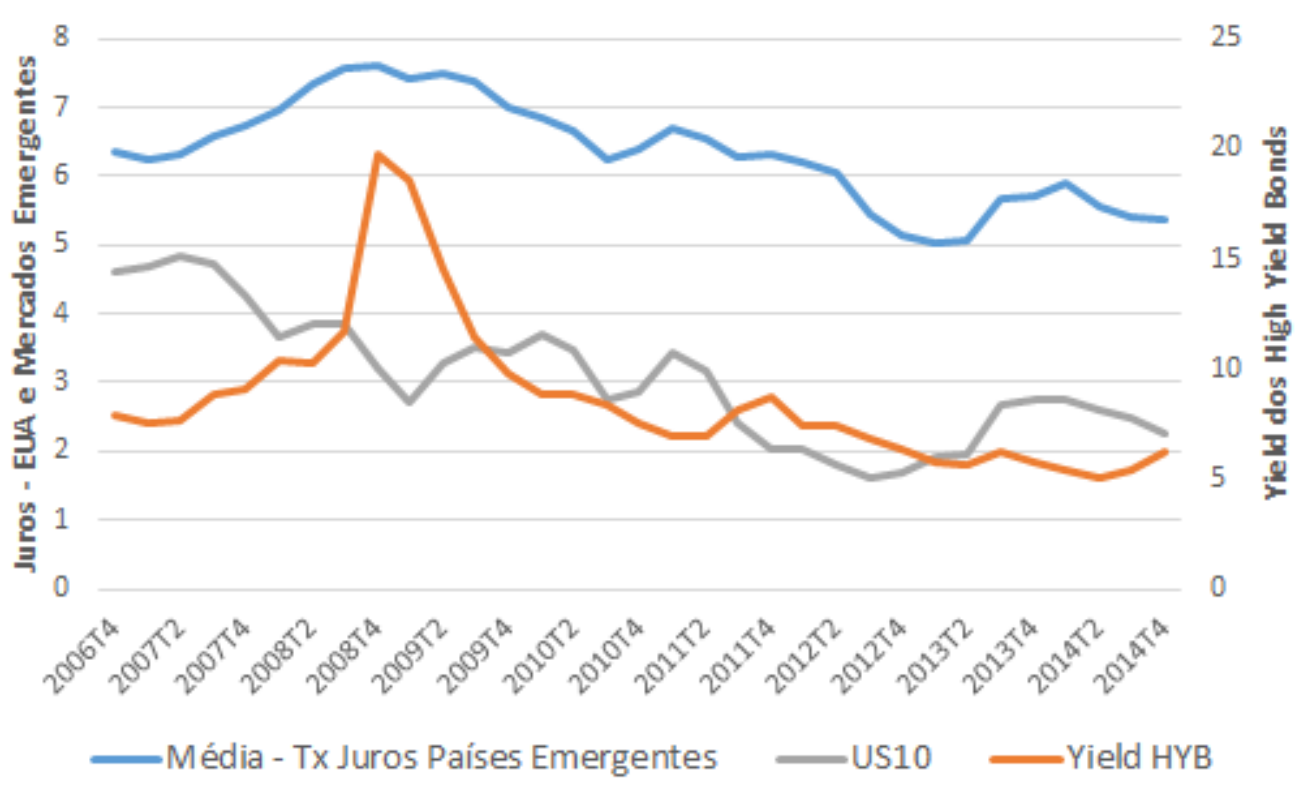

Compreender o papel que os fundamentos internos e os fatores externos exercem sobre a taxa de juros de um país em específico é de substancial importância para decisões de política econômica. Pode-se avaliar, por exemplo, se o influxo de capitais em determinado país, que gera uma redução na taxa de juros da sua dívida, está ocorrendo devido à melhora dos seus fundamentos internos ou é devido somente à condições de crédito internacionais. Se for o primeiro caso, pode-se reavaliar a política fiscal contando com essa fonte de crédito mais barata no longo prazo, contudo, se for o segundo caso é recomendável que o país não conte com esses recursos para projetos de longo prazo, pois qualquer mudança nas condições internacionais pode encarecer de forma substancial essa fonte de crédito. E isso não está sob o controle dos formuladores de política econômica. 



\section{Metodologia}

Este estudo utiliza dados trimestrais que englobam treze países emergentes entre o último trimestre de 2006 e o último de 2014. A dimensão temporal dos dados é de 33 observações e a dimensão cross-section é de 13. Totalizando, portanto, 429 observações. Base de dados desse tipo são chamadas de Macro Panels, Time Series Cross Section Data ou Panel Time Series e as técnicas ecométricas mais apropriadas para lidar com esse tipo de base vem sendo desenvolvida só mais recentemente.

A elevada dimensão temporal em relação à dimensão cross-section torna relevante o problema de regressão espúria descrito por Yule (1926) e demonstrado por Phillips (1986). Caso as séries sejam não estacionárias e não cointegradas podemos ter resultados estatisticamente significantes mesmo que as séries não tenham nenhuma relação uma com a outra. A metodologia para tratar esse problema para dados em painel começou a ser desenvolvida nos anos 2000 e ainda está sob construção, entre seus principais colaboradores se destacam Hashem Pesaran, Jorg Breitung, In Choi, Peter Pedroni e Joakim Westerlund.

Portanto, quando se trata de Macro Panels é necessário, primeiramente, verificar se as séries possuem raiz unitária ou não antes de prosseguir para a estimação final. Caso as séries sejam estacionárias, pode se prosseguir normalmente, tratando os dados como um painel usual e realizando estimações de efeito fixo ou efeito aleatório.

Para verificar se as séries são estacionárias poderíamos utilizar testes de raiz unitária univariado em cada uma das diferentes séries de cada país, contudo, é amplamente conhecido o problema de baixa potência que esses testes possuem. Testes como o Augmented Dickey Fuller ${ }^{1}$ muitas vezes não conseguem rejeitar a hipótese nula de existência de raiz unitária mesmo quando as séries são estacionárias. Este problema piora consideravelmente quando se trata de Macro Panels, devido ao fato de que séries desse tipo em geral possuem uma dimensão temporal muito baixa (dados macroeconômicos são normalmente obtidos em bases anuais ou trimestrais).

Para contornar esse problema desenvolveram-se testes de raiz unitária em painel

$1 \quad$ Dickey e Fuller (1981) 
que aproveitam da dimensão cross section para aumentar a potência do teste. Estes podem ser divididos entre os da primeira geração (Im, Pesaran e Shin (2003), Levin, Lin e Chu (2002), Breitung (1999) e Choi (2001)) e os da segunda geração (Pesaran (2007) e Breitung e Das (2005)). A principal diferença entre os dois tipos se refere ao fato de que os testes de primeira geração necessitam que as séries não possuam correlação cross section. Isso significa que se estamos interessados em analisar se a série de taxa de juros possui raiz unitária, é necessário que a taxa de juros brasileira não seja correlacionada com a chilena e que a chilena não seja correlacionada com a colombiana e daí em diante.

Embora essa seja uma hipótese bastante irrealista, diversos estudos utilizam testes da primeira geração para verificar a estacionariedade das séries, como Ardagna, Caselli e Lane (2007) e Poghosyan (2014). A vantagem dos testes da segunda geração é exatamente não necessitar dessa hipótese, porém, caso ela seja verdadeira os testes da segunda apresentam menor potência que os da primeira.

É interessantes, portanto, analisar se as séries possuem correlação entre os países antes de realizar os testes de raiz unitária em painel. Para exatamente este propósito Pesaran (2004) desenvolveu um teste que analisa se as séries possuem ou não dependência cross section. Nesta dissertação será realizado primeiramente o teste de dependência cross section para decidir qual tipo de teste de raiz unitária será utilizado.

Se os testes de raiz unitária indicarem não estacionariedade das séries é necessário realizar um teste de cointegração para verificar se elas são cointegradas. Se elas não forem, a estimação entre elas pode produzir resultados espúrios e inconsistentes. Neste trabalho será utilizado o teste de cointegração em painel proposto por Westerlund (2007) que, como será explicado adiante, consiste em verificar se o termo de correção de erros é negativo ou não.

Por fim, após verificar a existência de raiz unitária e de cointegração, será estimado o modelo de correção de erros em painel Pooled Mean Group desenvolvido por Pesaran, Shin e Smith (1999). Este modelo permite separar os determinantes de longo prazo dos determinantes de curto prazo, acomodar a heterogeneidade existente entre os países e ainda 
consegue captar a natureza dinâmica do problema. Uma de suas principais característica está no fato de que ele permite que os coeficientes de curto prazo difiram ao longo da cross-section, mas restringe os coeficientes de longo prazo, de forma que eles sejam iguais entre os países.

Csonto e Ivaschenko (2013) descreve bem as vantagens do Pooled Mean Group: (i) Permitir que os coeficientes de curto prazo difiram ao longo da cross section, o que é crucial para explicar as taxas de juros em um conjunto heterogêneo de países e (ii) Como as variações nos fundamentos internos de cada país não é muito alta ao longo do tempo, estimações que utilizam séries univariadas de apenas um país tendem a subestimar o papel dos fundamentos internos. Ao restringir que os coeficientes de longo prazo sejam iguais entre os países, o Pooled Mean Group leva em conta as variações que existe na cross section, capturando melhor o impacto que os fundamentos internos exercem.

Portanto, toda a metodologia acima descrita pode ser resumida em cinco passos, segue abaixo:

(i) Realizar o teste de dependência cross section proposto por Pesaran (2004).

(ii) Caso as séries não apresentem dependência cross section realizar os testes de raiz unitária em painel da primeira geração, Im, Pesaran e Shin (2003) e Breitung (1999). Caso as séries apresentem dependência cross section realizar os da segunda geração, Pesaran (2007) e Breitung e Das (2005).

(iii) Se for constatado que as séries não possuem raiz unitária. Deve-se proceder estimando um modelo de efeito fixo ou aleatório. Realizando as devidas correções caso haja correlação serial. Se for constatado que as séries possuem raiz unitária deve-se ir para o passo (iv).

(iv) Estimar o modelo Pooled Mean Group proposto por Pesaran, Shin e Smith (1999) e interpretar os coeficientes obtidos.

(v) Verificar se as séries são cointegradas utilizando o teste de cointegração em painel proposto por Westerlund (2007). Se for constatado que as séries não são cointe- 
gradas os resultados devem ser interpretados com cautela, pois podemos estar diante de resultados espúrios. Se for constatado que as séries são cointegradas os resultados podem ser interpretados com mais confiabilidade.

Vale ressaltar ainda que caso os resultados indiquem que algumas séries possuem raiz unitária e outras não, também podemos estimar o modelo Pooled Mean Group, este é válido tanto para processos não estacionários quanto para estacionários. De qualquer forma, é importante que o teste de Westerlund (2007) indique existência de cointegração, caso contrário podemos estar diante de resultados espúrios.

No apêndice A descrevemos a metodologia de forma mais detalhada. Mostrando as hipóteses e demonstrando a consistência dos testes. 


\section{Resultados}

Esse capítulo seguirá os passos descritos no capítulo 4. Nas primeiras seções vamos verificar as propriedades de estacionaridade das séries, primeiro verificando a existência de dependência cross section e depois utilizando o teste de raiz unitária mais apropriado. Nas seções seguintes vamos estimar o modelo de correção de erros em painel Pooled Mean Group verificando se há cointegração entre a variável dependente e as variáveis explicativas.

\subsection{Teste de Dependência Cross Section}

Como ressaltado no apêndice A, a hipótese nula do teste de Pesaran (2004) consiste em independência cross section. Portanto, para as variáveis em que a hipótese nula for rejeitada devemos utilizar os testes de raiz unitária em painel da segunda geração e para as que a hipótese nula não for rejeitada devemos utilizar os testes da primeira geração.

Vale ressaltar que optamos por reportar os resultados dos testes para diferentes números de lags. O teste para ser realizado necessita que não haja correlação serial dos erros, esta pode ser eliminada incluindo lags das variáveis, sendo a quantidade destes determinada por meio dos critérios AIC, Scharwz e Hanna-Quinn. Realizamos esse procedimento, contudo, cada critério indicava um número diferente de lags a serem incluídos (em geral variando de um a três). Por isso, optamos por reportar os resultados dos testes de dependência cross section utilizando de um a quatro lags.

Com exceção de uma variável, todas as outras apresentam forte dependência cross section. A única exceção se referem ao saldo em conta corrente, que mostra praticamente nenhuma dependência. 
Tabela 8 - Teste de Dependência Cross Section

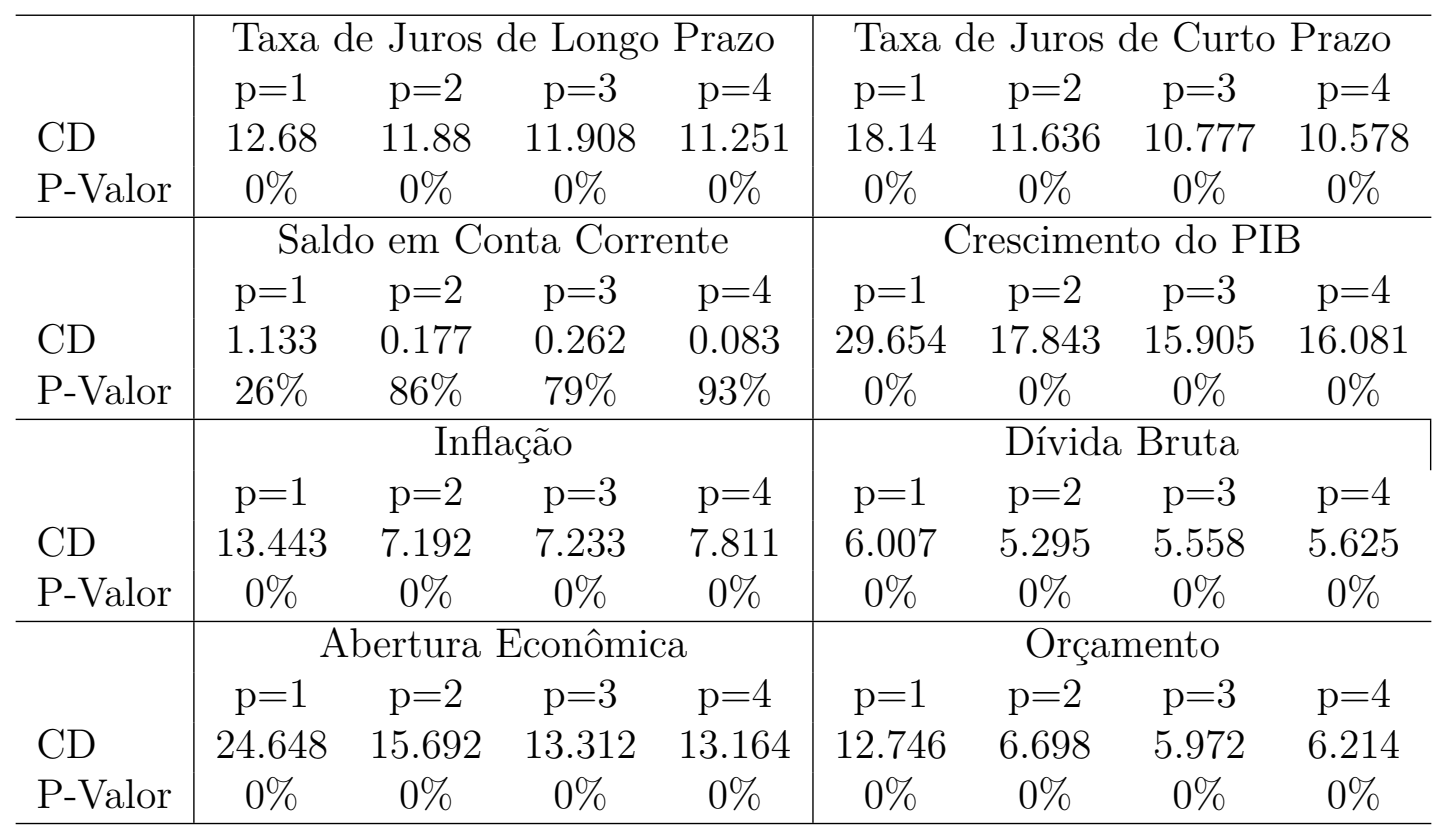




\subsection{Testes de Raiz Unitária}

Os testes de raiz unitária da segunda geração utilizados foram Pesaran (2007) e Breitung e Das (2005). Ambos possuem como hipótese nula a existência de raiz unitária, mas, diferem no que se refere a hipótese alternativa. Pesaran (2007) adota a alternativa heterogênea, isto significa que se houver rejeição da hipótese nula algumas séries são estacionárias, porém não necessariamente todas. Enquanto, Breitung e Das (2005) adotam a alternativa homogênea, isto significa que se houver rejeição da hipótese nula todas as séries são estacionárias.

Também utilizamos dois testes da primeira geração Im, Pesaran e Shin (2003) e Breitung (1999). Em ambos a hipótese nula é de existência de raiz unitária, sendo que o primeiro adota a alternativa heterogênea e o segundo a alternativa homogênea. Esses testes foram aplicados somente na variável saldo em conta corrente, por ter sido a única a não apresentar dependência cross section. 
Tabela 9 - Testes de Raiz Unitária Segunda Geração

\begin{tabular}{ll|llll|llll} 
& & \multicolumn{5}{|c|}{ Pesaran } & \multicolumn{5}{c}{ Breitung \& Das } \\
& & $\mathrm{p}=1$ & $\mathrm{p}=2$ & $\mathrm{p}=3$ & $\mathrm{p}=4$ & $\mathrm{p}=1$ & $\mathrm{p}=2$ & $\mathrm{p}=3$ & $\mathrm{p}=4$ \\
\hline Taxa de Juros & Estatística do Teste & -2.26 & -1.83 & -1.84 & -1.56 & -2.16 & -1.49 & -1.07 & -0.50 \\
de Longo Prazo & P-Valor & $3 \%$ & $42 \%$ & $40 \%$ & $79 \%$ & $2 \%$ & $7 \%$ & $14 \%$ & $31 \%$ \\
\hline Taxa de Juros & Estatística do Teste & -1.58 & -1.57 & -1.47 & -1.37 & -2.00 & -1.21 & -1.07 & -0.53 \\
de Curto Prazo & P-Valor & $77 \%$ & $78 \%$ & $88 \%$ & $94 \%$ & $2 \%$ & $11 \%$ & $14 \%$ & $30 \%$ \\
\hline Crescimento & Estatística do Teste & -2.19 & -1.77 & -1.60 & -1.32 & -3.30 & -2.17 & -1.50 & -0.72 \\
do PIB & P-Valor & $5 \%$ & $50 \%$ & $74 \%$ & $96 \%$ & $0 \%$ & $2 \%$ & $7 \%$ & $23 \%$ \\
\hline \multirow{2}{*}{ Inflação } & Estatística do Teste & -2.27 & -2.03 & -1.54 & -0.96 & -4.20 & -3.72 & -2.04 & 0.01 \\
& P-Valor & $3 \%$ & $16 \%$ & $81 \%$ & $100 \%$ & $0 \%$ & $0 \%$ & $2 \%$ & $50 \%$ \\
\hline Abertura & Estatística do Teste & -1.26 & -0.96 & -0.80 & -0.86 & -2.01 & -0.41 & -0.20 & -0.07 \\
Econômica & P-Valor & $97 \%$ & $100 \%$ & $100 \%$ & $100 \%$ & $2 \%$ & $34 \%$ & $42 \%$ & $47 \%$ \\
\hline \multirow{2}{*}{ Orçamento } & Estatística do Teste & -2.06 & -1.74 & -1.84 & -1.25 & -0.94 & -0.76 & -0.51 & -0.43 \\
& P-Valor & $13 \%$ & $54 \%$ & $40 \%$ & $98 \%$ & $17 \%$ & $22 \%$ & $30 \%$ & $33 \%$ \\
\hline \multirow{2}{*}{ Dívida Bruta } & Estatística do Teste & -2.12 & -1.53 & -1.49 & -1.42 & 0.94 & 0.31 & 0.45 & -0.23 \\
& P-Valor & $9 \%$ & $82 \%$ & $86 \%$ & $91 \%$ & $83 \%$ & $62 \%$ & $67 \%$ & $41 \%$ \\
\hline
\end{tabular}

Tabela 10 - Testes de Raiz Unitária Primeira Geração

\begin{tabular}{ll|llll|llll} 
& & \multicolumn{4}{|c|}{ Im, Pesaran \& Shin } & \multicolumn{5}{c}{ Breitung } \\
& & $\mathrm{p}=1$ & $\mathrm{p}=2$ & $\mathrm{p}=3$ & $\mathrm{p}=4$ & $\mathrm{p}=1$ & $\mathrm{p}=2$ & $\mathrm{p}=3$ & $\mathrm{p}=4$ \\
\hline Saldo em & Estatística do Teste & 0.37 & 0.51 & 0.70 & 2.35 & -0.35 & 0.33 & 0.88 & 1.72 \\
Conta Corrente & P-Valor & $64 \%$ & $70 \%$ & $76 \%$ & $99 \%$ & $36 \%$ & $63 \%$ & $81 \%$ & $96 \%$ \\
\hline
\end{tabular}


Para algumas variáveis como orçamento, dívida bruta e saldo em conta corrente praticamente nenhum resultado consegue rejeitar a existência de raiz unitária. Para outras, como taxa de juros de curto prazo e abertura econômica, apenas um resultado rejeita a hipótese nula de raiz unitária, todos os outros indicam que as séries são não estacionárias.

Contudo, muitas outras variáveis apresentam resultados pouco conclusivos. Sendo que alguns testes indicam inexistência de raiz unitária e outros existência. De fato, a obtenção de resultados mistos é comum na literatura ${ }^{1}$. Pode-se observar que o teste de Pesaran (2007) em geral rejeita com menos frequência a hipótese nula do que o de Breitung e Das (2005). Inflação e crescimento do PIB são as séries que melhor refletem essa situação. No caso dessas variáveis, o primeiro teste indica que todas as séries não são estacionárias (com exceção da utilização de um lag), enquanto o segundo indica que as séries são estacionárias. O teste de Breitung e Das (2005) é mais restritivo, ele impõe que os coeficientes sejam iguais entre os países, enquanto o de Pesaran (2007) permite heterogeneidade dos coeficientes.

Portanto, como os testes em painel não apresentaram resultados muito conclusivos para certas variáveis, utilizamos o teste de raiz unitária univariado Augmented Dickey Fuller para ajudar na interpretação dos resultados, embora seja conhecido o problema de baixa potência desse. Os resultados estão no apêndice B.

Os testes univariados indicam que a maioria das séries são não estacionárias, embora, haja forte evidência de estacionariedade para algumas variáveis, como taxa de juros de longo prazo da China, inflação da China, Chile e Malásia, orçamento da Hungria e da Coréia do Sul, e o crescimento do PIB de grande parte dos países.

Apesar dos testes em painel não terem apresentado resultados muito conclusivos e dos testes univariados terem problema de baixa potência, é difícil negar que as evidências indicam que grande parte das séries possuem raiz unitária. Tanto os testes em painel quanto os univariados apontam para essa conclusão. Além disso, os resultados apontam que não existe um padrão de estacionariedade para a maior parte das séries. Isto é, a

$1 \quad$ Ver Ardagna, Caselli e Lane (2007) e Poghosyan (2014) 
variável taxa de juros pode ser estacionária ou não, depende a qual país ela se refere, o mesmo pode-se dizer para o orçamento, inflação e outras. Os motivos para isso podem ser vários, provavelmente países com melhor gestão econômica tendem a possuir séries de inflação e orçamento mais bem comportadas. Contudo, não é objetivo dessa dissertação analisar essas razões. A única variável que aparenta ser estacionária, talvez para todos os países, é o crescimento do PIB.

Por fim, a relevância dessa seção está no fato dela mostrar que diversas séries utilizadas nesse trabalho não são estacionárias. É importante, portanto, utilizar um modelo mais apropriado para esse problema, como o Pooled Mean Group ao invés de efeito fixo, e após qualquer estimação, verificar se existe cointegração entre as variáveis ou se pelo menos o resíduo é estacionário. Caso contrário, podemos estar enfrentando resultados espúrios.

\subsection{Cointegração e Estimação dos Modelos}

Essa seção contém os principais resultados deste trabalho. Nela será estimado os principais modelos e verificado a existência de cointegração entre as variáveis. A equação a ser estimada será:

$$
\Delta y_{i t}=\alpha_{i}+\delta_{1 i} \Delta X_{i t}^{c}+\delta_{2 i} \Delta Z_{t}^{c}+\phi_{i}\left(y_{i t-1}-\beta_{1} X_{i t-1}^{l}-\beta_{2} Z_{t-1}^{l}\right)+\epsilon_{i t}
$$

Onde $y_{i t}$ é a taxa de juros nominal referente a títulos soberanos com prazo de dez anos, $\alpha_{i}$ é o efeito fixo referente ao pais $i, \delta_{1 i}$ e $\delta_{2 i}$ são vetores linhas dos coeficientes de curto prazo, heterogêneo entre os países. $\beta_{1}$ e $\beta_{2}$ são os vetores linhas dos coeficientes de longo prazo, homogêneo entre os países. $X_{i t}$ é o vetor coluna de variáveis explicativas referentes a fundamentos internos, $Z_{t}$ é o vetor coluna de variáveis explicativas referente a fatores externos. As variáveis explicativas de curto e longo prazo não são necessariamente iguais, por isso foi utilizado o sobrescrito $c$ e $l$. $\phi_{i}$ é o coeficiente de correção de erros e $\epsilon_{i t}$ é o erro do modelo. Os coeficientes do modelo são todos estimados de forma conjunta pelo 
método de máxima verossimilhança.

Junto com a estimação dos modelos serão reportados os testes de cointegração de Westerlund (2007). Como reportado no apêndice A, a hipótese nula desses testes consistem na não existência de cointegração.

Abaixo descrevemos os fundamentos internos escolhidos como variáveis explicativas e o sinal esperado do seus respectivos coeficientes, bem como a explicação teórica de seus efeitos.

Dívida Bruta como percentual do PIB (DivBruta): Esperamos que a dívida afete de forma positiva a taxa de juros. Essa variável afeta o juros via três canais principais: crowding-out, risco de default e risco de monetização. Todos estes exercem efeito positivo. Contudo, diversos estudos na literatura mostram que esse efeito não ocorre de forma linear. Portanto, vamos incluir a variável dívida ao quadrado para captar essa não linearidade.

Superávit Nominal como percentual do PIB (SupNom): Similar a dívida, esperamos que o superávit afete a taxa de juros de forma negativa atuando via três canais: crowdingout, risco de default e risco de monetização.

Saldo em Conta Corrente como percentual do PIB (SaldoCC): Esperamos que esta variável afete de forma negativa a taxa de juros. Um saldo em conta corrente positivo significa que o país produz mais do que consome, ou seja, há um excesso de oferta em relação a demanda interna, há sobra de poupança o que pressiona para baixo as taxas de juros. Quando o saldo em conta corrente é negativo o país consome mais do que produz, há necessidade de absorver poupança externa, a poupança interna é insuficiente para satisfazer a demanda, o que pressiona para cima as taxas de juros.

Crescimento do PIB (CrescPIB): Não há consenso se essa variável afeta de forma positiva ou negativa a taxa de juros. Por um lado, maior crescimento do PIB reduz o nível de endividamento, propicia maior crescimento da receita e maior facilidade para pagamento da dívida, reduzindo o risco de default e monetização, pressionando para baixo a taxa de juros. Por outro lado, maior crescimento do PIB representa maior demanda por recursos na economia, o que pressiona para cima as taxas de juros. 
Inflação (Inflacao): Esperamos que a inflação afete de forma positiva a taxa de juros. Quanto maior a inflação maior a taxa de juros exigida para manter a estabilidade dos preços.

Abertura Econômica (AbertEcon): Esperamos que essa variável afete de forma negativa a taxa de juros. Um país com maior abertura econômica tende a ser mais eficiente na utilização de seus recursos e é mais propenso a conseguir financiamento externo quando necessita, pressionando para baixo a sua taxa de juros.

Juros de Curto Prazo (TaxaMeta): Essa variável é medida pela taxa meta definida pelo Banco Central do país. É esperado que seu efeito seja positivo nos juros de longo prazo, contudo, sua utilização será realizada apenas com o objetivo de controlar pelos efeitos de política monetária. Portanto, vamos inclui-la somente como variável explicativa no curto prazo (em diferença). Um dos objetivos desse trabalho é compreender porque em alguns países o nível da taxa de juros de longo prazo é mais alto que em outros, se incluirmos o nível da taxa de curto prazo dentro do termo de correção de erros estaremos eliminado o efeito que os outros fundamentos internos exercem sobre o nível da variável dependente.

Com relação aos fatores externos escolhemos quatro variáveis explicativas, são elas:

Taxa livre de risco (TaxaLivreRisco): Apesar das controvérsias existentes na literatura esperamos que seu efeito seja positivo. Essa variável será representada pela taxa de juros dos títulos do Tesouro americano com vencimento de 10 anos. Uma menor taxa de juros aumenta a liquidez no sistema financeiro mundial e favorece a entrada de capitais nos países emergentes reduzindo a taxa de juros nestes países.

Aversão ao Risco dos Investidores Internacionais (HighYield): Utilizamos o yield dos High Yield Bonds americanos para representar essa variável. Esperamos que seu efeito seja positivo, uma maior aversão ao risco favorece a retirada de capitais de países emergentes, pressionando para cima suas taxas de juros.

Política Fiscal Mundial (USASupNom e USADivBruta): Para representar esse indicador utilizamos duas variáveis: o superávit nominal e a dívida do governo americano. 
Esperamos que o efeito da primeira seja negativo e o da segunda positivo. Tanto o aumento do déficit (redução do superávit) quanto o aumento da dívida americana exercem pressão substantiva sobre a liquidez mundial, retirando recursos dos países emergentes para financiar o governo americano, o que pressiona para cima as taxas de juros dos países de menor renda.

\subsubsection{Apenas Fundamentos Internos}

Nessa primeira estimação vamos avaliar apenas os efeitos dos fundamentos internos sobre a taxa de juros nominal de longo prazo. Abaixo reportarmos apenas o modelo final que foi obtido depois de eliminar todas as variáveis não significativas. No apêndice C apresentamos todos os passos.

Tabela 11 - Resultados Estimados - Pooled Mean Group

\begin{tabular}{|c|c|c|c|}
\hline Variável & Coeficiente & (Erro Padrão) & P-Valor \\
\hline \multicolumn{4}{|c|}{ Coeficientes de LP } \\
\hline CrescPIB & $-0.146^{* *}$ & $(0.036)$ & $0,0 \%$ \\
\hline AbertEcon & $-0.072^{* *}$ & $(0.014)$ & $0,0 \%$ \\
\hline DivBruta & $-0.333^{* *}$ & $(0.074)$ & $0,0 \%$ \\
\hline DivBruta2 & $0.003^{* *}$ & $(0.001)$ & $0,3 \%$ \\
\hline \multicolumn{4}{|c|}{ Coeficientes de CP - Média ${ }^{3}$} \\
\hline CorrErros & $-0.152^{* *}$ & $(0.052)$ & $0,4 \%$ \\
\hline TaxaMeta & $0.334^{* *}$ & $(0.088)$ & $0,0 \%$ \\
\hline Intercepto & $2.849^{* *}$ & $(0.995)$ & $0,4 \%$ \\
\hline $\mathrm{N}$ & & 416 & \\
\hline Log-likelihood & & 6.575 & \\
\hline Significância : & $*: 5 \%$ & $* *: 1 \%$ & \\
\hline
\end{tabular}

Tabela 12 - Testes de Cointegração de Westerlund

\begin{tabular}{lrr}
\hline & Estatística & P-Valor \\
\hline Gt & -2.411 & $34 \%$ \\
$\mathrm{Ga}$ & -9.162 & $47 \%$ \\
$\mathrm{Pt}$ & -6.315 & $68 \%$ \\
$\mathrm{~Pa}$ & -7.284 & $53 \%$ \\
\hline
\end{tabular}

As variáveis significativas apresentaram coeficientes dentro do esperado. Abertura econômica se mostrou significante e negativo, um aumento de 1 p.p. no nível de exportações 
mais importações sobre o PIB reduz a taxa de juros em 0.07 p.p.. A dívida apresentou efeito não linear, em linha com grande parte da literatura ${ }^{2}$, de acordo com os coeficientes o efeito da dívida sobre o juros só se torna positivo a partir de $55 \%$ do PIB, e aumenta cada vez mais à medida que a dívida cresce. As observações da nossa amostra indicam que a mediana da dívida é de $35 \%$, o terceiro quartil é de $49 \%$ e o valor máximo é de 81\%. Portanto, a dívida só começa a pressionar o juros para cima quando o país já está consideravelmente endividado.

O coeficiente do crescimento do PIB se mostrou significante e negativo, um aumento de 1 p.p. no crescimento reduz a taxa de juros em 0.15 p.p.. Isso mostra indícios de que o efeito que o crescimento do PIB exerce na redução do risco de calote e de monetização da dívida é superior ao efeito de aumento da demanda. A taxa de juros de curto prazo apresentou-se positiva e significante mostrando-se uma boa variável de controle para os efeitos da política monetária. Por fim, o coeficiente de correção de erros se mostrou negativo e significativo indicando existência de cointegração entre as variáveis.

É importante também ressaltar as variáveis que não se mostraram significativas como o superávit nominal, a inflação e o saldo em conta corrente. É relativamente comum na literatura a obtenção de resultados onde ou o déficit ou a dívida (mas não os dois) são significativos. A não significância da inflação também é um quebra cabeça a ser resolvido, vamos verificar como essa variável se comporta nas próximas estimações.

Vale ainda ressaltar o fato de que os fundamentos internos se mostraram significantes apenas no longo prazo, isto é, eles afetam somente o nível de equilíbrio da taxa de juros. Um aumento do crescimento do PIB ou da abertura econômica não ira reduzir de imediato os juros em 0.15 p.p. e 0.07 p.p., mas irá mudar o nível de equilíbrio dessa variável, que irá convergir para o novo valor com o passar do tempo.

Apesar do coeficiente de correção de erros ter se mostrado negativo e significante, os testes de cointegração de Westerlund não conseguiram rejeitar a hipótese de não cointegração do modelo. Portando, todos os coeficientes devem ser interpretados com

$\overline{2}$ Ardagna, Caselli e Lane (2007) e Alper e Forni (2011) 
cautela, visto que podemos estar diante de resultados espúrios.

Cabe ressaltar que essa primeira estimação possui caráter meramente ilustrativo. Como mostrado na seção 5.1, as séries possuem dependência cross-section, portanto, é necessário que se inclua na estimação uma variável que capte o fator comum existente entre as séries dos diferentes países. Caso contrário, os erros possuirão correlação cross-section, o que viola uma das hipóteses do Pooled Mean Group descritas no apêndice A. Em linha com grande parte da literatura, nas próximas seções, vamos incluir a taxa livre de risco, a taxa dos high yield bonds e variáveis de política fiscal mundial para captar esse fator comum.

Pesaran (2003) recomenda utilizar a média da variável dependente para representar o fator comum, portanto, também vamos realizar essa estimação reportando os resultado no Apêndice E. Consideramos, porém, que a utilização das variáveis citadas no parágrafo anterior possuem razões teóricas mais fortes e possibilitam interpretações mais condizentes com os objetivos estipulados neste trabalho.

\subsubsection{Fatores Externos: Aversão ao Risco e Política Monetária Global}

Nessa segunda estimação incluímos entre as variáveis explicativas a taxa de juros livre de risco e a aversão ao risco dos investidores internacionais. Abaixo reportarmos apenas o modelo final que foi obtido depois de eliminar todas as variáveis não significativas. No apêndice $\mathrm{C}$ apresentamos todos os passos.

Nesse modelo fica evidente o papel que os fatores externos exercem sobre as taxas de juros. A taxa livre de risco exerce efeito positivo tanto no curto como no longo prazo, sendo que o aumento de um ponto percentual eleva o nível de equilíbrio da taxa de juros interna em 0,48 p.p.. A aversão ao risco dos investidores exercem efeito apenas no longo prazo, seu efeito no nível de equilíbrio é de 0,18 p.p..

A inflação, abertura econômica e saldo em conta corrente possuem coeficientes com sinais de acordo com o esperado, de 0,11 p.p., -0,06 p.p. e -0,2 p.p., respectivamente. O

3 Os valores reportados se referem à média cross section dos coeficientes estimados. Os resultados por país estão reportados no apêndice $\mathrm{D}$. 
Tabela 13 - Resultados Estimados - Pooled Mean Group

\begin{tabular}{lccc}
\hline \hline \multicolumn{1}{c}{ Variável } & Coeficiente & (Erro Padrão) & P-Valor \\
\hline \hline \multicolumn{4}{c}{ Coeficientes de LP } \\
\hline TaxaLivreRisco & $0.480^{* *}$ & $(0.113)$ & $0.0 \%$ \\
HighYield & $0.183^{* *}$ & $(0.022)$ & $0.0 \%$ \\
SaldoCC & $-0.208^{* *}$ & $(0.052)$ & $0.0 \%$ \\
CrescPIB & $0.091^{* *}$ & $(0.029)$ & $0.1 \%$ \\
Inflacao & $0.113^{* *}$ & $(0.037)$ & $0.2 \%$ \\
AbertEcon & $-0.056^{* *}$ & $(0.009)$ & $0.0 \%$ \\
DivBruta & -0.051 & $(0.044)$ & $25.1 \%$ \\
DivBruta2 & $0.002^{* *}$ & $(0.001)$ & $0.0 \%$ \\
\hline \multicolumn{4}{c}{ Coeficientes de CP - Média ${ }^{3}$} \\
\hline CorrErros & $-0.165^{*}$ & $(0.068)$ & $1.5 \%$ \\
TaxaLivreRisco & $0.385^{* *}$ & $(0.106)$ & $0.0 \%$ \\
TaxaMeta & $0.353^{* *}$ & $(0.083)$ & $0.0 \%$ \\
Intercepto & $0.927^{*}$ & $(0.400)$ & $2.0 \%$ \\
\hline \multicolumn{4}{c}{416} \\
\hline N & -128.046 \\
Log-likelihood & \multirow{4}{c}{$* * 1 \%$}
\end{tabular}

Tabela 14 - Testes de Cointegração de Westerlund

\begin{tabular}{lrr}
\hline & Estatística & P-Valor \\
\hline $\mathrm{Gt}$ & -3.241 & $2 \%$ \\
$\mathrm{Ga}$ & -10.672 & $17 \%$ \\
$\mathrm{Pt}$ & -10.799 & $7 \%$ \\
$\mathrm{~Pa}$ & -10.591 & $15 \%$ \\
\hline
\end{tabular}

efeito da abertura econômica é levemente inferior ao observado no modelo anterior, porém, ainda assim, bastante semelhante. A dívida continua com efeito não linear. Contudo, neste modelo o efeito da dívida sobre os juros passa a ser positivo para níveis de dívida de $13 \%$ do PIB, valor bastante diferente dos $55 \%$ antes obtido.

Outra mudança em relação ao modelo anterior se refere ao crescimento do PIB, que passa a exercer efeito positivo e significante sobre a taxa de juros. Mostrando indícios de que maior crescimento exerce pressão sobre os recursos escassos da economia de tal forma que esse efeito possui magnitude maior que o referente à diminuição do risco de calote e/ou monetização da dívida.

Por fim, os testes de cointegração de Westerlund mostraram resultados dúbios, 
porém, mais favoráveis a existência de cointegração do que no modelo anterior. O que sinaliza a importância de incluir os fatores externos no modelo para explicar a taxa de juros interna dos países emergentes. 


\subsubsection{Fatores Externos: Aversão ao Risco, Políticas Monetária e Fiscal Globais}

Em nosso modelo final incluímos também variáveis referentes à política fiscal mundial. Nenhuma se mostrou significativa no longo prazo e apenas o déficit do governo americano se mostrou positivo e significante no curto prazo. Isso mostra que um afrouxamento da política fiscal dos Estados Unidos pressiona para cima as taxas de juros dos países emergentes no curto prazo, mas não altera seu valor de equilíbrio.

Tabela 15 - Resultados Estimados - Pooled Mean Group

\begin{tabular}{|c|c|c|c|}
\hline Variável & Coeficiente & (Erro Padrão) & P-Valor \\
\hline \multicolumn{4}{|c|}{ Coeficientes de LP } \\
\hline TaxaLivreRisco & $0.500^{* *}$ & $(0.101)$ & $0.0 \%$ \\
\hline HighYield & $0.106^{* *}$ & $(0.027)$ & $0.0 \%$ \\
\hline SaldoCC & $-0.313^{* *}$ & $(0.060)$ & $0.0 \%$ \\
\hline Inflacao & $0.088^{*}$ & $(0.044)$ & $4.4 \%$ \\
\hline AbertEcon & $-0.039^{* *}$ & $(0.009)$ & $0.0 \%$ \\
\hline DivBruta & $-0.157^{* *}$ & $(0.050)$ & $0.2 \%$ \\
\hline DivBruta2 & $0.003^{* *}$ & $(0.001)$ & $0.0 \%$ \\
\hline \multicolumn{4}{|c|}{ Coeficientes de CP - Média ${ }^{3}$} \\
\hline CorrErros & $-0.185^{*}$ & $(0.074)$ & $1.2 \%$ \\
\hline TaxaLivreRisco & $0.346^{* *}$ & $(0.110)$ & $0.2 \%$ \\
\hline TaxaMeta & $0.393^{* *}$ & $(0.080)$ & $0.0 \%$ \\
\hline USASupNom & $-0.141^{* *}$ & $(0.038)$ & $0.0 \%$ \\
\hline Intercepto & $1.472^{*}$ & $(0.608)$ & $1.5 \%$ \\
\hline $\mathrm{N}$ & & 416 & \\
\hline Log-likelihood & & 6.574 & \\
\hline
\end{tabular}

Tabela 16 - Testes de Cointegração de Westerlund

\begin{tabular}{lrr}
\hline & Estatística & P-Valor \\
\hline $\mathrm{Gt}$ & -3.241 & $2 \%$ \\
$\mathrm{Ga}$ & -10.672 & $15 \%$ \\
$\mathrm{Pt}$ & -10.799 & $6 \%$ \\
$\mathrm{~Pa}$ & -10.591 & $12 \%$ \\
\hline
\end{tabular}

As variáveis que afetam a taxa de juros no longo prazo são semelhantes aos da especificação anterior. O saldo em conta corrente possui efeito negativo sobre as taxas de juros, o crescimento de 1 p.p. reduz a taxa em 0,3 p.p., valor semelhante ao coeficiente do modelo anterior que é de 0,2 p.p.. Abertura econômica também possui efeito negativo, mas 
esta possui magnitude menor do que nas especificações anteriores, de -0,04 p.p.. A taxa de juros livre de risco, aversão ao risco dos investidores e inflação afeta de forma positiva o valor de equilíbrio da taxa de juros, em 0,5 p.p., 0,1 p.p. e 0,09 p.p., respectivamente, valores semelhantes ao modelo anterior.

A dívida possui efeito não linear sobre a taxa de juros sendo que apenas para valores acima de $26 \%$ do PIB seu efeito passa a ser positivo. Esse limiar é bastante diferente dos obtidos nas especificações anteriores que foram de $13 \%$ e $55 \%$. De qualquer forma, os três modelos mostram que o efeito da dívida sobre os juros é não linear e aumenta a medida que se eleva o valor da dívida.

A principal diferença entre essa especificação e as anteriores se refere ao fato de que o crescimento do PIB deixa de ser significativo. De fato, os três modelos estimados nesta dissertação mostraram resultados bastante diferentes para essa variável. No primeiro obteve-se o resultado de que seu efeito é negativo, no segundo que seu efeito é positivo e no terceiro que seu efeito não é significante. Existem razões teóricas que indicam o crescimento do PIB afeta a taxa de juros por diferentes canais, em alguns canais este efeito é positivo enquanto em outros é negativo. Além disso, as evidências empíricas obtidas em estudo anteriores também não mostram resultados conclusivos. Portanto, ao que tudo indica o efeito do crescimento sobre os juros é dúbio, pode ser positivo ou negativo, depende da magnitude de cada canal que varia de acordo com a base de dados utilizada.

Os testes de Westerlund mostram evidências de cointegração um pouco mais favoráveis que no modelo anterior.

O modelo possui poder de predição adequado, nos gráficos abaixo comparamos os valores previstos com os valores observados: 
70

Figura 13 - Valores Previstos vs Observados 1

Brasil

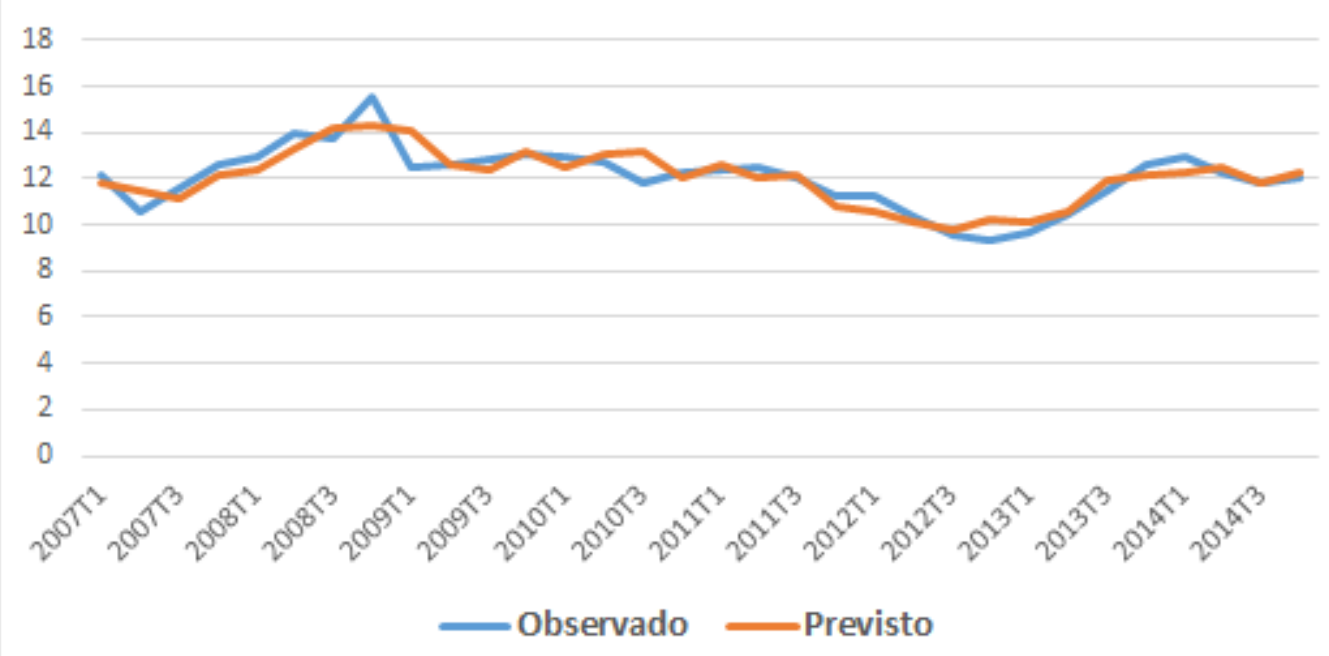

Bulgária
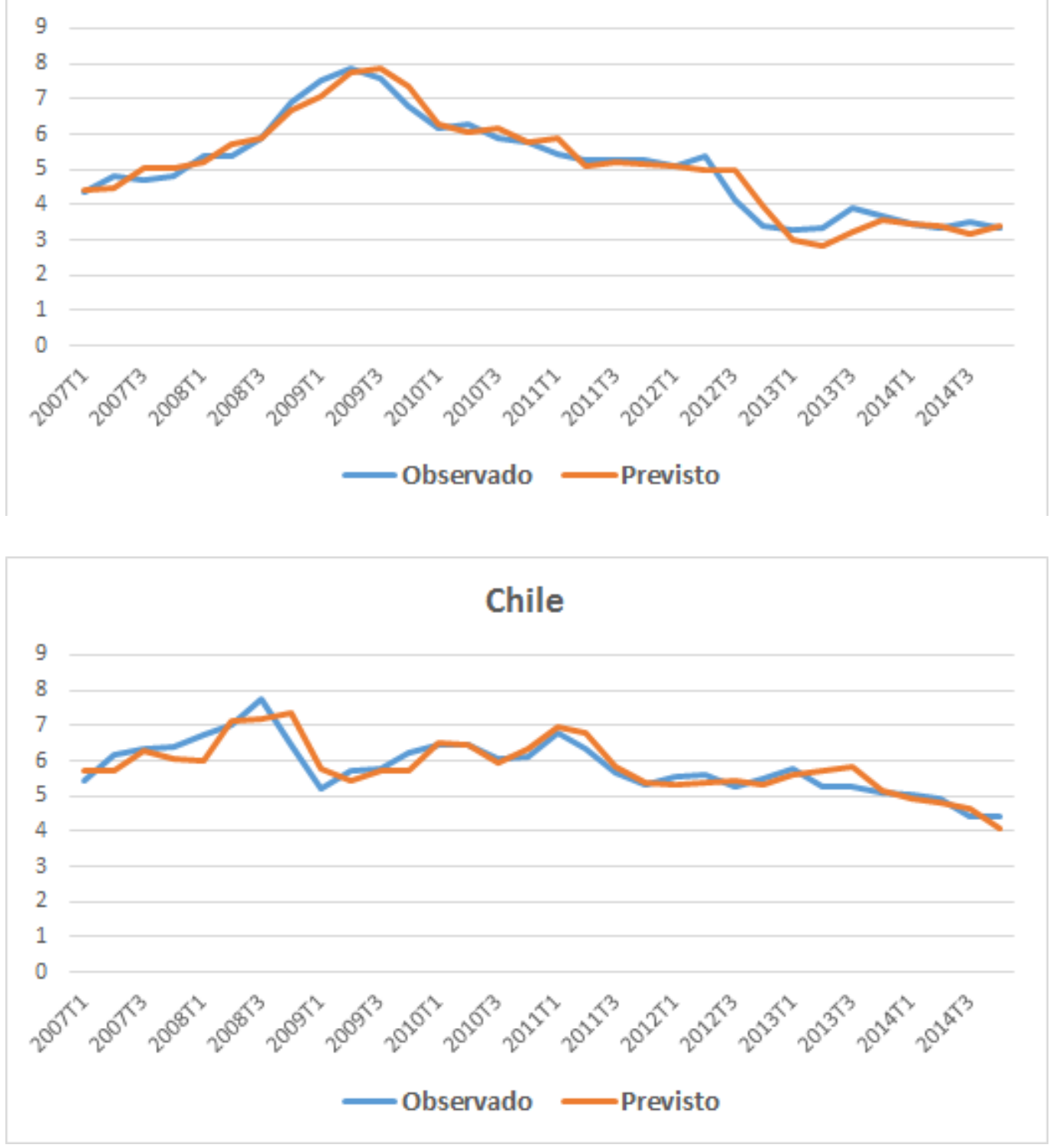
71

Figura 14 - Valores Previstos vs Observados 2

China

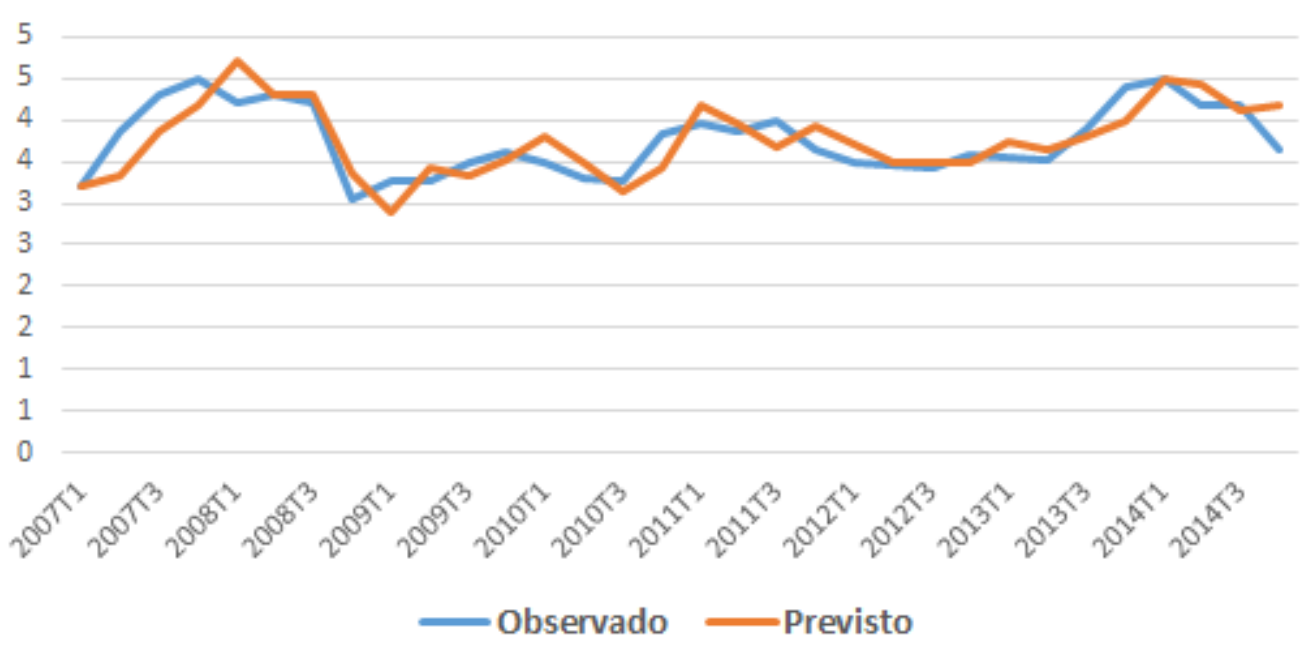

Colômbia

14

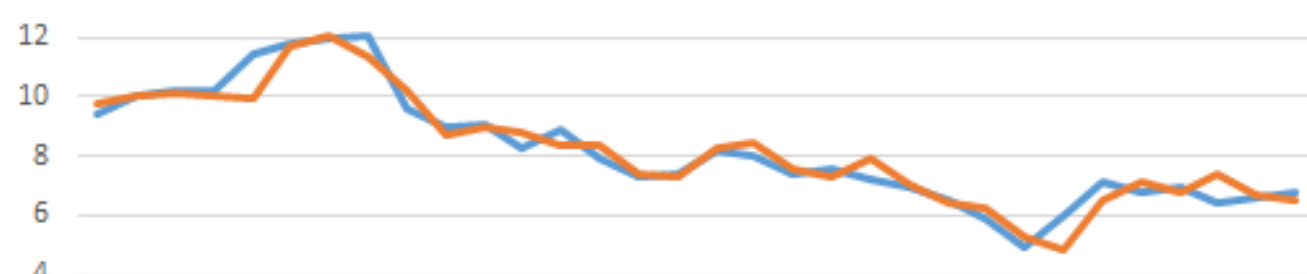

4

2

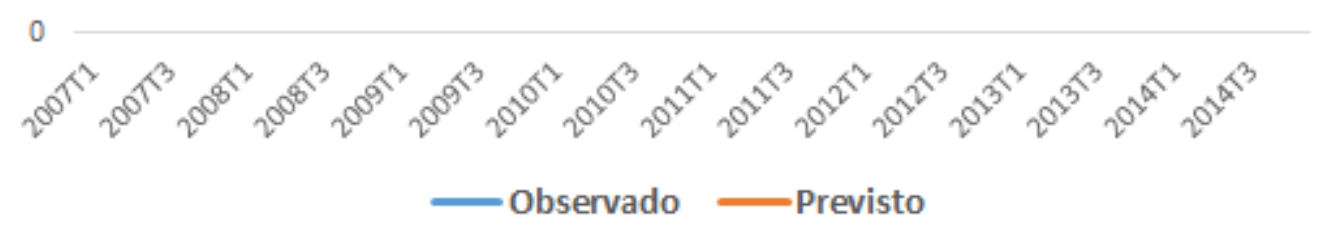

República Tcheca

6

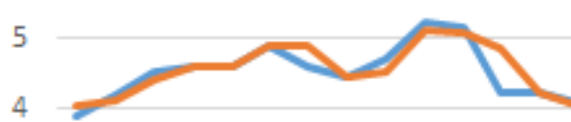

3

2

1

0

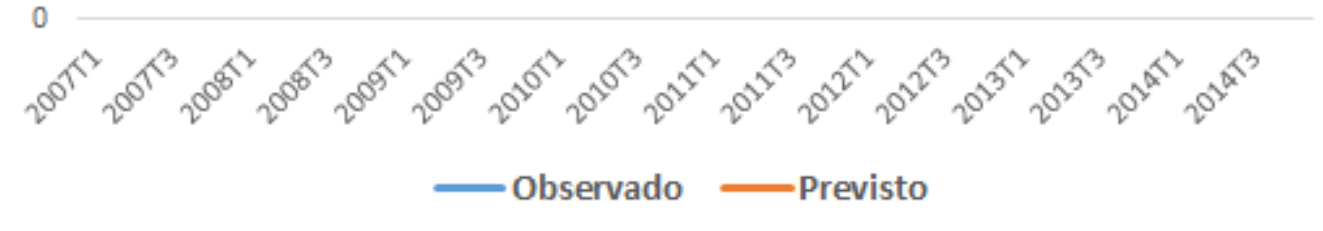


72

Figura 15 - Valores Previstos vs Observados 3

Hungria

12

10

8

6

4

2

0

Malásia

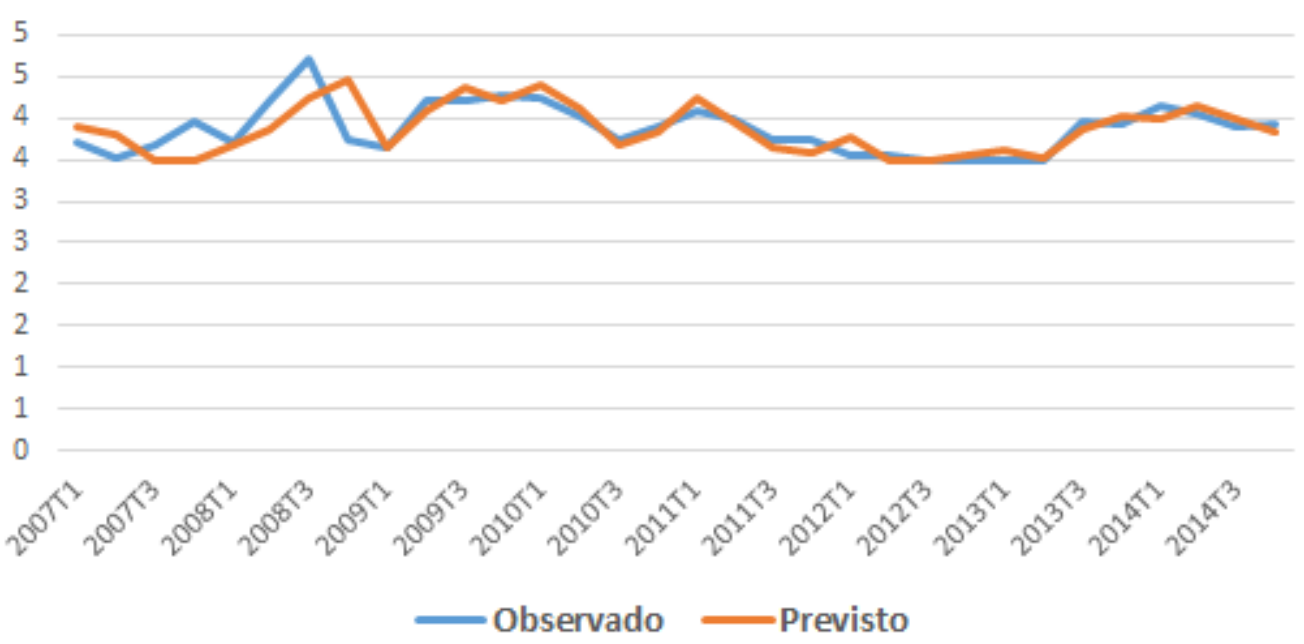

México

10

9

8

7

5

4

3

2

1

0

v

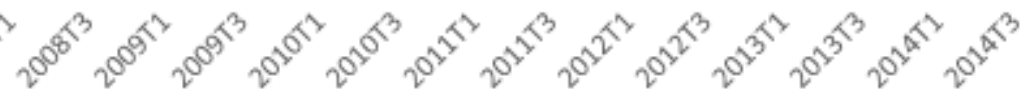

—observado Previsto 
73

Figura 16 - Valores Previstos vs Observados 4

Polônia

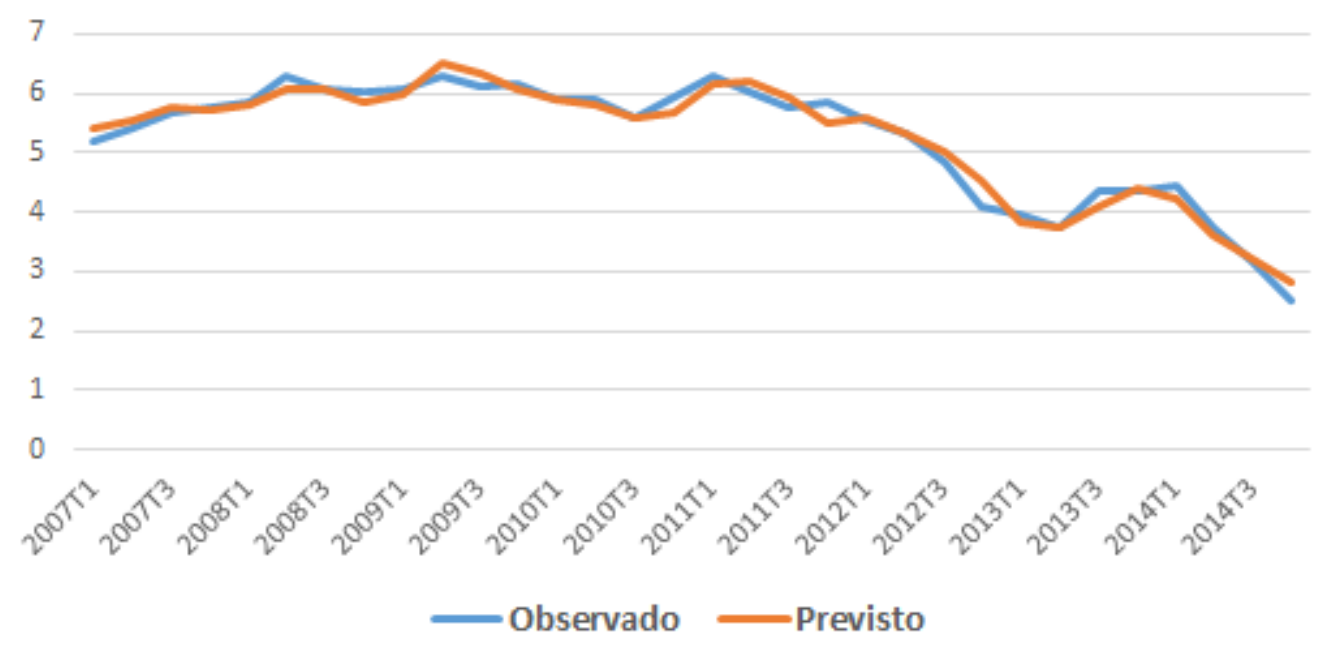

Rússia

14

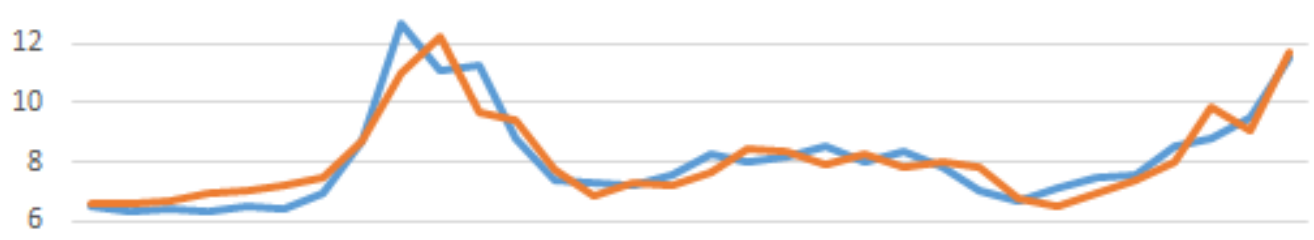

4

2

0

$\nu^{\circ}$

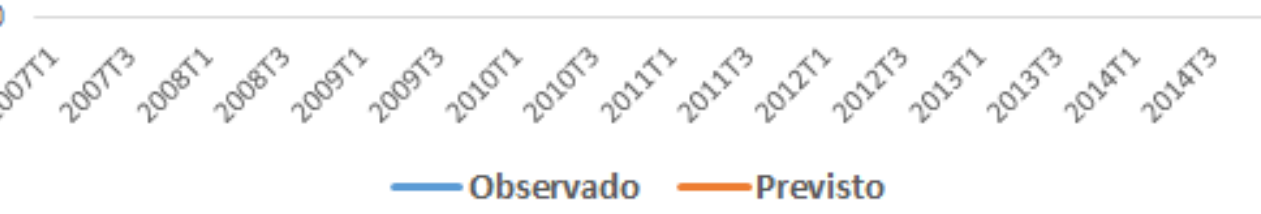

África do Sul

12

10

8

6

4

2

0

$\operatorname{los}^{2}$

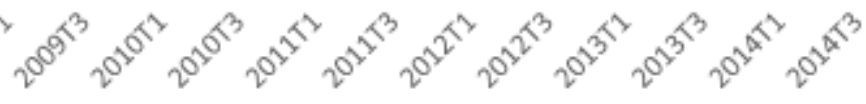

Observado Previsto 
Figura 17 - Valores Previstos vs Observados 5

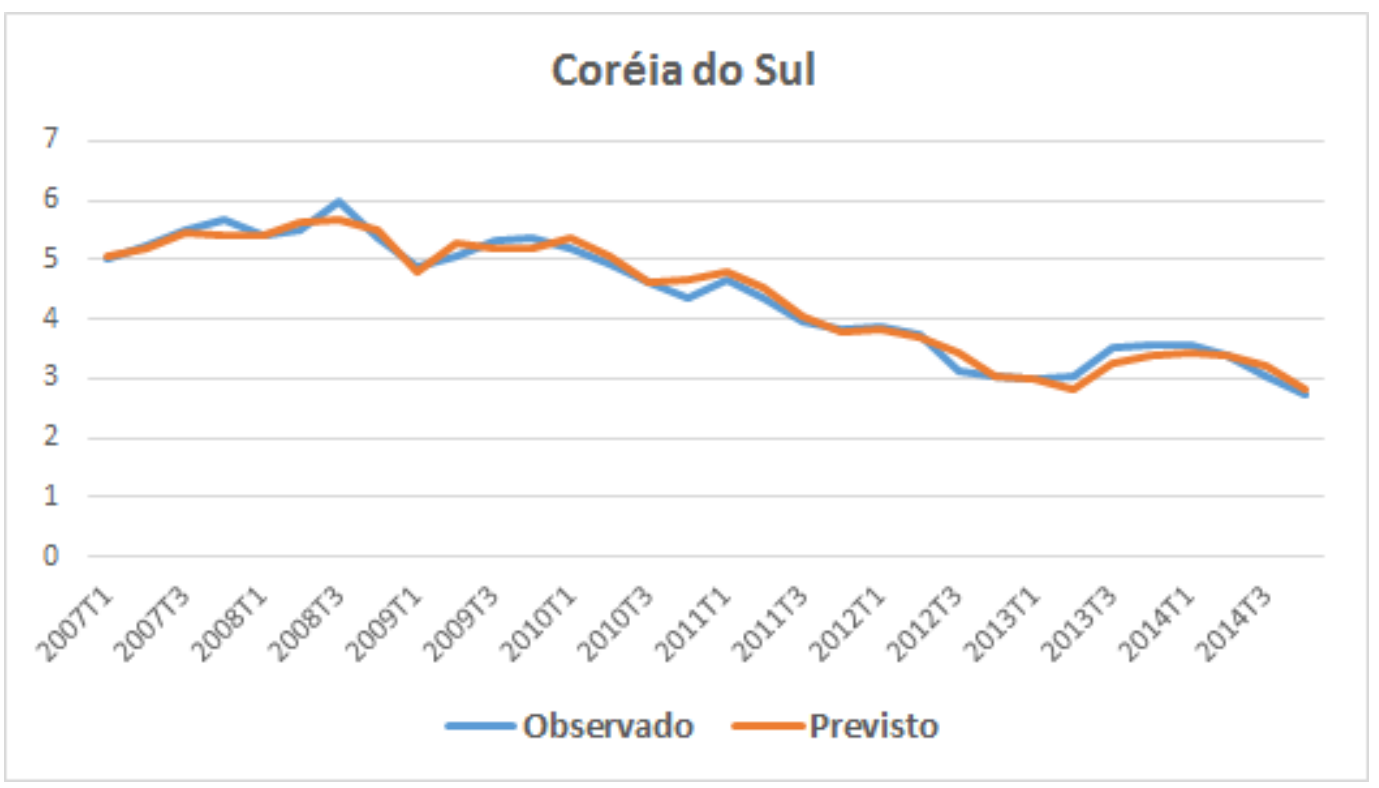

Vale ressaltar que optamos por não realizar alguma análise de quebra estrutural devido ao pouco número de observações. A base de dados constitui de 13 países ao longo de 33 trimestres, totalizando 429 observações. No último modelo, por exemplo, estimamos 72 parâmetros, 65 de curto prazo e 7 de longo prazo, número já bastante elevado para o número de observações. Incluir alguma quebra estrutural iria diminuir excessivamente o número de graus de liberdade, portanto, optamos por não entrar nessa análise.

Outro ponto que deve ser mencionado se refere à utilização da taxa de juros nominal como variável dependente e não da taxa de juros real. Ao utilizar a taxa de juros nominal, torna-se mais provável a existência de endogeneidade no modelo. Um aumento da taxa nominal pode advir simplesmente de um aumento da inflação, a qual tende a afetar negativamente o saldo em conta corrente. Portanto, um aumento do juros nominal pode resultar em piora no saldo em conta corrente, criando uma dupla causalidade entre essas duas variáveis. De fato, o ideal seria utilizar a taxa de juros real como variável dependente, contudo, não foi possível obter dados de expectativa de inflação para a maior parte dos países da amostra. Impossibilitando o cálculo do juro real.

Em linha com a maior parte da literatura, neste trabalho não será realizada uma análise mais detalhada sobre a existência ou não de endogeneidade. Ficando, portanto, 
como sugestão para trabalhos posteriores, bem como a utilização da taxa de juros real. 



\section{O Caso Brasileiro}

Nesse capítulo será analisado como se comportaria a taxa de juros brasileira se o país apresentasse fundamentos internos em linha com a média dos países emergentes. O Brasil apresentou durante o período analisado indicadores bastante piores que a média dos outros 12 países em nossa amostra e o nível da taxa de juros foi muito mais elevado também. Os gráficos abaixo retratam essa situação:

Figura 18 - Brasil Comparativo - Juros Nominal de Longo Prazo

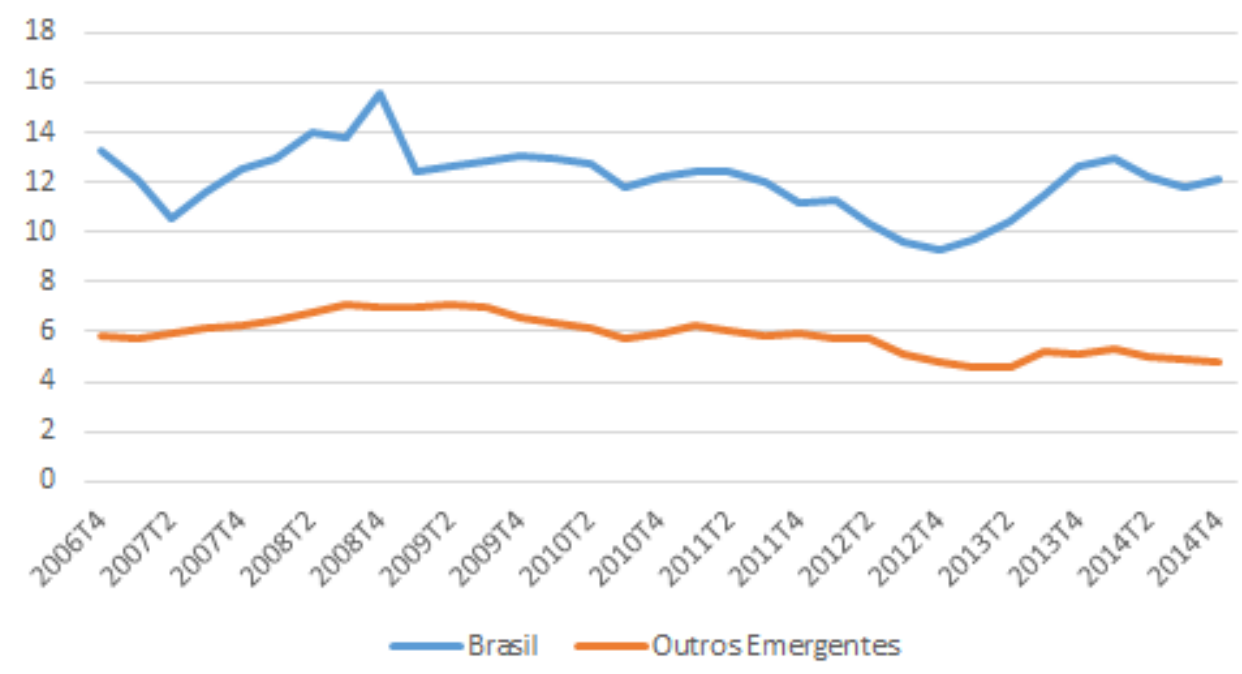

Figura 19 - Brasil Comparativo - Inflação

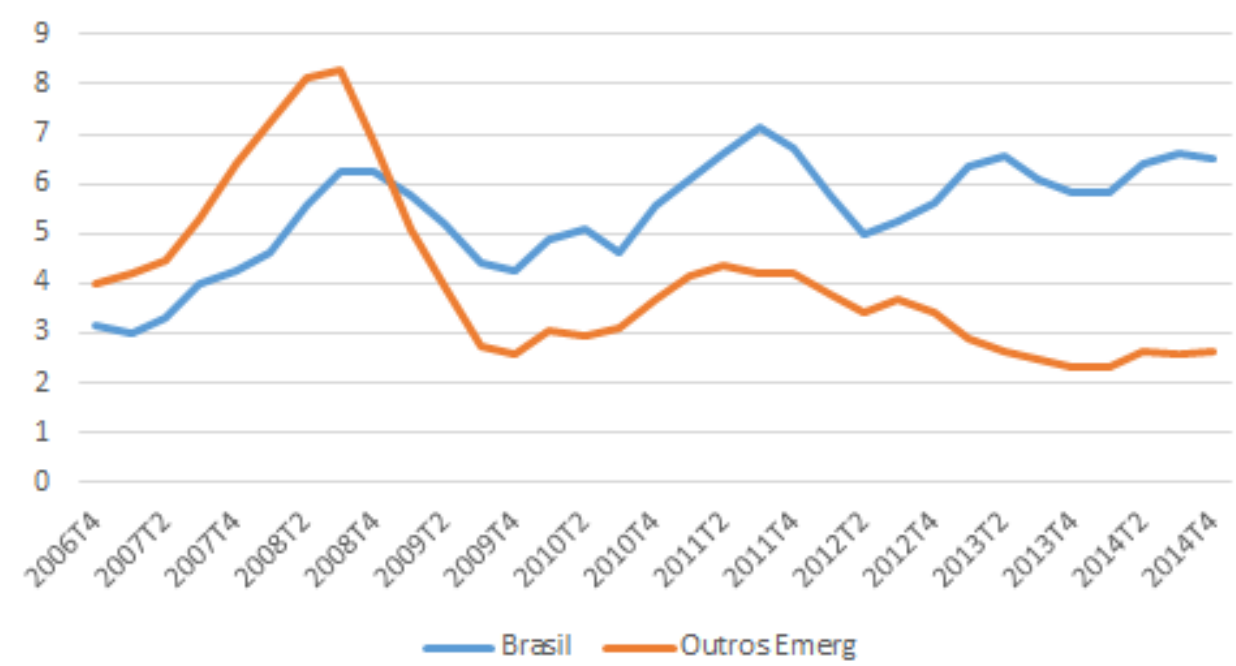


Figura 20 - Brasil Comparativo - Saldo em Conta Corrente

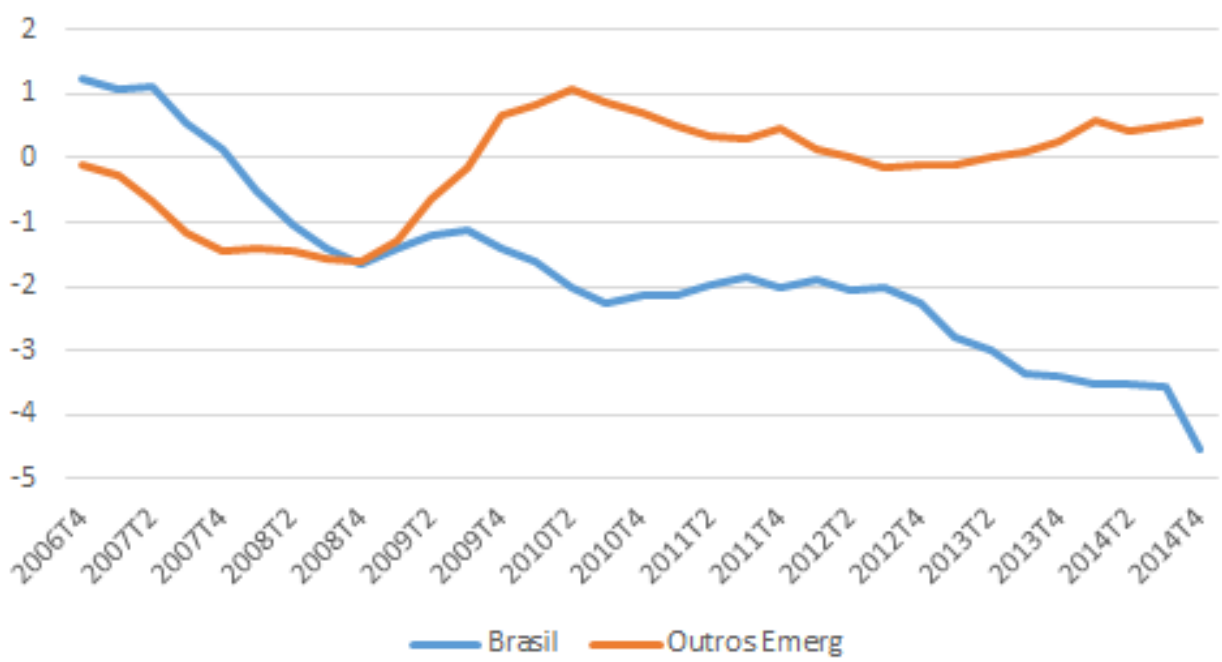

Figura 21 - Brasil Comparativo - Abertura Econômica

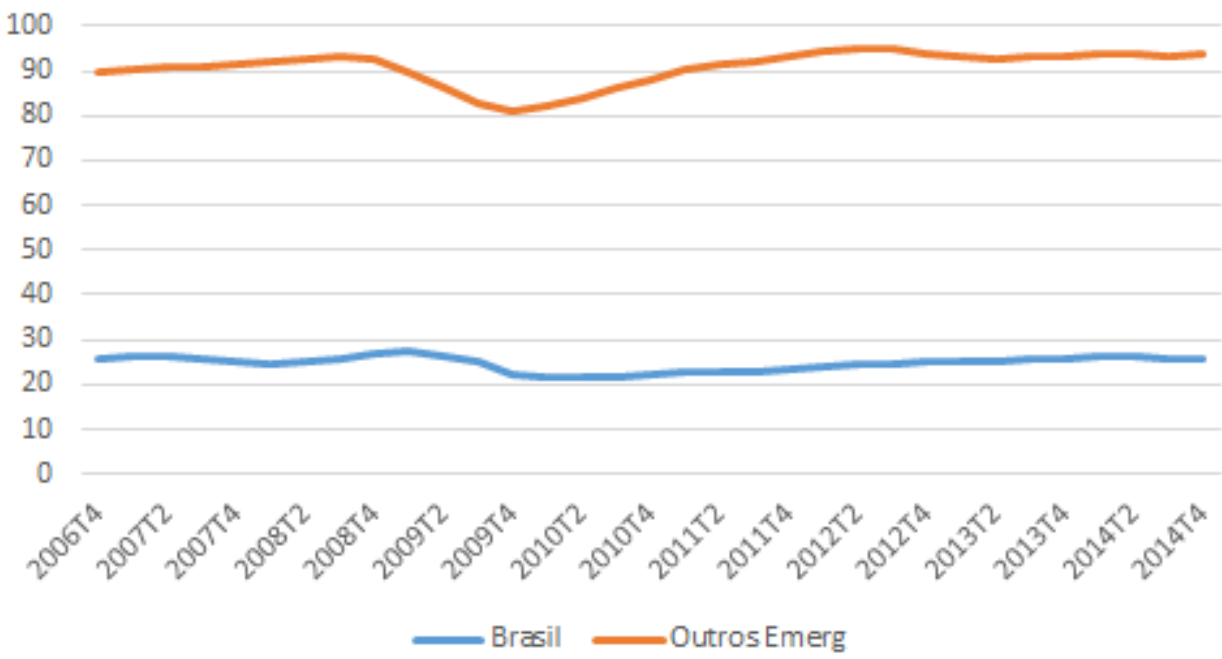


Figura 22 - Brasil Comparativo - Dívida Bruta

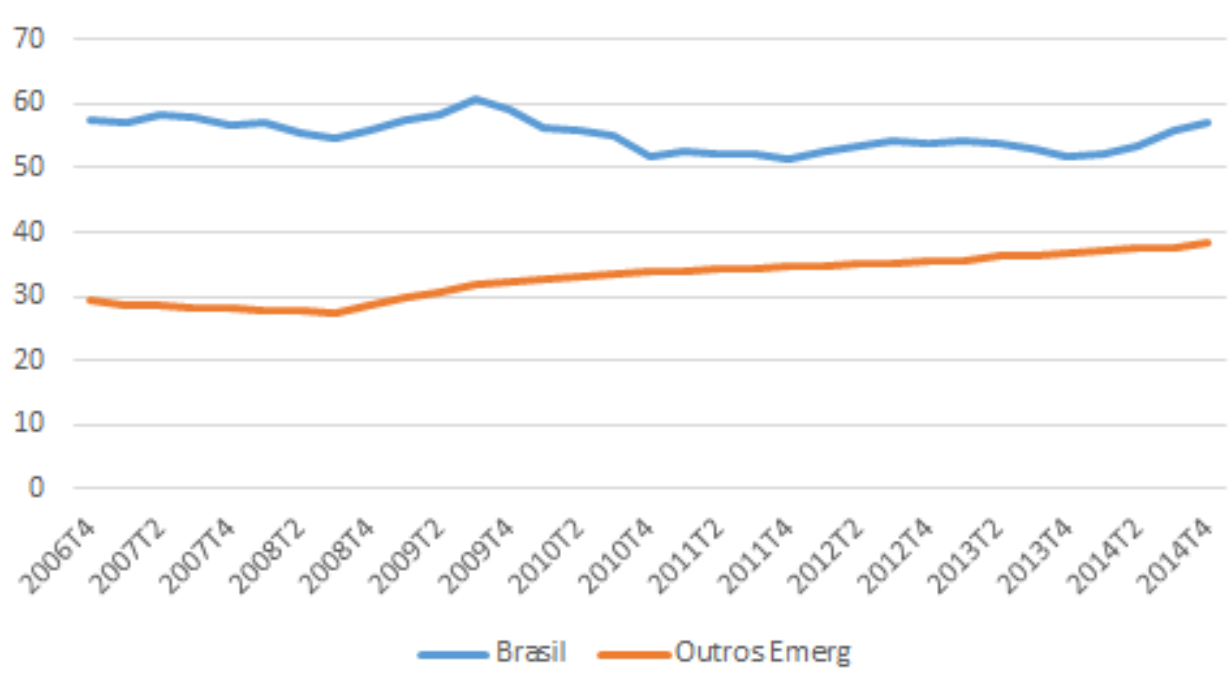

Apenas pela análise dos gráficos é incerto até que ponto as variáveis analisadas são responsáveis pela diferença entre a taxa de juros brasileira e a taxa média dos outros países emergentes. Certamente, a melhora nos fundamentos internos do Brasil deve levar a uma redução substancial da taxa de juros, porém, é difícil saber se essa redução é suficiente para que a taxa atinja a média dos outros países.

Para analisar essa questão vamos utilizar o último modelo que estimamos que inclui todos os fatores externos, taxa livre de risco, aversão ao risco e política fiscal mundial. Este se mostrou o modelo com o melhor poder explanatório, com o valor da função de máxima verossimilhança de -117 . Substituindo os valores dos fundamentos internos do Brasil pelo valor médio dos países emergentes e obtendo a taxa de juros prevista utilizando os coeficientes de curto prazo referente ao Brasil, conseguimos estimar qual seria a taxa de juros brasileira se o país tivesse indicadores iguais a média dos outros países. E, por fim, comparamos essa taxa de juros estimada com a taxa média retratada no primeiro gráfico. 
Figura 23 - Brasil Estimado - Juros Nominal de Longo Prazo

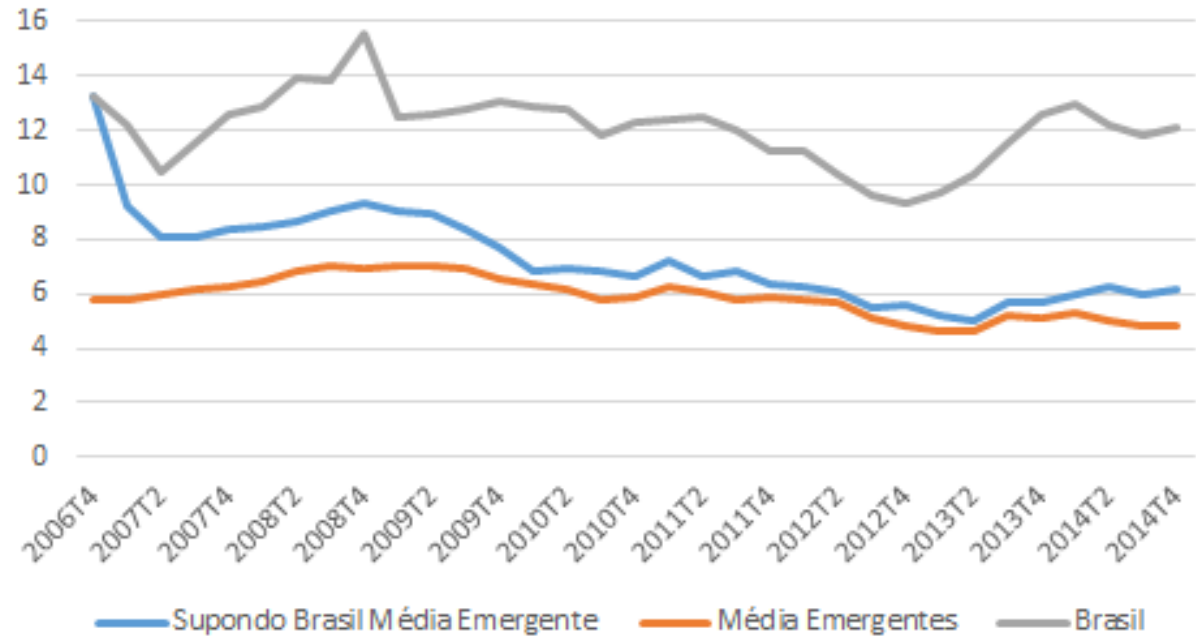

O gráfico acima mostra que caso o Brasil possuísse o nível médio dos fundamentos que os outros países emergentes possuem desde o último trimestre de 2006, o país iria observar uma rápida redução e forte convergência de sua taxa de juros para o nível médio observado em outros países. No final de 2014 a taxa de juros nominal de longo do Brasil atingiria 6,1\%, 6 p.p. abaixo da taxa efetivamente observada (12,1\%) e 1,3 p.p. acima da taxa média dos outros emergentes $(4,8 \%)$.

Nosso modelo mostra, portanto, que a maior parte do diferencial de juros brasileiros para o resto do mundo pode ser explicado pelos fundamentos internos. Contudo, ainda há uma pequena diferença que permanece sem explicação. Em Arida, Bacha e Lara-Resende (2004) os autores levantam algumas hipóteses sobre possíveis fatores não usuais que poderiam estar afetando de forma positiva a taxa de juros brasileira, entre eles citam a incerteza jurisdicional e a inconversibilidade da moeda ${ }^{1}$. Gonçalves, Holland e Spacov (2007) testaram empiricamente a possível influência desses dois fatores, porém, não acharam resultados significativos.

De qualquer forma, ainda que Gonçalves, Holland e Spacov (2007) tivessem obtidos resultados contrários, não acreditamos que a incerteza jurisdicional poderia ser respon-

1 Incerteza Jurisdicional se refere à incerteza envolvendo os contratos firmados no país, está relacionado ao risco de redução no valor do contrato no momento de vencimento e viés pró devedor nas cortes do judiciário. O que faz com q o credor fique mais reticente em realizar uma operação de crédito e só a realize cobrando uma taxa de juros mais elevada. 
sável por essa diferença de 1,3 p.p., isso porque nossa amostra envolve apenas países emergentes que não necessariamente possuem instituições mais fortes ou um nível de contract-enforcement superior ao Brasil.

Uma variável que poderia ser responsável por essa pequena diferença, mas que não foi incluída no modelo por falta de dados, é o nível de crédito subsidiado existente no sistema econômico brasileiro. Embora, possuíssemos esse dado para a economia brasileira, não conseguimos obtê-lo para o restante dos países. Portanto, sugerimos a inclusão desse fator para trabalhos futuros.

De qualquer forma, vale ressaltar que essa diferença não explicada é consideravelmente baixa. O Brasil pode atingir taxas de juros bastante próxima das de outros países se focar em reduzir sua dívida, abrir a economia e melhorar os outros fundamentos internos. 



\section{Conclusão}

Este trabalho analisou quais foram os principais determinantes das taxas de juros dos títulos soberanos de longo prazo nos países emergentes durante os anos de 2006 a 2014. Foi certamente um estudo que trouxe importantes contribuições em sua área. A escassez de dados de países não desenvolvidos impedia a realização de estudos mais aprofundados sobre esse tema até então. Devido à importância e dificuldade na obtenção dos dados, disponibilizamos no apêndice F não só a fonte, como também o link para a obtenção de todos os dados utilizados no estudo.

Para estimar a relação entre a taxa de juros e seus determinantes foram utilizadas as técnicas econométricas mais recentes para lidar com dados macroeconômicos em painel. Técnicas estas que são apropriadas para o caso em que a dimensão temporal é elevada em relação a dimensão cross-section. Os testes mostraram que grande parte das variáveis utilizadas possuem raiz unitária, por isso, optamos por estimar o modelo de correção de erros em painel proposto em Pesaran, Shin e Smith (1999) (Pooled Mean Group) do que apenas um modelo de efeito fixo usual.

O modelo mais completo mostrou indícios de que no curto prazo as variáveis que afetam positivamente a taxa de juros dos países emergentes são a taxa de juros livre de risco $(+0,3)$, a taxa de curto prazo $(+0,4)$ e o déficit do governo americano $(+0,1)$. Já as variáveis que afetam o nível de equilíbrio são a taxa de juros livre de risco $(+0,5)$, a aversão ao risco dos investidores $(+0,1)$, o saldo em conta corrente $(-0,3)$, a inflação $(+0,1)$, a abertura econômica $(-0,04)$ e a dívida bruta (efeito positivo não linear).

O modelo também mostrou fortes evidências da importância da inclusão de fatores externos para explicar a taxa de juros nos países emergentes. Sem esses fatores os testes indicavam que não existia cointegração entre as variáveis, tornando provável a existência de regressão espúria. Ao incluir os fatores externos a função de máxima verossimilhança apresentou resultados mais significativos e as evidências de cointegração entre as variáveis aumentaram, tornando maior a confiabilidade sobre os resultados obtidos.

O efeito das variáveis utilizadas sobre a taxa de juros se mostrou em linha com 
grande parte da literatura, como pode ser observado nas tabelas 3 e 5 . Contudo, duas diferenças relevantes foram observadas, (i) o déficit fiscal não se mostrou significativo e (ii) a variável abertura econômica, que até então tinha sido pouco utilizada na literatura, se mostrou altamente relevante na determinação da taxa de juros de longo prazo. A ideia de incluir abertura econômica como variável explicativa veio da literatura paralela que se refere ao spread da dívida externa. Mostrando-se uma decisão acertada.

Este trabalho também realizou uma análise específica para o caso brasileiro, observou-se que grande parte da diferença de juros entre o país e os outros emergentes pode ser explicada pelas variáveis utilizadas (saldo em conta corrente, inflação, abertura econômica e dívida bruta). De fato, se o Brasil tivesse mantido os fundamentos internos em linha com a média dos outros emergentes desde o final de 2006, o país iria chegar ao final de 2014 com uma taxa de juros de longo prazo de 6,1\%, 6 p.p. abaixo do valor efetivamente observado que foi de $12,1 \%$, e apenas 1,3 p.p. acima da taxa média dos outros emergentes (de 4,8\%).

Por fim, vale ressaltar que não foram incluídos países desenvolvidos na amostra devido às diversas diferenças que existem entre estes e os países emergentes. Diferenças essas que não são fáceis de medir utilizando variáveis explicativas usuais. Entre elas se destacam o nível de desenvolvimento institucional, maior confiabilidade nas finanças públicas, nível de riqueza, entre outros. O que acaba permitindo com que os países mais ricos apresentem fundamentos internos aparentemente piores ${ }^{1}$ e, ao mesmo tempo, juros menores. Este estudo também não desenvolve um modelo teórico que descreve os canais pelos quais as variáveis explicativas afetam a taxa de juros. Apenas se limita em descrever as razões lógicas e estimar empiricamente os efeitos.

Novos estudos que consigam reunir dados sobre taxa de juros de longo prazo tanto de países emergentes quanto de países desenvolvidos e consiga incluir variáveis explicativas que captam as principais diferenças, certamente irão contribuir para o desenvolvimento da literatura.

1 Por exemplo, Reino Unido, Estados Unidos e Japão possuem dívida bruta acima e taxa de juros abaixo de qualquer país da nossa amostra. 


\section{Referências}

AFONSO, A.; RAULT, C. Short-and long-run behaviour of long-term sovereign bond yields. Applied Economics, Taylor \& Francis, n. ahead-of-print, p. 1-23, 2015. 26, 27

AISEN, A.; HAUNER, D. Budget Deficits and Interest Rates: A Fresh Perspective. [S.1.]: International Monetary Fund, 2008. 27

ALEXOPOUlOU, I.; BUNDA, I.; FERRANDO, A. Determinants of government bond spreads in new eu countries. Eastern European Economics, Taylor \& Francis, v. 48, n. 5, p. 5-37, 2010. 34

ALPER, E.; FORNI, L. Public debt in advanced economies and its spillover effects on long-term yields. IMF Working Papers, p. 1-23, 2011. 28, 31, 64

ARDAGNA, S.; CASELLI, F.; LANE, T. Fiscal discipline and the cost of public debt service: some estimates for oecd countries. The BE Journal of Macroeconomics, v. 7, n. 1, 2007. 19, 25, 26, 27, 30, 32, 52, 59, 64

ARIDA, P.; BACHA, E.; LARA-RESENDE, A. High interest rates in brazil: conjectures on the jurisdictional uncertainty. Núcleo de Estudos de Política Econômica da Casa das Garças (NUPE/CdG), Rio de Janeiro, 2004. 20, 80

BALDACCI, E.; GUPTA, S.; MATI, A. Is it (still) mostly fiscal? determinants of sovereign spreads in emerging markets. IMF Working Papers, p. 1-23, 2008. 34

BALDACCI, E.; KUMAR, M. Fiscal deficits, public debt, and sovereign bond yields. IMF Working Papers, p. 1-28, 2010. 20, 28, 30

BARTH, J. R. Effects of federal budget deficits on interest rates and the composition of domestic output. [S.1.]: Urban Institute, 1989. 24

BREITUNG, J. The local power of some unit root tests for panel data. [S.1.], 1999. 52, 53, 57, 91, 93

BREITUNG, J.; DAS, S. Panel unit root tests under cross-sectional dependence. Statistica Neerlandica, Wiley Online Library, v. 59, n. 4, p. 414-433, 2005. 52, 53, 57, 59, 99

BREITUNG, J.; PESARAN, M. H. Unit roots and cointegration in panels. [S.l.]: Springer, 2008. 99

CANTOR, R.; PACKER, F. Determinants and impact of sovereign credit ratings.

Economic policy review, v. 2, n. 2, 1996. 34

CANZONERI, M.; CUMBY, R.; DIBA, B. Should the european central bank and the federal reserve be concerned about fiscal policy? Rethinking stabilization policy, p. 29-31, 2002. 23, 27

CHOI, I. Unit root tests for panel data. Journal of international money and Finance, Elsevier, v. 20, n. 2, p. 249-272, 2001. 52

COMELLI, F. Emerging market sovereign bond spreads: Estimation and back-testing. Emerging Markets Review, Elsevier, v. 13, n. 4, p. 598-625, 2012. 34 
CSONTO, M. B.; IVASCHENKO, M. I. V. Determinants of sovereign bond spreads in emerging markets: Local fundamentals and Global factors vs. Ever-changing misalignments. [S.1.]: International Monetary Fund, 2013. 34, 53

DAILAMI, M.; MASSON, P. R.; PADOU, J. J. Global monetary conditions versus country-specific factors in the determination of emerging market debt spreads. Journal of International Money and Finance, Elsevier, v. 27, n. 8, p. 1325-1336, 2008. 34

DELL'ERBA, M. S.; SOLA, M. S. Does fiscal policy affect interest rates? Evidence from a factor-augmented panel. [S.l.]: International Monetary Fund, 2013. 26, 27

DICKEY, D. A.; FULLER, W. A. Likelihood ratio statistics for autoregressive time series with a unit root. Econometrica: Journal of the Econometric Society, JSTOR, p. 1057-1072, 1981. 51

EICHENGREEN, B.; MODY, A. What explains changing spreads on emerging-market debt: fundamentals or market sentiment? [S.l.], 1998. 32

ELMENDORF, D. W.; MANKIW, N. G. Government debt. Handbook of macroeconomics, Elsevier, v. 1, p. 1615-1669, 1999. 24

EVANS, P. Do large deficits produce high interest rates? The American Economic Review, JSTOR, p. 68-87, 1985. 19, 23

FELDSTEIN, M. Budget deficits, tax rules, and real interest rates. [S.l.], 1986. 24

FRANCO, G. et al. Por que os juros são altos no brasil? 2011. 20

GALE, W. G. The economic effects of long-term fiscal discipline. The Urban Institute, 2003. 24, 29, 38

GONCALVES, C. E. Too Tight and Too Loose: Monetary Policy in Brazil in the Last Decade. [S.l.], 2015. 43

GONÇALVES, F. M.; HOLLAND, M.; SPACOV, A. D. Can jurisdictional uncertainty and capital controls explain the high level of real interest rates in brazil? evidence from panel data. Revista Brasileira de Economia, SciELO Brasil, v. 61, n. 1, p. 49-75, 2007. 20, 80

IM, K. S.; PESARAN, M. H.; SHIN, Y. Testing for unit roots in heterogeneous panels. Journal of econometrics, Elsevier, v. 115, n. 1, p. 53-74, 2003. 25, 52, 53, 57, 91, 93, 94

JARAMILLO, L.; TEJADA, M. Sovereign credit ratings and spreads in emerging markets: does investment grade matter? IMF Working Papers, p. 1-17, 2011. 34

KAMIN, S. B.; KLEIST, K. V. The evolution and determinants of emerging markets credit spreads in the 1990s. BIS working paper, 1999. 34

KINOSHITA, N. Government debt and long-term interest rates. IMF Working Paper, 2006. 25

LEAL, R. B. C. Efeitos da Política Fiscal Sobre o Nível da Taxa de Juros Nominal de Longo Prazo de 25 Países da OCDE1. Tese (Doutorado) — Universidade de São Paulo, 2011. 17,26 
LEVIN, A.; LIN, C.-F.; CHU, C.-S. J. Unit root tests in panel data: asymptotic and finite-sample properties. Journal of econometrics, Elsevier, v. 108, n. 1, p. 1-24, 2002. 52, 91, 93, 94

MEGALE, C. Fatores Externos e o Risco-País. Tese (Doutorado) - PUC-Rio, 2005. 32, $34,38,48$

MESQUITA, M. et al. A política econômica do governo dilma: a volta do experimentalismo. A política econômica do governo Dilma: a volta do experimentalismo, p. 3, 2014. 39, 43

MIYAJIMA, K.; MOHANTY, M. S.; CHAN, T. Emerging market local currency bonds: diversification and stability. Emerging Markets Review, Elsevier, v. 22, p. 126-139, 2015. 34

NABEYA, S. et al. Asymptotic moments of some unit root test statistics in the null case. Econometric Theory, Cambridge Univ Press, v. 15, n. 1, p. 139-149, 1999. 93, 94

ORR, A.; EDEY, M.; KENNEDY, M. The determinants of real long-term interest rates. OECD Publishing, 1995. 23, 24

PEDRONI, P. Critical values for cointegration tests in heterogeneous panels with multiple regressors. Oxford Bulletin of Economics and statistics, Wiley Online Library, v. 61, n. S1, p. $653-670,1999.25$

PEROVIĆ, L. M. The impact of fiscal positions on government bond yields in cee countries. Economic systems, Elsevier, 2015. 29, 30, 31

PERSYN, D.; WESTERLUND, J. et al. Error-correction-based cointegration tests for panel data. Stata Journal, Citeseer, v. 8, n. 2, p. 232, 2008. 103

PESARAN, M. Estimation and inference in large heterogenous panels with cross section dependence. CESifo Working Paper Series, 2003. 65

PESARAN, M. General diagnostic tests for cross section dependence in panels. CESifo working paper series, 2004. 52, 53, 55, 89, 90

PESARAN, M. H. A simple panel unit root test in the presence of cross-section dependence. Journal of Applied Econometrics, Wiley Online Library, v. 22, n. 2, p. 265-312, 2007. 52, 53, 57, 59, 95, 98

PESARAN, M. H.; SHIN, Y.; SMITH, R. P. Pooled mean group estimation of dynamic heterogeneous panels. Journal of the American Statistical Association, Taylor \& Francis, v. 94, n. 446 , p. 621-634, 1999. 8, 9, 26, 52, 53, 83, 99

PETROVA, I.; PAPAiOAnnOU, M. M. G.; BELLAS, M. D. Determinants of emerging market sovereign bond spreads: fundamentals vs financial stress. [S.l.]: International Monetary Fund, 2010. 34

PHILLIPS, P. C. Understanding spurious regressions in econometrics. Journal of econometrics, Elsevier, v. 33, n. 3, p. 311-340, 1986. 51

POGHOSYAN, T. Long-run and short-run determinants of sovereign bond yields in advanced economies. Economic Systems, Elsevier, v. 38, n. 1, p. 100-114, 2014. 26, 52, 59 
SEGURA-UBIERGO, M. A. The Puzzle of Brazil's High Interest Rates. [S.l.]: International Monetary Fund, 2012. 20, 28, 30

WACHTEL, P.; YOUNG, J. Deficit announcements and interest rates. The American Economic Review, JSTOR, p. 1007-1012, 1987. 23

WESTERLUND, J. Testing for error correction in panel data*. Oxford Bulletin of Economics and statistics, Wiley Online Library, v. 69, n. 6, p. 709-748, 2007. 52, 53, 54, 61, 101, 102, 103

YULE, G. U. Why do we sometimes get nonsense-correlations between time-series?-a study in sampling and the nature of time-series. Journal of the royal statistical society, JSTOR, p. 1-63, 1926. 51 


\section{Apêndice A}

\subsection{Teste de Dependência Cross Section}

Abaixo vamos descrever brevemente o teste de dependência cross section desenvolvido em Pesaran (2004).

Suponha um modelo em painel heterogêneo e dinâmico como o seguinte:

$$
y_{i t}=\left(1-\alpha_{i}\right) \mu_{i}+\alpha_{i} y_{i, t-1}+\epsilon_{i t}, i=1,2, \ldots N ; t=1,2, \ldots, T
$$

É assumido que $\epsilon_{i t}, t=0,1, \ldots, T$ é serialmente não correlacionado, possui média zero e variância $\sigma_{i}$.

Sob a hipótese nula tem-se que:

$$
H_{0}: \epsilon_{i t} \sim I I D\left(0, \sigma_{i}\right) \text { para todo } i \text { e } t
$$

Pesaran (2004) mostra que se a hipótese nula é verdadeira então:

$$
C D=\sqrt{\frac{2 T}{N(N-1)}} \sum_{i=1}^{N-1} \sum_{j=i+1}^{N} \hat{\rho}_{i j} \rightarrow N(0,1)
$$

À medida que $T$ e $N$ tendem ao infinito, independente da ordem.

Onde

$$
\hat{\rho}_{i j}=\frac{\sum_{t=1}^{T} e_{i t} e_{j t}}{\left(\sum_{t=1}^{T} e_{i t}^{2}\right)^{1 / 2}\left(\sum_{t=1}^{T} e_{j t}^{2}\right)^{1 / 2}}
$$

E $e$ é o resíduo da regressão $e_{i t}=y_{i t}-\left(1-\hat{\alpha}_{i}\right) \hat{\mu}_{i}-\hat{\alpha}_{i} y_{i, t-1}$, sendo $\hat{\alpha}_{i}$ e $\hat{\mu}_{i}$ estimados por Mínimos Quadrados Ordinários.

Portanto, se a hipótese nula é rejeitada isso indica existência de correlação cross section. 
É importante ressaltar que se $\epsilon_{i t}$ possui correlação serial, deve-se incluir lags de $y_{i t}$ na equação 8.1 para eliminar tal correlação. Pesaran (2004) também mostra a convergência da estatística $C D$ para o caso em que existem $p$ lags entre as variáveis explicativas.

\subsection{Testes de Raiz Unitária em Painel}

Essa seção é dividida em duas subseções, sendo que a primeira demonstra alguns testes da primeira geração e a segunda descreve brevemente os da segunda.

\subsubsection{Testes de Primeira Geração}

Assuma um modelo semelhante ao da equação 8.1:

$$
y_{i t}=\left(1-\alpha_{i}\right) \mu_{i}+\alpha_{i} y_{i, t-1}+\epsilon_{i t}
$$

Onde $y_{i 0}$ é dado, os erros $\epsilon_{i t}$ são independentes ao longo de $i$ e de $t$ sendo que $E\left(\epsilon_{i t}\right)=0, E\left(\epsilon_{i t}^{2}\right)=\sigma_{i}<\infty$ e $E\left(\epsilon_{i t}^{4}\right)<\infty$. A equação 8.1 pode ser reescrita da seguinte forma:

$$
\Delta y_{i t}=-\phi_{i} \mu_{i}+\phi_{i} y_{i, t-1}+\epsilon_{i t}
$$

Onde, $\phi_{i}=-\left(1-\alpha_{i}\right)$

Seja $\widetilde{y}_{i t}=y_{i t}-\mu_{i}$. Então

$$
\Delta \widetilde{y}_{i t}=\phi_{i} \widetilde{y}_{i, t-1}+\epsilon_{i t}
$$

A hipótese nula a ser testada será a de existência de raiz unitária. Portanto:

$$
H_{0}: \phi_{1}=\phi_{2}=\ldots=\phi_{N}=0
$$


Contra as hipóteses alternativas:

$$
\begin{array}{r}
H_{1 a}: \phi_{1}=\phi_{2}=\ldots=\phi_{N}=\phi, \text { onde } \phi<0 \\
H_{1 b}: \phi_{1}<0, \phi_{2}<0, \ldots, \phi_{N_{0}}<0, \text { onde } N_{0} \leq N
\end{array}
$$

Sob $H_{1 a}$ assume-se que o parâmetro é idêntico para todas as cross-section, o que é chamado de alternativa homogênea. Já $H_{1 b}$ assume que $N_{0}$ dos $N$ painéis são estacionários e seus parâmetros são específicos, o que é chamado de alternativa heterogênea. Diferentes procedimentos de testes podem ser desenvolvidos dependendo de qual das duas alternativas estão sendo consideradas. Primeiramente, vamos analisar o teste sobre a alternativa homogênea, essa linha é seguida em Levin, Lin e Chu (2002) e Breitung (1999), depois vamos analisar o teste sobre a alternativa heterogênea, linha que é seguida por Im, Pesaran e Shin (2003) .

Na estimação de $\phi$ a função log de máxima verossimilhança é dada por:

$$
l_{N T}(\phi, \theta)=\sum_{i=1}^{N}\left(-\frac{T}{2} \log 2 \pi \sigma_{i}^{2}-\frac{1}{2 \sigma_{i}^{2}} \sum_{t=1}^{T}\left(\Delta y_{i t}+\phi_{i} \mu_{i}-\phi_{i} y_{i, t-1}\right)^{2}\right)
$$

Onde $\phi=\left(\phi_{1}, \ldots, \phi_{N}\right)^{\prime}, \theta_{i}=\left(\mu_{i}, \sigma_{i}^{2}\right)^{\prime}$ e $\theta=\left(\theta_{1}^{\prime}, \ldots, \theta_{N}^{\prime}\right)^{\prime}$. Supondo a alternativa homogêneas, i.e., $\phi_{i}=\phi$, e maximizando a função 8.10 o estimador de máxima verossimilhança é dado por:

$$
\hat{\phi}(\theta)=\frac{\sum_{i=1}^{N} \sum_{t=1}^{T} \sigma_{i}^{-2} \Delta y_{i t}\left(y_{i, t-1}-\mu_{i}\right)}{\sum_{i=1}^{N} \sum_{t=1}^{T} \sigma_{i}^{-2}\left(y_{i, t-1}-\mu_{i}\right)^{2}}
$$

A estatística do teste é dado por

$$
\tau_{\phi}=\frac{\sum_{i=1}^{N} \hat{\sigma}_{i}^{-2} \Delta \mathbf{y}_{i}^{\prime} \mathbf{M}_{e} \mathbf{y}_{i,-1}}{\sqrt{\sum_{i=1}^{N} \hat{\sigma}_{i}^{-2} \mathbf{y}_{i}^{\prime} \mathbf{M}_{e} \mathbf{y}_{i,-1}}}
$$


Onde $\Delta \mathbf{y}_{i}=\left(\Delta y_{i 1}, \Delta y_{i 2}, \ldots, \Delta y_{i T}\right)^{\prime}, \mathbf{y}_{i,-1}=\left(y_{i 0}, y_{i 1}, \ldots, y_{i, T-1}\right)^{\prime}, \mathbf{M}_{e}=\mathbf{I}_{T}-\mathbf{e}_{T}\left(\mathbf{e}_{T}^{\prime} \mathbf{e}_{T}\right)^{-1} \mathbf{e}_{T}^{\prime}$ sendo $\mathbf{e}_{T}$ um vetor unitário $T \times 1$ e

$$
\hat{\sigma}_{i}^{2}=\frac{\Delta \mathbf{y}_{i}^{\prime} \mathbf{M}_{e} \Delta \mathbf{y}_{i}}{T-1}
$$

Observe que sob a hipótese nula $\phi_{i}=0$ tem-se:

$$
\Delta y_{i t}=\epsilon_{i t}
$$

Supondo $y_{i 0}=0$ ou simplesmente trabalhando com $\widetilde{y}_{i t}$ e reescrevendo $\epsilon_{i t}=\sigma_{i} v_{i t}$ onde $v_{i t}$ possui valor esperado igual a zero e variância igual a 1 . Podemos reescrever 8.14

$$
\Delta y_{i t}=\sigma_{i} v_{i t}
$$

Obtendo dois resultados na forma vetorial

$$
\begin{array}{r}
\mathbf{y}_{i,-1}=\sigma_{i} \mathbf{s}_{i,-1} \\
\Delta \mathbf{y}_{i}=\sigma_{i} \mathbf{v}_{i}
\end{array}
$$

Onde $\mathbf{v}_{i}=\left(v_{i 1}, v_{i 2}, \ldots, v_{i T}\right), \mathbf{s}_{i,-1}=\left(s_{i, 0}, s_{i, 1}, \ldots, s_{i, T-1}\right), s_{i t}=\sum_{j=1}^{t} v_{i j}, t=1,2, \ldots, T$ e $s_{i 0}=0$. Substituindo os resultados 8.16 na estatística de teste 8.12 temos

$$
\tau_{\phi}=\frac{\sum_{i=1}^{N}\left(\frac{\sqrt{T-1} \mathbf{v}_{i}^{\prime} \mathbf{M}_{e} \mathbf{s}_{i,-1}}{\mathbf{v}_{i}^{\prime} \mathbf{M}_{e} \mathbf{v}_{i}}\right)}{\sqrt{\sum_{i=1}^{N}\left(\frac{\mathbf{s}_{i,-1}^{\prime} \mathbf{M}_{e} \mathbf{s}_{i,-1}}{\mathbf{v}_{i}^{\prime} \mathbf{M}_{e} \mathbf{v}_{i}}\right)}}
$$

Observe que sobre a hipótese nula a estatística do teste não depende de nenhum parâmetro, podendo sua distribuição ser simulada para obter os valores críticos para cada $N$ e $T$, basta apenas assumir distribuição normal para $\epsilon_{i t}$ (ou para $v_{i t}$ ). De fato Levin, 
Lin e Chu (2002) demonstra que:

$$
\frac{\tau_{\phi}-E\left(\tau_{\phi}\right)}{\sqrt{\operatorname{Var}\left(\tau_{\phi}\right)}} \underset{T, N \rightarrow \infty}{\stackrel{d}{T}} N(0,1)
$$

Portanto, se rejeitarmos a hipótese nula podemos inferir que nenhuma série possui raiz unitária unitária.

Abaixo descrevemos uma breve derivação do teste sob a alternativa heterogênea, lógica seguida por Im, Pesaran e Shin (2003) e Breitung (1999).

Sob a alternativa heterogênea, teremos um parâmetro $\phi_{i}$ a ser estimado para cada cross section. Portanto, para cada uma tem-se uma estatística $\tau_{i}$ :

$$
\tau_{i}=\frac{\Delta \mathbf{y}_{i}^{\prime} \mathbf{M}_{e} \mathbf{y}_{i,-1}}{\hat{\sigma}_{i} \sqrt{\mathbf{y}_{i,-1}^{\prime} \mathbf{M}_{e} \mathbf{y}_{i,-1}}}
$$

que é a estatística $t$ de Dickey Fuller da cross section $i$. A estatística do teste de raiz unitária em painel sob a alternativa heterogênea é dada por

$$
\bar{\tau}=\frac{1}{N} \sum_{i=1}^{N} \tau_{i}
$$

Sob a hipótese nula e utilizando os resultados das equações 8.16 tem-se que:

$$
\bar{\tau}=N^{-1} \sum_{i=1}^{N} \frac{\sqrt{T-1} \mathbf{v}_{i}^{\prime} \mathbf{M}_{e} \mathbf{s}_{i,-1}}{\sqrt{\mathbf{v}_{i}^{\prime} \mathbf{M}_{e} \mathbf{v}_{i}} \sqrt{\mathbf{s}_{i,-1}^{\prime} \mathbf{M}_{e} \mathbf{s}_{i,-1}}}
$$

Assim como na equação 8.17, a estatística do teste não depende de nenhum parâmetro, podendo sua distribuição ser simulada para obter os valores críticos para cada $N$ e $T$. De fato, Nabeya et al. (1999) mostra que à medida que $T \rightarrow \infty, \tau_{i}$ tende a uma razão de movimentos brownianos que possui momentos finitos. Portanto, se $\tau_{i}$ converge 
para uma distribuição com momentos finitos então pelo Teorema do Limite Central:

$$
\frac{\sqrt{N}\left(\bar{\tau}-E\left(\tau_{i}\right)\right)}{\sqrt{\operatorname{Var}\left(\tau_{i}\right)}} \underset{T \rightarrow \infty}{\stackrel{d}{\longrightarrow}} \frac{\sqrt{N}\left(\bar{\eta}-E\left(\eta_{i}\right)\right)}{\sqrt{\operatorname{Var}\left(\eta_{i}\right)}} \underset{N \rightarrow \infty}{\stackrel{d}{\longrightarrow}} N(0,1)
$$

Onde $\eta_{i}$ é a distribuição descrita por Nabeya et al. (1999).

Portanto, se rejeitarmos a hipótese nula podemos inferir que nem todas as séries possuem raiz unitária.

Observe que toda a metodologia descrita até o momento trabalha com a hipótese de independência dos erros ao longo de $t$, isto é, hipótese de não autocorrelação dos erros.

De qualquer forma, essa hipótese pode ser facilmente flexibilizada como descrito nos próprios artigos originais Levin, Lin e Chu (2002) e Im, Pesaran e Shin (2003). Basta apenas incluir um número de lags suficiente para eliminar a autocorrelação.

$$
\Delta y_{i t}=\delta_{i}^{\prime} d_{i t}+\phi_{i} y_{i, t-1}+\sum_{u=1}^{p} \gamma_{i u} \Delta y_{i, t-u}+\epsilon_{i t}
$$

Onde, $\mathbf{d}_{i t}$ pode assumir valor de $\mathbf{d}_{i t}=1$ se for o caso de existência de um termo constante ou $\mathbf{d}_{i t}=(1, t)^{\prime}$ se tiver termo constante e tendência. Os erros $\epsilon_{i t}$ são i.i.d. em $i$ e em $t$ sendo que $E\left(\epsilon_{i t}\right)=0, E\left(\epsilon_{i t}^{2}\right)=\sigma_{i}<\infty$ e $E\left(\epsilon_{i t}^{4}\right)<\infty$. O valor de $p$ pode ser determinado utilizando, por exemplo, o critério de Hanna-Quin ou Akaike.

As estatísticas dos testes e seus valores críticos podem ser obtidos em Levin, Lin e Chu (2002) e Im, Pesaran e Shin (2003).

\subsubsection{Testes de Segunda Geração}

Como descrito acima, os testes de primeira geração tem como hipótese a ausência de correlação entre os erros ao longo da cross-section, o que em geral é bastante irrealista quando se trata de dados macro. No capítulo 5 fica claro a não veracidade dessa hipótese.

Portanto, alguns testes que levam em conta essa correlação foram desenvolvidos 
posteriormente. Nesta subseção vamos descrever brevemente o teste proposto por Pesaran (2007)

Seja $y_{i t}$ uma observação da cross-section $i$ no tempo $t$ e suponha que ela seja gerada de acordo com o seguinte modelo:

$$
y_{i t}=\left(1-\phi_{i}\right) \mu_{i}+\phi_{i} y_{i, t-1}+u_{i t}
$$

Onde os valores iniciais $y_{i 0}$ são dados e o termo de erro segue a seguinte estrutura.

$$
u_{i t}=\gamma_{i} f_{t}+\epsilon_{i t}
$$

$f_{t}$ é chamado de fator comum não observado e $\epsilon_{i t}$ é o erro indiossincrático. É conveniente reescrever as equações 8.24 e 8.25 da seguinte forma:

$$
\Delta y_{i t}=\alpha_{i}+\beta_{i} y_{i, t-1}+\gamma_{i} f_{t}+\epsilon_{i t}
$$

onde $\alpha_{i}=\left(1-\phi_{i}\right) \mu_{i}$ e $\beta_{i}=-\left(1-\phi_{i}\right)$. A hipótese de raiz unitária pode ser então descrita:

$$
H_{0}: \beta_{i}=0 \text { para todo } i
$$

contra a alternativa heterogênea,

$$
H_{1}: \beta_{i}<0 \text { para } i=1,2, \ldots, N_{1} ; \beta_{i}=0 \text { para } i=N_{1}+1, N_{1}+2, \ldots, N \text {. }
$$

Assume-se que N1/N é maior que zero e tende a um valor fixo $\delta$ tal que $0<\delta \leq 1$ a medida que $N \rightarrow \infty$. Também deve-se realizar as seguinte hipóteses: (i) os erros indiossincráticos $\epsilon_{i t}$ são i.i.d. ao longo de $i$ e ao longo de $t$, possuem média zero, variância 
$\sigma_{i}^{2}$ e momento de quarta ordem finito; (ii) o fator comum $f_{t}$ não possui autocorrelação, possui média zero, variância constante $\sigma_{f}^{2}$ e momento de quarta ordem finito, sem perda de generalidade pode-se assumir que $\sigma_{f}^{2}=1$.

Seja $\bar{\gamma}=\sum_{j=1}^{N} \gamma_{j}$ e suponha que $\bar{\gamma} \neq 0$. Somando a equação 8.26 ao longo de $i$, isolando $f_{t}$ e o substituindo na equação inicial temos:

$$
\Delta y_{i t}=a_{i}+\beta_{i} y_{i, t-1}-\delta_{i} \frac{\sum_{j=1}^{N} \beta_{j} y_{i, t-1}}{N}+\delta_{i} \Delta \bar{y}_{t}+\xi_{i t}
$$

Onde $\delta_{i}=\gamma_{i} / \bar{\gamma}, a_{i}=\alpha_{i}-\delta_{i} \bar{\alpha}$ e $\xi_{i t}=\epsilon_{i t}-\delta_{i} \bar{\epsilon}_{t}, \bar{\alpha}=\sum_{i=1}^{N} \alpha_{i}, \bar{y}_{t}=\sum_{i=1}^{N} y_{i t} \mathrm{e}$ $\bar{\epsilon}_{t}=\sum_{i=1}^{N} \epsilon_{i t}$

A estatítistica $t$ de cada cross-section é obtida pela seguinte formula:

$$
t_{i}(N, T)=\frac{\Delta \mathbf{y}_{i}^{\prime} \overline{\mathbf{M}}_{w} \mathbf{y}_{i,-1}}{\hat{\sigma}_{i}\left(\mathbf{y}_{i,-1}^{\prime} \overline{\mathbf{M}}_{w} \mathbf{y}_{i,-1}\right)^{1 / 2}}
$$

Onde

$$
\begin{array}{r}
\Delta \mathbf{y}_{i}=\left(\Delta y_{i 1}, \Delta y_{i 2}, \ldots, \Delta y_{i N}\right)^{\prime}, \mathbf{y}_{i,-1}=\left(y_{i 0}, y_{i 1}, \ldots, y_{i N}\right)^{\prime} \\
\overline{\mathbf{M}}_{w}=\mathbf{I}_{T}-\overline{\mathbf{W}}\left(\overline{\mathbf{W}}^{\prime} \overline{\mathbf{W}}\right)^{-1} \overline{\mathbf{W}}^{\prime}, \overline{\mathbf{W}}=\left(\boldsymbol{\tau}, \Delta \overline{\mathbf{y}}, \overline{\mathbf{y}}_{-1}\right) \\
\boldsymbol{\tau}=(1,1, \ldots, 1)^{\prime}, \Delta \overline{\mathbf{y}}=\left(\Delta \bar{y}_{i 1}, \Delta \bar{y}_{i 2}, \ldots, \Delta \bar{y}_{i N}\right)^{\prime} \\
\overline{\mathbf{y}}_{-1}=\left(\bar{y}_{0}, \bar{y}_{1}, \ldots, \bar{y}_{T-1}\right) \\
\hat{\sigma}_{i}^{2}=\frac{\Delta \mathbf{y}_{i}^{\prime} \mathbf{M}_{i, w} \Delta \mathbf{y}_{i}}{T-4} \\
\mathbf{M}_{i, w}=\mathbf{I}_{T}-\mathbf{G}_{i}\left(\mathbf{G}_{i}^{\prime} \mathbf{G}_{i}\right)^{-1} \mathbf{G}_{i}^{\prime}, \text { e } \mathbf{G}_{i}=\left(\overline{\mathbf{W}}, \mathbf{y}_{i,-1}\right)
\end{array}
$$

Supondo verdadeira a hipótese nula, i.e., $\beta_{i}=0$ para todo $i$, de 8.29 temos que $\Delta y_{i t}=a_{i}+\delta_{i} \Delta \bar{y}_{t}+\xi_{i t}$. Supondo também que $a_{i}=0$ ou simplesmente trabalhando com $\tilde{y}_{i t}$ 
como na seção anterior, chegamos na seguinte forma vetorial:

$$
\Delta \mathbf{y}_{i}=\delta_{i} \Delta \overline{\mathbf{y}}+\boldsymbol{\xi}_{i}
$$

onde $\boldsymbol{\xi}_{i}=\left(\xi_{i 1}, \xi_{i 2}, \ldots, \xi_{i T}\right)^{\prime} \sim\left(\mathbf{0}, \omega_{i}^{2} \mathbf{I}_{T}\right)$

$$
\omega_{i}^{2}=\sigma_{i}^{2}\left(1-\frac{2 \delta_{i}}{N}\right)+\frac{\delta_{i}^{2}}{N} \bar{\sigma}^{2}
$$

e $\bar{\sigma}^{2}=N^{-1} \sum_{j=1}^{N} \sigma_{j}^{2}<\infty$

Portanto, podemos obter o seguinte resultado:

$$
\overline{\mathbf{M}}_{w} \Delta \mathbf{y}_{i}=\overline{\mathbf{M}}_{w} \boldsymbol{\xi}_{i}, \quad \text { e } \mathbf{M}_{i, w} \Delta \mathbf{y}_{i}=\mathbf{M}_{i, w} \boldsymbol{\xi}_{i}
$$

Simplificando:

$$
\overline{\mathbf{M}}_{w} \Delta \mathbf{y}_{i}=\omega_{i} \overline{\mathbf{M}}_{w} \mathbf{v}_{i}, \text { e } \mathbf{M}_{i, w} \Delta \mathbf{y}_{i}=\omega_{i} \mathbf{M}_{i, w} \mathbf{v}_{i}
$$

onde $\mathbf{v}_{i}=\boldsymbol{\xi}_{i} / \omega_{i} \sim\left(0, \mathbf{I}_{T}\right)$.

Também supondo verdadeira a hipótese nula e supondo $a_{i}=0$ ou simplesmente trabalhando com $\tilde{y}_{i t}$, de 8.26 podemos chegar nas seguintes formulas vetoriais:

$$
\begin{gathered}
\mathbf{y}_{i,-1}=y_{i 0} \boldsymbol{\tau}+\gamma_{i} \mathbf{s}_{f,-1}+\mathbf{s}_{i,-1} \\
\overline{\mathbf{y}}_{-1}=\bar{y}_{0} \boldsymbol{\tau}+\bar{\gamma} \mathbf{s}_{f,-1}+\overline{\mathbf{s}}_{-1}
\end{gathered}
$$

Onde $\mathbf{s}_{i,-1}=\left(0, s_{i 1}, \ldots, s_{i, T-1}\right)^{\prime}, \mathbf{s}_{f,-1}=\left(s_{f 0}, s_{f 1}, \ldots, s_{f, T-1}\right)^{\prime}, \overline{\mathbf{s}}_{-1}=\left(0, \bar{s}_{1}, \ldots \bar{s}_{T-1}\right)$ sendo que $s_{i t}=\sum_{j=1}^{t} \epsilon_{i j}$ e $\bar{s}_{t}=N^{-1} \sum_{j=1}^{N} s_{j t}$ e $s_{f t}=\sum_{j=1}^{t} f_{j}$. 
Utilizando 8.38 para eliminar $s_{f,-1}$ em 8.37 obtemos

$$
\mathbf{y}_{i,-1}=\left(y_{i 0}-\delta_{i} \bar{y}_{0}\right) \boldsymbol{\tau}+\delta_{i} \overline{\mathbf{y}}_{-1}+\mathbf{s}_{i,-1}-\delta_{i} \overline{\mathbf{s}}_{-1}
$$

e portanto

$$
\overline{\mathbf{M}}_{w} \mathbf{y}_{i,-1}=\omega_{i} \overline{\mathbf{M}}_{w}\left(\mathbf{s}_{i,-1}-\delta_{i} \overline{\mathbf{s}}_{-1}\right) / \omega_{i}
$$

Utilizando 8.32, 8.36, 8.40 em 8.30 temos:

$$
t_{i}(N, T)=\frac{\sqrt{T-4} \mathbf{v}_{i}^{\prime} \overline{\mathbf{M}}_{w}\left(\mathbf{s}_{i,-1}-\delta_{i} \overline{\mathbf{s}}_{-1}\right) / \omega_{i}}{\left(\mathbf{v}_{i}^{\prime} \overline{\mathbf{M}}_{i, w} \mathbf{v}_{i}\right)^{1 / 2}\left(\left[\left(\mathbf{s}_{i,-1}-\delta_{i} \overline{\mathbf{s}}_{-1}\right) / \omega_{i}\right]^{\prime} \overline{\mathbf{M}}_{w}\left[\left(\mathbf{s}_{i,-1}-\delta_{i} \overline{\mathbf{s}}_{-1}\right) / \omega_{i}\right]\right)^{1 / 2}}
$$

A distribuição de $t_{i}(N, T)$ irá depender de parâmetros somente pelo efeito indireto via $\overline{\mathbf{M}}_{w}$ e $\mathbf{M}_{i, w}$. Contudo, Pesaran (2007) mostra que esse efeito tende a zero à medida que $N \rightarrow \infty$ independente se $T$ é fixo ou também tende ao infinito. De fato o autor mostra que quando $T, N \rightarrow \infty$ a estatística $t_{i}(N, T)$ converge para uma distribuição chamada de $C A D F_{i f}$, uma razão de movimentos brownianos com média e variância finitas.

A estatística $t_{i}(N, T)$ pode ser utilizada como um teste de raiz unitária para a série individual que leva em consideração a existência de um fator comum na cross section. De qualquer forma, Pesaran (2007) sugere utilizar a média das estatísticas $t_{i}(N, T)$ para testar a hipótese nula em questão. O teste é dado por:

$$
t-b a r=N^{-1} \sum_{i=1}^{N} t_{i}(N, T)
$$

Os valores críticos da distribuição de t-bar são reportados em Pesaran (2007). O autor também trabalha com o caso onde existe autocorreção nos erros, o procedimento para a correção desse problema segue a mesma lógica da reportada na seção anterior, onde se insere os lags da variável para eliminar a autocorrelação. 
Os testes da segunda geração também podem ser desenvolvidos sob a hipótese alternativa homogênea, por exemplo, Breitung e Das (2005).

Vale ressaltar que o artigo Breitung e Pesaran (2008) faz um resumo e descreve de forma didática os principais testes de raiz unitária em painel da primeira e da segunda geração.

\subsection{Pooled Mean Group}

O modelo Pooled Mean Group foi desenvolvido por Pesaran, Shin e Smith (1999) para trabalhar com painéis em que a dimensão cross section $(N)$ e a dimensão temporal são elevadas $(T)$. A prática usual até a época era ou estimar as $N$ equações separadamente e calcular a média dos coeficientes (Mean Group Estimator $M G$ ), ou supor que todos os coeficientes são iguais ao longo da cross section, inclusive a variância dos erros, e estimar tudo de forma agregada. O Pooled Mean Group entra como um procedimento intermediário entre esses dois casos, pois restringe os coeficientes de longo prazo de forma que eles sejam homogêneos ao longo da cross section, mas permite que os coeficientes de curto prazo varie. Pesaran, Shin e Smith (1999) mostra que o modelo é válido tanto para quando os regressores são estacionário quanto para regressores que possuem raiz unitária.

O modelo supõe que a variável dependente comporta de forma dinâmica, isto é, seu valor presente depende de seus valores passados, dos valores presentes das variáveis explicativas e dos valores passados das mesmas. Essa dinâmica pode ser retratada por um modelo $A R D L(p, q, q, \ldots, q)$ :

$$
y_{i t}=\sum_{j=1}^{p} \lambda_{i j} y_{i, t-j}+\sum_{j=0}^{q} \boldsymbol{\delta}_{i j}^{\prime} \mathbf{x}_{i, t-j}+\mu_{i}+\epsilon_{i t}
$$

Onde $\mathbf{x}_{i t}(K x 1)$ é o vetor de variáveis explicativas para o grupo $i, \mu_{i}$ é o coeficiente de efeito fixo, $\lambda_{i j}$ são os coeficientes escalares da variável dependente defasadas, $\boldsymbol{\delta}_{i j}(K x 1)$ são os vetores dos coeficientes das variáveis explicativas defasadas e no tempo presente e $\epsilon_{i t}$ é o erro do modelo. 
A equação 8.43 pode ser reescrita da seguinte forma:

$$
\Delta y_{i t}=\phi_{i} y_{i, t-1}+\beta_{i}^{\prime} \mathbf{x}_{i, t-1}+\sum_{j=1}^{p-1} \lambda_{i j}^{*} \Delta y_{i, t-j}+\sum_{j=0}^{q-1} \boldsymbol{\delta}_{i j}^{*^{\prime}} \Delta \mathbf{x}_{i, t-j}+\mu_{i}+\epsilon_{i t}
$$

onde $\phi_{i}=-\left(1-\sum_{j=1}^{p} \lambda_{i j}\right), \boldsymbol{\beta}_{i}=\sum_{j=0}^{q} \boldsymbol{\delta}_{i j}, \lambda_{i j}^{*}=-\sum_{m=j+1}^{p} \lambda_{i m}$, e $\boldsymbol{\delta}_{i j}^{*}=-\sum_{m=j+1}^{q} \boldsymbol{\delta}_{i m}$ É mais conveniente ainda trabalhar com a seguinte forma:

$$
\Delta y_{i t}=\phi_{i}\left(y_{i, t-1}-\boldsymbol{\alpha}_{i}^{\prime} \mathbf{x}_{i, t-1}\right)+\sum_{j=1}^{p-1} \lambda_{i j}^{*} \Delta y_{i, t-j}+\sum_{j=0}^{q-1} \boldsymbol{\delta}_{i j}^{*^{\prime}} \Delta \mathbf{x}_{i, t-j}+\mu_{i}+\epsilon_{i t}
$$

onde $\boldsymbol{\alpha}_{i}^{\prime}=-\frac{\beta_{i}^{\prime}}{\phi_{i}}$

Por fim, são feitas três hipóteses sobre o modelo:

(i) Os erros $\epsilon_{i t}$ são independentes ao longo de $i$ e ao longo de $t$, com média zero, variância $\sigma_{i}^{2}>0$, possuem quarto momento finito e são independentes em relação aos regressores $\boldsymbol{x}_{i t}$.

(ii) Existe uma relação de cointegração entre $y_{i t}$ e os regressores $\boldsymbol{x}_{i t}$ definida por $y_{i t}=\boldsymbol{\alpha}_{i}^{\prime} x_{i t}+\eta_{i t}$, onde $\eta_{i t}$ é um processo estacionário, o que implica que $\phi_{i}<0$. De fato $\phi_{i}$ representa a velocidade de convergência para o equilíbrio, quanto maior a sua magnitude maior é a velocidade de convergência.

(iii) Os coeficiente de longo prazo são homogêneos ao longo da cross section, isto é $\boldsymbol{\alpha}_{i}^{\prime}=\boldsymbol{\alpha}$ para todo $i$.

Portanto, o modelo final pode ser escrito da seguinte forma:

$$
\Delta y_{i t}=\phi_{i}\left(y_{i, t-1}-\boldsymbol{\alpha}^{\prime} \mathbf{x}_{i, t-1}\right)+\sum_{j=1}^{p-1} \lambda_{i j}^{*} \Delta y_{i, t-j}+\sum_{j=0}^{q-1} \boldsymbol{\delta}_{i j}^{*^{\prime}} \Delta \mathbf{x}_{i, t-j}+\mu_{i}+\epsilon_{i t}
$$

Existe diversas vantagens em trabalhar com a equação 8.46, a principal consiste no fato de que o modelo separa de forma clara os parâmetros que afetam o nível de equilíbrio da variável dependente (relação que está dentro do parenteses) dos que afetam apenas 
a dinâmica de curto prazo. Essa vantagem ficará clara no capítulo 5, quando formos interpretar os resultados.

\subsection{Testes de Cointegração}

Nessa seção vamos descrever brevemente os quatros testes de cointegração em painel proposto por Westerlund (2007). Estes testes são baseados principalmente na estrutura do modelo e não na dinâmica dos erros, como a maior parte dos testes. A ideia por traz dos testes de Westerlund (2007) é testar, sob a hipótese nula de não cointegração, se o termo de correção de erros é igual a zero. Dois grupos de testes são desenvolvidos, no primeiro utiliza-se a hipótese alternativa de que pelo menos um termo de erro é negativo, enquanto no segundo grupo a hipótese alternativa consiste de que todos os termos de erro de todas cross section são negativos .

Se não houver rejeição da hipótese nula não se pode rejeitar a hipótese de não cointegração das variáveis. Enquanto se houver rejeição da hipótese nula, no primeiro grupo, pode-se inferir que pelo menos uma cross section é cointegrada, e no segundo grupo, pode-se inferir que existe cointegração em todo o painel.

Os testes são baseados no mesmo modelo da equação 8.45, recapitulando:

$$
\Delta y_{i t}=\phi_{i}\left(y_{i, t-1}-\boldsymbol{\alpha}_{i}^{\prime} \mathbf{x}_{i, t-1}\right)+\sum_{j=1}^{p-1} \lambda_{i j}^{*} \Delta y_{i, t-j}+\sum_{j=0}^{q-1} \boldsymbol{\delta}_{i j}^{*^{\prime}} \Delta \mathbf{x}_{i, t-j}+\mu_{i}+\epsilon_{i t}
$$

O parâmetro $\phi_{i}$ determina a velocidade em que o sistema volta para o equilíbrio após uma choque externo. Se $\phi_{i}<0$ então a tendência de retorno ao equilíbrio existe, indicando existência de cointegração, se $\phi_{i}=0$ não existe tendência de retorno ao equilíbrio, logo, não há cointegração. Portanto, a hipótese nula de não cointegração é $H_{0}: \phi_{i}=0 \forall i$. Quanto à hipótese alternativa depende do que se assume sobre a homogeneidade de $\phi_{i}$. Dois dos quatro testes são chamados de group mean tests, não requer que $\phi_{i}$ seja igual para todo $i$, o que significa que $H_{0}: \phi_{i}=0 \forall i$ é testado contra $H_{a}^{g}: \phi_{i}<0$ para pelo menos um $i$. O segundo par de testes, panel tests, assume que $\phi_{i}$ é igual para todo $i$, nesse 
caso a hipótese alternativa é dada por $H_{a}^{p}: \phi_{i}=\phi<0 \forall i$

O cômputo do group mean tests requer três etapas. A primeira consiste em estimar por minímos quadrados a equação:

$$
\Delta y_{i t}=\hat{\phi}_{i} y_{i, t-1}+\hat{\boldsymbol{\gamma}}_{i}^{\prime} \mathbf{x}_{i, t-1}+\sum_{j=1}^{p-1} \hat{\lambda}_{i j}^{*} \Delta y_{i, t-j}+\sum_{j=0}^{q-1} \hat{\boldsymbol{\delta}}_{i j}^{*^{\prime}} \Delta \mathbf{x}_{i, t-j}+\hat{\mu}_{i}+\hat{\epsilon}_{i t}
$$

Onde $\hat{\boldsymbol{\gamma}}_{i}$ e a estatística que representa a multiplicação dos parâmetros $\phi_{i}$ e $\boldsymbol{\alpha}_{i}$ da equação 8.47, isto é, $\gamma_{i}=-\phi_{i} * \boldsymbol{\alpha}_{i}$. Obtendo $\hat{\epsilon}_{i t}$ e $\hat{\boldsymbol{\delta}}_{i j}^{*^{\prime}}$, o segundo passo consiste em calcular:

$$
\hat{u}_{i t}=\sum_{j=0}^{p_{i}} \hat{\boldsymbol{\delta}}_{i j}^{*^{\prime}} \Delta \mathbf{x}_{i, t-j}+\hat{\epsilon}_{i t}
$$

que então é utilizado para calcular $\hat{\alpha}_{i}(1)=\frac{\hat{\omega}_{u i}}{\hat{\omega}_{y i}}$, onde $\hat{\omega}_{u i}$ e $\hat{\omega}_{y i}$ são os estimadores da variância de longo prazo de $\hat{u}_{i t}$ e $\Delta y_{i t}$, respectivamente, como descrito em Westerlund (2007).

Por fim, a terceira etapa consiste em computar as duas estatísticas dos testes group-mean:

$$
G_{\tau}=\frac{1}{N} \sum_{i=1}^{N} \frac{\hat{\phi}_{i}}{S E\left(\hat{\phi}_{i}\right)}, \quad G_{\alpha}=\frac{1}{N} \sum_{i=1}^{N} \frac{T \hat{\phi}_{i}}{\hat{\alpha}_{i}(1)}
$$

Onde, $S E\left(\hat{\phi}_{i}\right)$ é o desvio padrão de $\hat{\phi}_{i}$.

Os panel tests também podem ser calculados em três etapas. O primeiro consiste em estimar por Minimos Quadrados as seguintes equações:

$$
\begin{aligned}
& \Delta y_{i t}=\hat{\boldsymbol{\gamma}}_{i}^{\prime} \mathbf{x}_{i, t-1}+\sum_{j=1}^{p-1} \hat{\lambda}_{i j}^{*} \Delta y_{i, t-j}+\sum_{j=0}^{q-1} \hat{\boldsymbol{\delta}}_{i j}^{*^{\prime}} \Delta \mathbf{x}_{i, t-j}+\hat{\mu}_{i}+\hat{\epsilon}_{\Delta, i t} \\
& y_{i, t-1}=\hat{\boldsymbol{\gamma}}_{i}^{\prime} \mathbf{x}_{i, t-1}+\sum_{j=1}^{p-1} \hat{\lambda}_{i j}^{*} \Delta y_{i, t-j}+\sum_{j=0}^{q-1} \hat{\boldsymbol{\delta}}_{i j}^{*^{\prime}} \Delta \mathbf{x}_{i, t-j}+\hat{\mu}_{i}+\hat{\epsilon}_{y, i t}
\end{aligned}
$$


O segundo passo consiste em utilizar os erros $\hat{\epsilon}_{\Delta, i t}$ e $\hat{\epsilon}_{y, i t}$ para estimar o termo comum de correção de erros, $\phi$, e seu desvio padrão. O que é obtido nas seguintes equações:

$$
\begin{gathered}
\hat{\phi}=\left(\sum_{i=1}^{N} \sum_{t=2}^{T} \hat{\epsilon}_{y, i t}\right)^{-1} \sum_{i=1}^{N} \sum_{t=2}^{T} \frac{1}{\hat{\alpha}_{i}(1)} \hat{\epsilon}_{y, i t} \hat{\epsilon}_{\Delta, i t} \\
S E(\hat{\phi})=\left(\left(\hat{S}_{N}^{2}\right)^{-1} \sum_{i=1}^{N} \sum_{t=2}^{T} \hat{\epsilon}_{y, i t}^{2}\right)^{-1 / 2}
\end{gathered}
$$

onde $\hat{S}_{N}^{2}=\frac{1}{N} \sum_{i=1}^{N} \frac{\hat{\sigma}_{i}}{\hat{\alpha}_{i}(1)}$, sendo $\hat{\sigma}_{i}$ o desvio padrão do erro em 8.48.

Por fim, na terceira etapa basta computar as estatísticas dos testes,

$$
P_{\tau}=\frac{\hat{\phi}}{S E(\hat{\phi})}, \quad P_{\phi}=T \hat{\phi}
$$

Westerlund (2007) deriva a distribuição assintóticas dos testes sob a hipótese nula e reporta seus valores críticos. Uma aplicação prática dos testes podem ser encontradas em Persyn, Westerlund et al. (2008). 

9 Apêndice B 
Tabela 17 - Testes de Raiz Unitária Univarido Augmented Dickey Fuller (Parte 1) P-Valor

\begin{tabular}{|c|c|c|c|c|}
\hline & & $\mathrm{p}=1$ & $\mathrm{p}=2$ & $\mathrm{p}=3$ \\
\hline Taxa de Juros de Longo Prazo & Brasil & $27 \%$ & $22 \%$ & $38 \%$ \\
\hline & Bulgaria & $68 \%$ & $76 \%$ & $74 \%$ \\
\hline & Chile & $35 \%$ & $78 \%$ & $79 \%$ \\
\hline & China & $1 \%$ & $3 \%$ & $1 \%$ \\
\hline & Colombia & $69 \%$ & $71 \%$ & $65 \%$ \\
\hline & Rep Tcheca & $98 \%$ & $99 \%$ & $99 \%$ \\
\hline & Hungria & $64 \%$ & $86 \%$ & $87 \%$ \\
\hline & Malásia & $3 \%$ & $30 \%$ & $18 \%$ \\
\hline & Mexico & $73 \%$ & $82 \%$ & $83 \%$ \\
\hline & Poland & $99 \%$ & $98 \%$ & $99 \%$ \\
\hline & Russia & $26 \%$ & $6 \%$ & $11 \%$ \\
\hline & Africa do Sul & $6 \%$ & $21 \%$ & $33 \%$ \\
\hline & Coreia do Sul & $92 \%$ & $96 \%$ & $94 \%$ \\
\hline Taxa de Juros de Curto Prazo & Brasil & $0 \%$ & $14 \%$ & $27 \%$ \\
\hline & Bulgaria & $41 \%$ & $49 \%$ & $32 \%$ \\
\hline & Chile & $3 \%$ & $31 \%$ & $4 \%$ \\
\hline & China & $10 \%$ & $5 \%$ & $34 \%$ \\
\hline & Colombia & $20 \%$ & $31 \%$ & $24 \%$ \\
\hline & Rep Tcheca & $54 \%$ & $70 \%$ & $38 \%$ \\
\hline & Hungria & $84 \%$ & $53 \%$ & $83 \%$ \\
\hline & Malásia & $12 \%$ & $24 \%$ & $9 \%$ \\
\hline & Mexico & $57 \%$ & $72 \%$ & $67 \%$ \\
\hline & Poland & $37 \%$ & $73 \%$ & $81 \%$ \\
\hline & Russia & $52 \%$ & $53 \%$ & $69 \%$ \\
\hline & Africa do Sul & $38 \%$ & $68 \%$ & $52 \%$ \\
\hline & Coreia do Sul & $29 \%$ & $48 \%$ & $12 \%$ \\
\hline Crescimento do PIB & Brasil & $0 \%$ & $8 \%$ & $37 \%$ \\
\hline & Bulgaria & $1 \%$ & $6 \%$ & $21 \%$ \\
\hline & Chile & $1 \%$ & $2 \%$ & $12 \%$ \\
\hline & China & $3 \%$ & $38 \%$ & $16 \%$ \\
\hline & Colombia & $0 \%$ & $1 \%$ & $7 \%$ \\
\hline & Rep Tcheca & $0 \%$ & $9 \%$ & $12 \%$ \\
\hline & Hungria & $0 \%$ & $40 \%$ & $50 \%$ \\
\hline & Malásia & $0 \%$ & $14 \%$ & $29 \%$ \\
\hline & Mexico & $3 \%$ & $2 \%$ & $14 \%$ \\
\hline & Poland & $2 \%$ & $4 \%$ & $19 \%$ \\
\hline & Russia & $0 \%$ & $31 \%$ & $23 \%$ \\
\hline & Africa do Sul & $0 \%$ & $9 \%$ & $7 \%$ \\
\hline & Coreia do Sul & $0 \%$ & $0 \%$ & $11 \%$ \\
\hline
\end{tabular}


Tabela 18 - Testes de Raiz Unitária Univarido Augmented Dickey Fuller (Parte 2) P-Valor

\begin{tabular}{|c|c|c|c|c|}
\hline \multirow{14}{*}{ Saldo em Conta Corrente } & & $\mathrm{p}=1$ & $\mathrm{p}=2$ & $\mathrm{p}=3$ \\
\hline & Brasil & $86 \%$ & $72 \%$ & $96 \%$ \\
\hline & Bulgaria & $58 \%$ & $11 \%$ & $2 \%$ \\
\hline & Chile & $0 \%$ & $13 \%$ & $10 \%$ \\
\hline & China & $44 \%$ & $41 \%$ & $27 \%$ \\
\hline & Colombia & $99 \%$ & $99 \%$ & $100 \%$ \\
\hline & Rep Tcheca & $71 \%$ & $74 \%$ & $46 \%$ \\
\hline & Hungria & $76 \%$ & $69 \%$ & $78 \%$ \\
\hline & Malásia & $91 \%$ & $92 \%$ & $89 \%$ \\
\hline & Mexico & $44 \%$ & $39 \%$ & $16 \%$ \\
\hline & Poland & $65 \%$ & $64 \%$ & $75 \%$ \\
\hline & Russia & $5 \%$ & $37 \%$ & $67 \%$ \\
\hline & Africa do Sul & $52 \%$ & $48 \%$ & $34 \%$ \\
\hline & Coreia do Sul & $61 \%$ & $74 \%$ & $90 \%$ \\
\hline \multirow[t]{13}{*}{ Inflação } & Brasil & $1 \%$ & $6 \%$ & $14 \%$ \\
\hline & Bulgaria & $40 \%$ & $35 \%$ & $2 \%$ \\
\hline & Chile & $1 \%$ & $3 \%$ & $4 \%$ \\
\hline & China & $0 \%$ & $0 \%$ & $1 \%$ \\
\hline & Colombia & $16 \%$ & $22 \%$ & $29 \%$ \\
\hline & Rep Tcheca & $12 \%$ & $5 \%$ & $4 \%$ \\
\hline & Hungria & $58 \%$ & $87 \%$ & $84 \%$ \\
\hline & Malásia & $0 \%$ & $1 \%$ & $0 \%$ \\
\hline & Mexico & $36 \%$ & $33 \%$ & $3 \%$ \\
\hline & Poland & $83 \%$ & $86 \%$ & $78 \%$ \\
\hline & Russia & $12 \%$ & $24 \%$ & $55 \%$ \\
\hline & Africa do Sul & $24 \%$ & $28 \%$ & $17 \%$ \\
\hline & Coreia do Sul & $62 \%$ & $47 \%$ & $21 \%$ \\
\hline \multirow[t]{13}{*}{ Abertura Econômica } & Brasil & $5 \%$ & $15 \%$ & $56 \%$ \\
\hline & Bulgaria & $2 \%$ & $47 \%$ & $71 \%$ \\
\hline & Chile & $18 \%$ & $46 \%$ & $69 \%$ \\
\hline & China & $13 \%$ & $26 \%$ & $25 \%$ \\
\hline & Colombia & $30 \%$ & $49 \%$ & $66 \%$ \\
\hline & Rep Tcheca & $68 \%$ & $92 \%$ & $97 \%$ \\
\hline & Hungria & $32 \%$ & $57 \%$ & $71 \%$ \\
\hline & Malásia & $12 \%$ & $25 \%$ & $31 \%$ \\
\hline & Mexico & $80 \%$ & $81 \%$ & $88 \%$ \\
\hline & Poland & $82 \%$ & $90 \%$ & $95 \%$ \\
\hline & Russia & $7 \%$ & $27 \%$ & $45 \%$ \\
\hline & Africa do Sul & $0 \%$ & $57 \%$ & $44 \%$ \\
\hline & Coreia do Sul & $5 \%$ & $19 \%$ & $4 \%$ \\
\hline
\end{tabular}


Tabela 19 - Testes de Raiz Unitária Univarido Augmented Dickey Fuller (Parte 3) P-Valor

\begin{tabular}{|c|c|c|c|c|}
\hline & & $\mathrm{p}=1$ & $\mathrm{p}=2$ & $\mathrm{p}=3$ \\
\hline \multirow[t]{13}{*}{ Orçamento } & Brasil & $93 \%$ & $88 \%$ & $85 \%$ \\
\hline & Bulgaria & $45 \%$ & $30 \%$ & $13 \%$ \\
\hline & Chile & $23 \%$ & $10 \%$ & $8 \%$ \\
\hline & China & $9 \%$ & $20 \%$ & $31 \%$ \\
\hline & Colombia & $14 \%$ & $44 \%$ & $23 \%$ \\
\hline & Rep Tcheca & $27 \%$ & $24 \%$ & $20 \%$ \\
\hline & Hungria & $1 \%$ & $3 \%$ & $0 \%$ \\
\hline & Malásia & $37 \%$ & $34 \%$ & $37 \%$ \\
\hline & Mexico & $45 \%$ & $51 \%$ & $49 \%$ \\
\hline & Poland & $6 \%$ & $5 \%$ & $3 \%$ \\
\hline & Russia & $25 \%$ & $13 \%$ & $22 \%$ \\
\hline & Africa do Sul & $36 \%$ & $22 \%$ & $20 \%$ \\
\hline & Coreia do Sul & $2 \%$ & $1 \%$ & $0 \%$ \\
\hline \multirow[t]{13}{*}{ Dívida Bruta } & Brasil & $26 \%$ & $21 \%$ & $18 \%$ \\
\hline & Bulgaria & $90 \%$ & $91 \%$ & $93 \%$ \\
\hline & Chile & $96 \%$ & $95 \%$ & $94 \%$ \\
\hline & China & $16 \%$ & $47 \%$ & $57 \%$ \\
\hline & Colombia & $89 \%$ & $91 \%$ & $93 \%$ \\
\hline & Rep Tcheca & $61 \%$ & $58 \%$ & $42 \%$ \\
\hline & Hungria & $17 \%$ & $9 \%$ & $3 \%$ \\
\hline & Malásia & $64 \%$ & $69 \%$ & $72 \%$ \\
\hline & Mexico & $85 \%$ & $81 \%$ & $89 \%$ \\
\hline & Poland & $54 \%$ & $46 \%$ & $50 \%$ \\
\hline & Russia & $96 \%$ & $94 \%$ & $96 \%$ \\
\hline & Africa do Sul & $96 \%$ & $92 \%$ & $90 \%$ \\
\hline & Coreia do Sul & $84 \%$ & $100 \%$ & $98 \%$ \\
\hline Aversão ao Risco & & $12 \%$ & $22 \%$ & $20 \%$ \\
\hline Taxa de Juros Livre de Risco & & $26 \%$ & $76 \%$ & $36 \%$ \\
\hline Orçamento E.U.A. & & $84 \%$ & $47 \%$ & $59 \%$ \\
\hline Dívida E.U.A. & & $97 \%$ & $97 \%$ & $95 \%$ \\
\hline
\end{tabular}




\section{Apêndice C}

O método de eliminação das variáveis não significativas foi feito da seguinte forma: (i) Primeiro eliminamos todas as variáveis não significativas do curto prazo, a preferência de eliminar primeiro as de curto prazo para depois eliminar as de longo prazo se deve estritamente a razões econométricas, cada variável no curto prazo representa 13 parâmetros a serem estimados, enquanto no longo prazo representa apenas um. Portanto, a eliminação de uma variável no curto prazo representa uma ganho em graus de liberdade muito maior, aumentando de forma mais considerável a precisão do modelo. (ii) Após eliminar as variáveis não significativas de curto prazo, re-estimamos o modelo e eliminamos novamente as variáveis de curto prazo que se mostraram não significativas. Repetimos o procedimento até que todas as variáveis no curto prazo sejam significativas. (iii) Eliminamos as variáveis de longo prazo que se mostram "altamente"não significativas (definimos altamente não significativas as variáveis que apresentam P-Valor acima de 30\%). (iv) Re-estimamos o modelo e eliminamos o restante das variáveis não significativas. 
Tabela 20 - Resultados Prévios - Apenas Fundamentos Internos (1)

\begin{tabular}{|c|c|c|c|c|}
\hline & \multicolumn{2}{|c|}{ Modelo 1} & \multicolumn{2}{|c|}{ Modelo 2} \\
\hline Variável & Coeficiente & Erro Padrão & Coeficiente & Erro Padrão \\
\hline \multicolumn{5}{|c|}{ Coeficientes de LP } \\
\hline SaldoCC & $0.198^{* *}$ & $(0.0323)$ & 0.0707 & $(0.0477)$ \\
\hline CrescPIB & $-0.235^{* *}$ & $(0.0310)$ & $0.142^{* *}$ & $(0.0379)$ \\
\hline Inflacao & $0.364^{* *}$ & $(0.0435)$ & 0.0488 & $(0.0645)$ \\
\hline AbertEcon & $-0.0656^{* *}$ & $(0.00488)$ & $-0.0848^{* *}$ & $(0.0169)$ \\
\hline SupNom & $-0.067^{*}$ & $(0.0320)$ & 0.0230 & $(0.0578)$ \\
\hline DivBruta & $-0.249^{*}$ & $(0.126)$ & $-0.277^{* *}$ & $(0.0839)$ \\
\hline DivBruta2 & 0.00214 & $(0.00175)$ & $0.00273^{*}$ & $(0.00119)$ \\
\hline \multicolumn{5}{|c|}{ Coeficientes de CP - Média } \\
\hline CorrErros & $-0.221^{* *}$ & $(0.0778)$ & $-0.156^{* *}$ & $(0.0548)$ \\
\hline TaxaMeta & $0.349^{* *}$ & $(0.132)$ & $0.340^{* *}$ & $(0.0875)$ \\
\hline SaldoCC & -0.0848 & $(0.149)$ & & \\
\hline CrescPIB & -0.0754 & $(0.0523)$ & & \\
\hline Inflacao & 0.0843 & $(0.0539)$ & & \\
\hline AberEcon & -0.0217 & $(0.0446)$ & & \\
\hline SupNom & 0.0924 & $(0.107)$ & & \\
\hline DivBruta & 0.342 & $(0.553)$ & & \\
\hline DivBruta2 & -0.0159 & $(0.0187)$ & & \\
\hline Intercepto & $3.358^{* *}$ & $(1.259)$ & $2.847^{* *}$ & $(1.030)$ \\
\hline Significância & $\dagger: 10 \% *: 5 \% * *: 1 \%$ & & & \\
\hline
\end{tabular}

Tabela 21 - Resultados Prévios - Apenas Fundamentos Internos (2)

\begin{tabular}{l|cc}
\hline \hline & \multicolumn{2}{|c}{ Modelo 3 } \\
\hline Variável & Coeficiente & Erro Padrão \\
\hline \hline \multicolumn{3}{|c}{ Coeficientes de LP } \\
\hline CrescPIB & $-0.146^{* *}$ & $(0.0362)$ \\
AberEcon & $-0.0724^{* *}$ & $(0.0142)$ \\
DivBruta & $-0.333^{* *}$ & $(0.0736)$ \\
DivBruta2 & $0.00332^{* *}$ & $(0.00113)$ \\
\hline \multicolumn{3}{|c}{ Coeficientes de CP - Média } \\
\hline CorrErros & $-0.152^{* *}$ & $(0.0522)$ \\
TaxaMeta & $0.334^{* *}$ & $(0.0885)$ \\
Intercepto & $2.849^{* *}$ & $(0.995)$ \\
\hline Significância & $\dagger: 10 \% *: 5 \% * *: 1 \%$ &
\end{tabular}


Tabela 22 - Resultados Prévios - Fatores Externos: Aversão ao Risco e Políticas Monetária Global (1)

\begin{tabular}{|c|c|c|c|c|}
\hline & \multicolumn{2}{|c|}{ "Modelo 1} & \multicolumn{2}{|c|}{ Modelo 2} \\
\hline Variável & Coeficiente & Erro Padrão & Coeficiente & Erro Padrão \\
\hline \multicolumn{5}{|c|}{ Coeficientes de LP } \\
\hline TaxaLivreRisco & $0.645^{* *}$ & $(0.0668)$ & $0.376^{* *}$ & $(0.104)$ \\
\hline HighYield & $0.235^{* *}$ & $(0.0230)$ & $0.237^{* *}$ & $(0.0268)$ \\
\hline SaldoCC & $-0.112^{* *}$ & $(0.0208)$ & $-0.218^{* *}$ & $(0.0491)$ \\
\hline CrescPIB & -0.0206 & $(0.0219)$ & $0.0873^{* *}$ & $(0.0266)$ \\
\hline Inflacao & $0.156^{* *}$ & $(0.0307)$ & 0.0456 & $(0.0381)$ \\
\hline AbertEcon & $-0.0102^{\dagger}$ & $(0.00574)$ & $-0.0453^{* *}$ & $(0.0107)$ \\
\hline SupNom & $-0.0794^{* *}$ & $(0.0292)$ & $-0.0764^{*}$ & $(0.0366)$ \\
\hline DivBruta & $-0.143^{* *}$ & $(0.0496)$ & $-0.0969^{*}$ & $(0.0385)$ \\
\hline DivBruta2 & $0.00202^{* *}$ & $(0.000582)$ & $0.00237^{* *}$ & $(0.000455)$ \\
\hline \multicolumn{5}{|c|}{ Coeficientes de CP - Média } \\
\hline CorrErros & $-0.345^{* *}$ & $(0.0598)$ & $-0.167^{*}$ & $(0.0696)$ \\
\hline TaxaLivreRisco & $0.477^{* *}$ & $(0.0906)$ & $0.457^{* *}$ & $(0.106)$ \\
\hline HighYield & $0.0488^{*}$ & $(0.0227)$ & 0.0388 & $(0.0269)$ \\
\hline TaxaMeta & $0.392^{* *}$ & $(0.108)$ & $0.313^{* *}$ & $(0.0858)$ \\
\hline SaldoCC & -0.0196 & $(0.117)$ & & \\
\hline CrescPIB & -0.0508 & $(0.0411)$ & & \\
\hline Inflacao & 0.0559 & $(0.0475)$ & & \\
\hline AbertEcon & 0.00109 & $(0.0352)$ & & \\
\hline SupNom & 0.0579 & $(0.0620)$ & & \\
\hline DivBruta & -0.110 & $(0.472)$ & & \\
\hline DivBruta2 & -0.00383 & $(0.0218)$ & & \\
\hline Intercepto & $1.628^{* *}$ & $(0.425)$ & $0.961^{*}$ & $(0.416)$ \\
\hline Significância & $\dagger: 10 \% *: 5 \% * *: 1 \%$ & & & \\
\hline
\end{tabular}


Tabela 23 - Resultados Prévios - Fatores Externos: Aversão ao Risco e Políticas Monetária Global (2)

\begin{tabular}{|c|c|c|c|c|}
\hline & \multicolumn{2}{|c|}{ Modelo 3} & \multicolumn{2}{|c|}{ Modelo 4} \\
\hline Variável & Coeficiente & Erro Padrão & Coeficiente & Erro Padrão \\
\hline \multicolumn{5}{|c|}{ Coeficientes de LP } \\
\hline TaxaLivreRisco & $0.485^{* *}$ & $(0.113)$ & $0.480^{* *}$ & $(0.113)$ \\
\hline HighYield & $0.194^{* *}$ & $(0.0233)$ & $0.183^{* *}$ & $(0.0222)$ \\
\hline SaldoCC & $-0.211^{* *}$ & $(0.0509)$ & $-0.208^{* *}$ & $(0.0518)$ \\
\hline CrescPIB & $0.0884^{* *}$ & $(0.0280)$ & $0.0914^{* *}$ & $(0.0285)$ \\
\hline Inflacao & $0.103^{* *}$ & $(0.0366)$ & $0.113^{* *}$ & $(0.0367)$ \\
\hline AbertEcon & $-0.0480^{* *}$ & $(0.0112)$ & $-0.0561^{* *}$ & $(0.00923)$ \\
\hline SupNom & -0.0455 & $(0.0385)$ & & \\
\hline DivBruta & -0.0583 & $(0.0449)$ & -0.0505 & $(0.0441)$ \\
\hline DivBruta2 & $0.00190^{* *}$ & $(0.000530)$ & $0.00192^{* *}$ & $(0.000526)$ \\
\hline \multicolumn{5}{|c|}{ Coeficientes de CP - Média } \\
\hline CorrErros & $-0.166^{*}$ & $(0.0690)$ & $-0.165^{*}$ & $(0.0677)$ \\
\hline TaxaLivreRisco & $0.388^{* *}$ & $(0.105)$ & $0.385^{* *}$ & $(0.106)$ \\
\hline TaxaMeta & $0.352^{* *}$ & $(0.0840)$ & $0.353^{* *}$ & $(0.0828)$ \\
\hline Intercepto & $0.852^{*}$ & $(0.382)$ & $0.927^{*}$ & $(0.400)$ \\
\hline Significância & $\dagger: 10 \% *: 5 \% * *: 1 \%$ & & & \\
\hline
\end{tabular}

Tabela 24 - Resultados Prévios - Fatores Externos: Aversão ao Risco, Políticas Monetária e Fiscal Globais (1)

\begin{tabular}{l|cc|cc}
\hline \hline & \multicolumn{2}{|c|}{ Modelo 1 } & \multicolumn{2}{c}{ Modelo 2 } \\
\hline Variável & Coeficiente & Erro Padrão & Coeficiente & Erro Padrão \\
\hline \hline \multicolumn{3}{|c}{ Coeficientes de LP } & \\
\hline TaxaLivreRisco & $0.487^{* *}$ & $(0.172)$ & $0.376^{* *}$ & $(0.142)$ \\
HighYield & $0.170^{* *}$ & $(0.0403)$ & $0.0915^{*}$ & $(0.0387)$ \\
SaldoCC & $-0.307^{* *}$ & $(0.0704)$ & 0.0213 & $(0.0189)$ \\
CrescPIB & $0.0838^{*}$ & $(0.0409)$ & -0.0376 & $(0.0268)$ \\
Inflacao & $0.123^{*}$ & $(0.0522)$ & $0.0965^{* *}$ & $(0.0362)$ \\
AbertEcon & $-0.0822^{* *}$ & $(0.0203)$ & $-0.0267^{* *}$ & $(0.00843)$ \\
SupNom & -0.0891 & $(0.0602)$ & -0.0449 & $(0.0396)$ \\
DivBruta & -0.0538 & $(0.0552)$ & $-0.128^{*}$ & $(0.0502)$ \\
DivBruta2 & $0.00205^{* *}$ & $(0.000597)$ & $0.00131^{*}$ & $(0.000664)$ \\
USASupNom & $0.156^{*}$ & $(0.0649)$ & 0.0119 & $(0.0321)$ \\
USADivBruta & 0.0204 & $(0.0125)$ & -0.00555 & $(0.00984)$ \\
\hline \multicolumn{2}{l|}{ Coeficientes de CP - Média } & & $(0.0543)$ \\
CorrErros & $-0.158^{*}$ & $(0.0686)$ & $-0.281^{* *}$ & $(0.107)$ \\
TaxaLivreRisco & $0.400^{* *}$ & $(0.0931)$ & $0.314^{* *}$ & $(0.0809)$ \\
TaxaMeta & $0.384^{* *}$ & $(0.0793)$ & $0.400^{* *}$ & $(0.0494)$ \\
USASupNom & $-0.0921^{* *}$ & $(0.0239)$ & $-0.141^{* *}$ & $(0.720)$ \\
USADivBruta & 0.0182 & $(0.0173)$ & & \\
Intercepto & $0.874^{*}$ & $(0.380)$ & $2.753^{* *}$ & \\
\hline Significância & $\dagger: 10 \% *: 5 \% * *: 1 \%$ & & &
\end{tabular}


Tabela 25 - Resultados Prévios - Fatores Externos: Aversão ao Risco, Políticas Monetária e Fiscal Globais (2)

\begin{tabular}{|c|c|c|c|c|}
\hline & \multicolumn{2}{|c|}{ Modelo 3} & \multicolumn{2}{|c|}{ Modelo 4} \\
\hline Variável & Coeficiente & Erro Padrão & Coeficiente & Erro Padrão \\
\hline \multicolumn{5}{|c|}{ Coeficientes de LP } \\
\hline TaxaLivreRisco & $0.444^{* *}$ & $(0.0994)$ & $0.500^{* *}$ & $(0.101)$ \\
\hline HighYield & $0.124^{* *}$ & $(0.0256)$ & $0.106^{* *}$ & $(0.0271)$ \\
\hline SaldoCC & $-0.266^{* *}$ & $(0.0555)$ & $-0.313^{* *}$ & $(0.0601)$ \\
\hline CrescPIB & 0.0364 & $(0.0286)$ & & \\
\hline Inflacao & $0.0839^{*}$ & $(0.0396)$ & $0.0884^{*}$ & $(0.0439)$ \\
\hline AbertEcon & $-0.0413^{* *}$ & $(0.0125)$ & $-0.0392^{* *}$ & $(0.00939)$ \\
\hline SupNom & -0.0386 & $(0.0375)$ & & \\
\hline DivBruta & $-0.119^{* *}$ & $(0.0451)$ & $-0.157^{* *}$ & $(0.0497)$ \\
\hline DivBruta2 & $0.00232^{* *}$ & $(0.000519)$ & $0.00275^{* *}$ & $(0.000572)$ \\
\hline \multicolumn{5}{|c|}{ Coeficientes de CP - Média } \\
\hline CorrErros & $-0.192^{*}$ & $(0.0763)$ & $-0.185^{*}$ & $(0.0738)$ \\
\hline TaxaLivrRisco & $0.352^{* *}$ & $(0.110)$ & $0.346^{* *}$ & $(0.110)$ \\
\hline TaxaMeta & $0.396^{* *}$ & $(0.0791)$ & $0.393^{* *}$ & $(0.0802)$ \\
\hline USASupNom & $-0.134^{* *}$ & $(0.0359)$ & $-0.141^{* *}$ & $(0.0385)$ \\
\hline Intercepto & $1.386^{*}$ & $(0.570)$ & $1.472^{*}$ & $(0.608)$ \\
\hline Significância & $\dagger: 10 \% *: 5 \% * *: 1 \%$ & & & \\
\hline
\end{tabular}





\section{Apêndice D}

Tabela 26 - Resultados por País - Apenas Fundamentos Internos

\begin{tabular}{lcc}
\hline \hline Variável & Coeficiente & (Erro Padrão) \\
\hline \hline \multicolumn{3}{c}{ Coeficientes de LP } \\
\hline CrescPIB & $-0.146^{* *}$ & $(0.036)$ \\
AberEcon & $-0.072^{* *}$ & $(0.014)$ \\
DivBruta & $-0.333^{* *}$ & $(0.074)$ \\
DivBruta2 & $0.003^{* *}$ & $(0.001)$ \\
\hline \multicolumn{3}{c}{ Coeficientes de CP: Brasil } \\
\hline CorrErros & $-0.261^{* *}$ & $(0.100)$ \\
TaxaMeta & $0.447^{* *}$ & $(0.165)$ \\
Intercepto & $5.915^{*}$ & $(2.282)$ \\
\hline \multicolumn{3}{c}{ Coeficientes de CP: Bulgária } \\
\hline CorrErros & $0.156^{*}$ & $(0.068)$ \\
TaxaMeta & 0.214 & $(0.162)$ \\
Intercepto & $-2.949{ }^{*}$ & $(1.238)$ \\
\hline \multicolumn{3}{c}{ Coeficientes de CP: Chile } \\
\hline CorrErros & $-0.352^{* *}$ & $(0.103)$ \\
TaxaMeta & $0.150^{*}$ & $(0.076)$ \\
Intercepto & $4.982^{* *}$ & $(1.408)$ \\
\hline \multicolumn{3}{c}{ Coeficientes de CP: China } \\
\hline CorrErros & -0.033 & $(0.044)$ \\
TaxaMeta & $0.580^{* *}$ & $(0.179)$ \\
Intercepto & 0.462 & $(0.599)$ \\
\hline \multicolumn{2}{c}{ Coeficientes de CP: Colômbia } \\
\hline CorrErros & -0.025 & $(0.058)$ \\
TaxaMeta & $0.557^{* *}$ & $(0.135)$ \\
Intercepto & 0.461 & $(1.119)$ \\
\hline \multicolumn{3}{c}{}
\end{tabular}


Tabela 27 - Resultados por País - Apenas Fundamentos Internos (continuação)

\begin{tabular}{|c|c|c|}
\hline Variável & Coeficiente & (Erro Padrão) \\
\hline \multicolumn{3}{|c|}{ Coeficientes de CP: República Tcheca } \\
\hline CorrErros & $-0.153^{\dagger}$ & $(0.081)$ \\
\hline TaxaMeta & 0.222 & $(0.226)$ \\
\hline Intercepto & $3.082^{\dagger}$ & $(1.633)$ \\
\hline \multicolumn{3}{|c|}{ Coeficientes de CP: Hungria } \\
\hline CorrErros & -0.027 & $(0.079)$ \\
\hline TaxaMeta & $0.533^{* *}$ & $(0.169)$ \\
\hline Intercepto & 0.677 & $(1.990)$ \\
\hline \multicolumn{3}{|c|}{ Coeficientes de CP: Malásia } \\
\hline CorrErros & -0.051 & $(0.051)$ \\
\hline TaxaMeta & -0.203 & $(0.237)$ \\
\hline Intercepto & 1.232 & $(1.221)$ \\
\hline \multicolumn{3}{|c|}{ Coeficientes de CP: México } \\
\hline CorrErros & $-0.509^{* *}$ & $(0.107)$ \\
\hline TaxaMeta & $0.272^{\dagger}$ & $(0.156)$ \\
\hline Intercepto & $9.770^{* *}$ & $(2.191)$ \\
\hline \multicolumn{3}{|c|}{ Coeficientes de CP: Polônia } \\
\hline CorrErros & 0.035 & $(0.077)$ \\
\hline TaxaMeta & 0.020 & $(0.153)$ \\
\hline Intercepto & -0.803 & $(1.575)$ \\
\hline \multicolumn{3}{|c|}{ Coeficientes de CP: Russia } \\
\hline CorrErros & -0.163 & $(0.102)$ \\
\hline TaxaMeta & $1.096^{* *}$ & $(0.163)$ \\
\hline Intercepto & 2.409 & $(1.510)$ \\
\hline \multicolumn{3}{|c|}{ Coeficientes de CP: Africa do Sul } \\
\hline CorrErros & $-0.387^{* *}$ & $(0.108)$ \\
\hline TaxaMeta & $0.205^{\dagger}$ & $(0.122)$ \\
\hline Intercepto & $7.897^{* *}$ & $(2.263)$ \\
\hline \multicolumn{3}{|c|}{ Coeficientes de CP: Coreia do Sul } \\
\hline CorrErros & $-0.207^{*}$ & $(0.081)$ \\
\hline TaxaMeta & $0.244^{*}$ & $(0.106)$ \\
\hline Intercepto & $3.910^{* *}$ & $(1.490)$ \\
\hline
\end{tabular}

Significância $\dagger: 10 \% *: 5 \% * *: 1 \%$ 
Tabela 28 - Resultados por País - Fatores Externos: Aversão ao Risco e Política Monetária Global

\begin{tabular}{|c|c|c|}
\hline Variável & Coeficiente & (Erro Padrão) \\
\hline \multicolumn{3}{|c|}{ Coeficientes de LP } \\
\hline TaxaLivreRisco & $0.480^{* *}$ & $(0.113)$ \\
\hline HighYield & $0.183^{* *}$ & $(0.022)$ \\
\hline SaldoCC & $-0.208^{* *}$ & $(0.052)$ \\
\hline CrescPIB & $0.091^{* *}$ & $(0.029)$ \\
\hline Inflacao & $0.113^{* *}$ & $(0.037)$ \\
\hline AbertEcon & $-0.056^{* *}$ & $(0.009)$ \\
\hline DivBruta & -0.051 & $(0.044)$ \\
\hline DivBruta2 & $0.002^{* *}$ & $(0.001)$ \\
\hline \multicolumn{3}{|c|}{ Coeficientes de CP: Brasil } \\
\hline CorrErros & $-0.611^{* *}$ & $(0.143)$ \\
\hline TaxaLivreRisco & 0.344 & $(0.348)$ \\
\hline TaxaMeta & $0.628^{* *}$ & $(0.149)$ \\
\hline Intercepto & $3.742^{* *}$ & $(1.306)$ \\
\hline \multicolumn{3}{|c|}{ Coeficientes de CP: Bulgária } \\
\hline CorrErros & $-0.075^{* *}$ & $(0.024)$ \\
\hline TaxaLivreRisco & -0.063 & $(0.192)$ \\
\hline TaxaMeta & 0.104 & $(0.149)$ \\
\hline Intercepto & $0.475^{*}$ & $(0.235)$ \\
\hline \multicolumn{3}{|c|}{ Coeficientes de CP: Chile } \\
\hline CorrErros & 0.165 & $(0.132)$ \\
\hline TaxaLivreRisco & $0.885^{* *}$ & $(0.185)$ \\
\hline TaxaMeta & -0.006 & $(0.120)$ \\
\hline Intercepto & -1.008 & $(0.853)$ \\
\hline \multicolumn{3}{|c|}{ Coeficientes de CP: China } \\
\hline CorrErros & -0.073 & $(0.077)$ \\
\hline TaxaLivreRisco & $0.317^{*}$ & $(0.135)$ \\
\hline TaxaMeta & $0.502^{* *}$ & $(0.168)$ \\
\hline Intercepto & 0.313 & $(0.294)$ \\
\hline
\end{tabular}


Tabela 29 - Resultados por País - Fatores Externos: Aversão ao Risco e Política Monetária Global (continuação)

\begin{tabular}{|c|c|c|}
\hline Variável & Coeficiente & (Erro Padrão) \\
\hline \multicolumn{3}{|c|}{ Coeficientes de CP: Colômbia } \\
\hline CorrErros & 0.046 & $(0.081)$ \\
\hline TaxaLivreRisco & $0.794^{* *}$ & $(0.260)$ \\
\hline TaxaMeta & $0.607^{* *}$ & $(0.120)$ \\
\hline Intercepto & -0.202 & $(0.427)$ \\
\hline \multicolumn{3}{|c|}{ Coeficientes de CP: República Tcheca } \\
\hline CorrErros & $-0.611^{* *}$ & $(0.092)$ \\
\hline TaxaLivreRisco & $0.396^{* *}$ & $(0.093)$ \\
\hline TaxaMeta & $0.389^{*}$ & $(0.188)$ \\
\hline Intercepto & $4.040^{* *}$ & $(1.131)$ \\
\hline \multicolumn{3}{|c|}{ Coeficientes de CP: Hungria } \\
\hline CorrErros & $-0.182^{*}$ & $(0.091)$ \\
\hline TaxaLivreRisco & -0.243 & $(0.274)$ \\
\hline TaxaMeta & $0.442^{* *}$ & $(0.151)$ \\
\hline Intercepto & 0.911 & $(0.653)$ \\
\hline \multicolumn{3}{|c|}{ Coeficientes de CP: Malásia } \\
\hline CorrErros & 0.000 & $(0.024)$ \\
\hline TaxaLivreRisco & $0.491^{* *}$ & $(0.111)$ \\
\hline TaxaMeta & -0.142 & $(0.189)$ \\
\hline Intercepto & 0.033 & $(0.230)$ \\
\hline \multicolumn{3}{|c|}{ Coeficientes de CP: México } \\
\hline CorrErros & -0.009 & $(0.102)$ \\
\hline TaxaLivreRisco & $0.715^{* *}$ & $(0.174)$ \\
\hline TaxaMeta & $0.347^{*}$ & $(0.141)$ \\
\hline Intercepto & 0.092 & $(0.580)$ \\
\hline
\end{tabular}


Tabela 30 - Resultados por País - Fatores Externos: Aversão ao Risco e Política Monetária Global (continuação)

\begin{tabular}{lcc}
\hline \multicolumn{1}{c}{ Variável } & Coeficiente & (Erro Padrão) \\
\hline \hline \multicolumn{3}{c}{ Coeficientes de CP: Polônia } \\
\hline CorrErros & $-0.459^{* *}$ & $(0.104)$ \\
TaxaLivreRisco & $0.373^{* *}$ & $(0.106)$ \\
TaxaMeta & $0.376^{* *}$ & $(0.128)$ \\
Intercepto & 1.289 & $(0.930)$ \\
\hline \multicolumn{3}{c}{ Coeficientes de CP: Russia } \\
\hline CorrErros & $-0.127^{\dagger}$ & $(0.074)$ \\
TaxaLivreRisco & -0.284 & $(0.351)$ \\
TaxaMeta & $0.980^{* *}$ & $(0.165)$ \\
Intercepto & 1.004 & $(0.613)$ \\
\hline \multicolumn{3}{c}{ Coeficientes de CP: Africa do Sul } \\
\hline CorrErros & -0.094 & $(0.078)$ \\
TaxaLivreRisco & $0.751^{* *}$ & $(0.169)$ \\
TaxaMeta & 0.118 & $(0.105)$ \\
Intercepto & 0.652 & $(0.512)$ \\
\hline \multicolumn{4}{c}{ Coeficientes de CP: Coreia do Sul } \\
\hline CorrErros & $-0.114^{* *}$ & $(0.037)$ \\
TaxaLivreRisco & $0.527^{* *}$ & $(0.085)$ \\
TaxaMeta & $0.239^{* *}$ & $(0.077)$ \\
Intercepto & $0.712^{*}$ & $(0.297)$ \\
\hline Significância & $\dagger: 10 \% *: 5 \% * *: 1 \%$ &
\end{tabular}


Tabela 31 - Resultados por País - Fatores Externos: Aversão ao Risco, Políticas Monetária e Fiscal Globais

\begin{tabular}{lcc}
\hline \hline \multicolumn{1}{c}{ Variável } & Coeficiente & (Erro Padrão) \\
\hline \hline TaxaLivreRisco & $0.500^{* *}$ & $(0.101)$ \\
HighYield & $0.106^{* *}$ & $(0.027)$ \\
SaldoCC & $-0.313^{* *}$ & $(0.060)$ \\
Inflacao & $0.088^{*}$ & $(0.044)$ \\
AbertEcon & $-0.039^{* *}$ & $(0.009)$ \\
DivBruta & $-0.157^{* *}$ & $(0.050)$ \\
DivBruta2 & $0.003^{* *}$ & $(0.001)$ \\
\hline \multicolumn{3}{c}{ Coeficientes de CP: Brasil } \\
\hline CorrErros & $-0.735^{* *}$ & $(0.139)$ \\
TaxaLivreRisco & 0.091 & $(0.329)$ \\
TaxaMeta & $0.693^{* *}$ & $(0.144)$ \\
USASupNom & $-0.501^{* *}$ & $(0.173)$ \\
Intercepto & $7.276^{* *}$ & $(1.708)$ \\
\hline \multicolumn{3}{c}{ Coeficientes de CP: Bulgária } \\
\hline CorrErros & -0.024 & $(0.021)$ \\
TaxaLivreRisco & -0.071 & $(0.175)$ \\
TaxaMeta & $0.362^{*}$ & $(0.160)$ \\
USASupNom & $-0.298^{* *}$ & $(0.105)$ \\
Intercepto & 0.139 & $(0.152)$ \\
\hline \multicolumn{3}{c}{ Coeficientes de CP: Chile } \\
\hline CorrErros & 0.155 & $(0.121)$ \\
TaxaLivreRisco & $0.930^{* *}$ & $(0.184)$ \\
TaxaMeta & 0.030 & $(0.122)$ \\
USASupNom & -0.086 & $(0.095)$ \\
Intercepto & -1.044 & $(0.868)$ \\
\hline
\end{tabular}


Tabela 33 - Resultados por País- Fatores Externos: Aversão ao Risco, Políticas Monetária e Fiscal Globais (continuação)

\begin{tabular}{|c|c|c|}
\hline Variável & Coeficiente & (Erro Padrão) \\
\hline \multicolumn{3}{|c|}{ Coeficientes de CP: China } \\
\hline CorrErros & -0.005 & $(0.062)$ \\
\hline TaxaLivreRisco & $0.313^{*}$ & $(0.136)$ \\
\hline TaxaMeta & $0.483^{* *}$ & $(0.175)$ \\
\hline USASupNom & 0.038 & $(0.066)$ \\
\hline Intercepto & 0.080 & $(0.402)$ \\
\hline \multicolumn{3}{|c|}{ Coeficientes de CP: Colômbia } \\
\hline CorrErros & 0.001 & $(0.092)$ \\
\hline TaxaLivreRisco & $0.754^{* *}$ & $(0.267)$ \\
\hline TaxaMeta & $0.654^{* *}$ & $(0.141)$ \\
\hline USASupNom & -0.100 & $(0.166)$ \\
\hline Intercepto & 0.030 & $(0.751)$ \\
\hline \multicolumn{3}{|c|}{ Coeficientes de CP: República Tcheca } \\
\hline CorrErros & $-0.481^{* *}$ & $(0.103)$ \\
\hline TaxaLivreRisco & $0.387^{* *}$ & $(0.108)$ \\
\hline TaxaMeta & 0.139 & $(0.199)$ \\
\hline USASupNom & -0.086 & $(0.066)$ \\
\hline Intercepto & $3.560^{* *}$ & $(1.069)$ \\
\hline \multicolumn{3}{|c|}{ Coeficientes de CP: Hungria } \\
\hline CorrErros & -0.135 & $(0.087)$ \\
\hline TaxaLivreRisco & -0.296 & $(0.278)$ \\
\hline TaxaMeta & $0.415^{* *}$ & $(0.158)$ \\
\hline USASupNom & -0.092 & $(0.128)$ \\
\hline Intercepto & 0.812 & $(0.646)$ \\
\hline \multicolumn{3}{|c|}{ Coeficientes de CP: Malásia } \\
\hline CorrErros & -0.004 & $(0.025)$ \\
\hline TaxaLivreRisco & $0.487^{* *}$ & $(0.112)$ \\
\hline TaxaMeta & -0.096 & $(0.243)$ \\
\hline USASupNom & -0.022 & $(0.071)$ \\
\hline Intercepto & 0.084 & $(0.310)$ \\
\hline \multicolumn{3}{|c|}{ Coeficientes de CP: México } \\
\hline CorrErros & $-0.270^{*}$ & $(0.112)$ \\
\hline TaxaLivreRisco & $0.597^{* *}$ & $(0.159)$ \\
\hline TaxaMeta & $0.577^{* *}$ & $(0.149)$ \\
\hline USASupNom & $-0.210^{* *}$ & $(0.079)$ \\
\hline Intercepto & $2.254^{*}$ & $(1.001)$ \\
\hline
\end{tabular}


Tabela 35 - Resultados por País - Fatores Externos: Aversão ao Risco, Políticas Monetária e Fiscal Globais (continuação)

\begin{tabular}{lcc}
\hline \multicolumn{1}{c}{ Variável } & Coeficiente & (Erro Padrão) \\
\hline \hline \multicolumn{3}{c}{ Coeficientes de CP: Polônia } \\
\hline CorrErros & $-0.612^{* *}$ & $(0.118)$ \\
TaxaLivreRisco & $0.346^{* *}$ & $(0.098)$ \\
TaxaMeta & $0.399^{* *}$ & $(0.136)$ \\
USASupNom & -0.087 & $(0.066)$ \\
Intercepto & $3.217^{*}$ & $(1.366)$ \\
\hline \multicolumn{3}{c}{ Coeficientes de CP: Russia } \\
\hline CorrErros & $-0.149^{\dagger}$ & $(0.086)$ \\
TaxaLivreRisco & -0.326 & $(0.342)$ \\
TaxaMeta & $0.959^{* *}$ & $(0.161)$ \\
USASupNom & -0.218 & $(0.145)$ \\
Intercepto & $1.398^{\dagger}$ & $(0.832)$ \\
\hline \multicolumn{3}{c}{ Coeficientes de CP: Africa do Sul } \\
\hline CorrErros & -0.048 & $(0.070)$ \\
TaxaLivreRisco & $0.773^{* *}$ & $(0.167)$ \\
TaxaMeta & 0.203 & $(0.125)$ \\
USASupNom & -0.110 & $(0.090)$ \\
Intercepto & 0.461 & $(0.579)$ \\
\hline \multicolumn{4}{c}{ Coeficientes de CP: Coreia do Sul } \\
\hline CorrErros & $-0.102^{*}$ & $(0.043)$ \\
TaxaLivreRisco & $0.510^{* *}$ & $(0.086)$ \\
TaxaMeta & $0.290^{* *}$ & $(0.085)$ \\
USASupNom & -0.064 & $(0.044)$ \\
Intercepto & $0.868^{*}$ & $(0.390)$ \\
\hline Significâcia & $: 10 \% * 5 \% * * 1 \%$ & \\
\hline
\end{tabular}

Significância $\quad \dagger: 10 \% *: 5 \% * *: 1 \%$ 


\section{Apêndice $E$}

Tabela 37 - Resultados Estimados - Pooled Mean Group

\begin{tabular}{lccc}
\hline \multicolumn{1}{c}{ Variável } & Coeficiente & (Erro Padrão) & P-Valor \\
\hline \hline \multicolumn{4}{c}{ Coeficientes de LP } \\
\hline JurosMedio & $1.361^{* *}$ & $(0.146)$ & $0.0 \%$ \\
SaldoCC & -0.084 & $(0.073)$ & $25.2 \%$ \\
CrescPIB & $-0.101^{* *}$ & $(0.038)$ & $0.1 \%$ \\
Inflacao & $0.308^{* *}$ & $(0.099)$ & $0.0 \%$ \\
AbertEcon & 0.018 & $(0.020)$ & $37.8 \%$ \\
DivBruta & -0.100 & $(0.080)$ & $21.0 \%$ \\
DivBruta2 & $0.002^{\dagger}$ & $(0.001)$ & $8.3 \%$ \\
\hline \multicolumn{4}{c}{ Coeficientes de CP - Média ${ }^{3}$} \\
\hline CorrErros & $-0.109^{\dagger}$ & $(0.061)$ \\
JurosMedio & $0.944^{* *}$ & $(0.148)$ & $7.6 \%$ \\
TaxaMeta & $0.216^{\dagger}$ & $(0.125)$ & $8.0 \%$ \\
Intercepto & -0.037 & $(0.216)$ \\
\hline \multicolumn{4}{c}{$86.5 \%$} \\
\hline N & 416 \\
Log-likelihood & \multicolumn{4}{c}{$* 114.75$} \\
\hline Significância : $\dagger: 10 \%$ & $*: 5 \%$ \\
\hline
\end{tabular}

Tabela 38 - Resultados Estimados - Pooled Mean Group

\begin{tabular}{|c|c|c|c|}
\hline Variável & Coeficiente & (Erro Padrão) & P-Valor \\
\hline \multicolumn{4}{|c|}{ Coeficientes de LP } \\
\hline JurosMedio & $1.210^{* *}$ & $(0.133)$ & $0.0 \%$ \\
\hline SaldoCC & 0.203 & $(0.067)$ & $76.3 \%$ \\
\hline Inflacao & $0.561^{* *}$ & $(0.094)$ & $0.0 \%$ \\
\hline AbertEcon & -0.015 & $(0.018)$ & $41.2 \%$ \\
\hline DivBruta & $-0.419^{* *}$ & $(0.084)$ & $0.0 \%$ \\
\hline DivBruta2 & $0.006^{* *}$ & $(0.001)$ & $0.0 \%$ \\
\hline \multicolumn{4}{|c|}{ Coeficientes de CP - Média ${ }^{3}$} \\
\hline CorrErros & $-0.124^{\dagger}$ & $(0.073)$ & $8.9 \%$ \\
\hline JurosMedio & $0.915^{* *}$ & $(0.144)$ & $0.0 \%$ \\
\hline TaxaMeta & $0.236^{*}$ & $(0.109)$ & $3.0 \%$ \\
\hline USASupNom & -0.011 & $(0.037)$ & $75.9 \%$ \\
\hline Intercepto & 0.784 & $(0.478)$ & $10.1 \%$ \\
\hline $\mathrm{N}$ & & 416 & \\
\hline Log-likelihood & & 05.94 & \\
\hline
\end{tabular}



13 Apêndice $F$ 
Tabela 39 - Taxas de Juros de Longo Prazo

\begin{tabular}{lll} 
& Fonte & Link \\
\hline Brasil & Thomson Reuters & Ticker DataStream: BRGBOND. \\
Bulgaria & Thomson Reuters & Ticker DataStream: BLGBOND. \\
Chile & OECD & Ticker DataStream: CLMIR080R \\
China & Data Stream & Ticker DataStream: CHGBOND. \\
Colombia & Thomson Reuters & Ticker DataStream: CBGB10.. \\
Republica Tcheca & OECD & Ticker DataStream: CZOIR080R \\
Hungria & OECD & Ticker DataStream: HNOIR080R \\
Malasia & Central Bank of Malaysia & Ticker DataStream: MYGBOND. \\
Mexico & OECD & Ticker DataStream: MXMIR080R \\
Polonia & Thomson Reuters & Ticker DataStream: POGBOND. \\
Russia & Thomson Reuters & Ticker DataStream: RSGBOND. \\
Africa do Sul & OECD & Ticker DataStream: SAMIR080R \\
Coreia do Sul & OECD & Ticker DataStream: KOOIR080R \\
\hline
\end{tabular}


Tabela 40 - Dívida Bruta

Fonte Link

\begin{tabular}{lll}
\hline Brasil & Oxford Economics & Ticker DataStream: BRXGGG\%.R \\
Bulgaria & Oxford Economics & Ticker DataStream: BLXGGG\%.R \\
Chile & Oxford Economics & Ticker DataStream: CLXGGG\%.R \\
China & Oxford Economics & Ticker DataStream: CHXGGG\%.R \\
Colombia & Oxford Economics & Ticker DataStream: CBXGGG\%. \\
Republica Tcheca & Oxford Economics & Ticker DataStream: CZXGGG\%.R \\
Hungria & Oxford Economics & Ticker DataStream: HNXGGG\%.R \\
Malasia & Oxford Economics & Ticker DataStream: MYXGGG\%.R \\
Mexico & Oxford Economics & Ticker DataStream: MXXGGG\%.R \\
Polonia & Oxford Economics & Ticker DataStream: POXGGG\%.R \\
Russia & Oxford Economics & Ticker DataStream: RSXGGG\%.R \\
Africa do Sul & Oxford Economics & Ticker DataStream: SAXGGG\%.R \\
Coreia do Sul & Oxford Economics & Ticker DataStream: KOXGGG\%.R \\
\hline
\end{tabular}


Tabela 41 - Superávit Nominal

\begin{tabular}{ll} 
Fonte & Link \\
\hline Bloomberg & Ticker Bloomberg: EHBBBR Index \\
NSI of Bulgaria & Ticker Bloomberg: BGGBRLEB Index \\
DIPRES & http://www.dipres.gob.cl/594/w3-propertyvalue-15407.html \\
National Bureau of Statistics of China & Ticker Bloomberg: CHGETTL Index e CHGRTTL Index \\
Banco Central de la Republica de Colombia & Ticker Bloomberg: CCGODESU Index \\
Ministry of Finance Czech Republic & Ticker Bloomberg: CZSBBAL Index \\
Hungary Finance Ministry & Ticker Bloomberg: HUGBCBAL Index \\
Ministry of Finance Malaysia & http://www.treasury.gov.my/index.php?option=com \\
& content\&view=category\&id=264\&Itemid=2480\&lang=en \\
Bloomberg & Ticker Bloomberg: EHBBMX Index \\
Eurostat & http://ec.europa.eu/eurostat/data/database \\
Bloomberg & Ticker Bloomberg: EHBBRU Index \\
Bloomberg & Ticker Bloomberg: EHBBZA Index \\
Bank of Korea & Ticker Bloomberg: KOGFBALM Index \\
&
\end{tabular}


Tabela 42 - Saldo em Conta Corrente

\begin{tabular}{lll} 
& Fonte & Link \\
\hline Brasil & Bloomberg & Ticker Bloomberg: EHCABR Index \\
Bulgaria & Bloomberg & Ticker Bloomberg: EHCABG Index \\
Chile & Bloomberg & Ticker Bloomberg: EHCACL Index \\
China & Bloomberg & Ticker Bloomberg: EHCACN Index \\
Colombia & Bloomberg & Ticker Bloomberg: EHCACO Index \\
Republica Tcheca & Bloomberg & Ticker Bloomberg: EHCACZ Index \\
Hungria & National Bank of Hungary & Ticker Bloomberg: HUCQEURO Index \\
Malasia & Bloomberg & Ticker Bloomberg: EHCAMY Index \\
Mexico & Bloomberg & Ticker Bloomberg: EHCAMX Index \\
Polonia & Bloomberg & Ticker Bloomberg: EHCAPL Index \\
Russia & Bloomberg & Ticker Bloomberg: EHCARU Index \\
Africa do Sul & Bloomberg & Ticker Bloomberg: EHCAZA Index \\
Coreia do Sul & Bloomberg & Ticker Bloomberg: EHCACZ Index \\
\hline
\end{tabular}


Tabela 43 - Taxa de Juros de Curto Prazo

\begin{tabular}{lll} 
& Fonte & Link \\
\hline Brasil & Oxford Economics & Ticker DataStream: BRXRCB..R \\
Bulgaria & Oxford Economics & Ticker DataStream: BLXRCB..R \\
Chile & Oxford Economics & Ticker DataStream: CLXRCB..R \\
China & Oxford Economics & Ticker DataStream: CHXRCB..R \\
Colombia & FMI & Ticker DataStream: CBQ60... \\
Republica Tcheca & Oxford Economics & Ticker DataStream: CZXRCB..R \\
Hungria & Oxford Economics & Ticker DataStream: HNXRCB..R \\
Malasia & Oxford Economics & Ticker DataStream: MYXRCB..R \\
Mexico & Oxford Economics & Ticker DataStream: MXXRCB..R \\
Polonia & Oxford Economics & Ticker DataStream: POXRCB..R \\
Russia & Oxford Economics & Ticker DataStream: RSXRCB..R \\
Africa do Sul & Oxford Economics & Ticker DataStream: SAXRCB..R \\
Coreia do Sul & Oxford Economics & Ticker DataStream: KOXRCB..R \\
\hline
\end{tabular}


Tabela 44 - Inflação

\begin{tabular}{lll} 
& Fonte & Link \\
\hline Brasil & FMI & Ticker Bloomberg: 2236640 Index \\
Bulgaria & FMI & Ticker Bloomberg: 9186640 Index \\
Chile & FMI & Ticker Bloomberg: 2286640 Index \\
China & FMI & Ticker Bloomberg: 9246640 Index \\
Colombia & FMI & Ticker Bloomberg: 2336640 Index \\
Republica Tcheca & FMI & Ticker Bloomberg: 9356640 Index \\
Hungria & FMI & Ticker Bloomberg: 9446640 Index \\
Malasia & FMI & Ticker Bloomberg: 5486640 Index \\
Mexico & FMI & Ticker Bloomberg: 2736640 Index \\
Polonia & FMI & Ticker Bloomberg: 9646640 Index \\
Russia & FMI & Ticker Bloomberg: 9226640 Index \\
Africa do Sul & FMI & Ticker Bloomberg: 1996640 Index \\
Coreia do Sul & Korea National Statistical Office & Ticker Bloomberg: KOCPIYOY Index \\
\hline
\end{tabular}


Tabela 45 - Exportações

\begin{tabular}{lll} 
& Fonte & Link \\
\hline Brasil & Oxford Economics & Ticker DataStream : BRXXTN\%.R \\
Bulgaria & Oxford Economics & Ticker DataStream : BLXXTN\%.R \\
Chile & Oxford Economics & Ticker DataStream : CLXXTN\%.R \\
China & Oxford Economics & Ticker DataStream : CHXXTN\%.R \\
Colombia & Oxford Economics & Ticker DataStream : CBXXTN\%. \\
Republica Tcheca & Oxford Economics & Ticker DataStream : CZXXTN\%.R \\
Hungria & Oxford Economics & Ticker DataStream : HNXXTN\%.R \\
Malasia & Oxford Economics & Ticker DataStream : MYXXTN\%.R \\
Mexico & Oxford Economics & Ticker DataStream : MXXXTN\%.R \\
Polonia & Oxford Economics & Ticker DataStream : POXXTN\%.R \\
Russia & Oxford Economics & Ticker DataStream : RSXXTN\%.R \\
Africa do Sul & Oxford Economics & Ticker DataStream : SAXXTN\%.R \\
Coreia do Sul & Oxford Economics & Ticker DataStream : KOXXTN\%.R \\
\hline
\end{tabular}


Tabela 46 - Importações

\begin{tabular}{lll} 
& Fonte & Link \\
\hline Brasil & Oxford Economics & Ticker DataStream: BRXMTN\%.R \\
Bulgaria & Oxford Economics & Ticker DataStream: BLXMTN\%.R \\
Chile & Oxford Economics & Ticker DataStream: CLXMTN\%.R \\
China & Oxford Economics & Ticker DataStream: CHXMTN\%.R \\
Colombia & Oxford Economics & Ticker DataStream: CBXMTN\%. \\
Republica Tcheca & Oxford Economics & Ticker DataStream: CZXMTN\%.R \\
Hungria & Oxford Economics & Ticker DataStream: HNXMTN\%.R \\
Malasia & Oxford Economics & Ticker DataStream: MYXMTN\%.R \\
Mexico & Oxford Economics & Ticker DataStream: MXXMTN\%.R \\
Polonia & Oxford Economics & Ticker DataStream: POXMTN\%.R \\
Russia & Oxford Economics & Ticker DataStream: RSXMTN\%.R \\
Africa do Sul & Oxford Economics & Ticker DataStream: SAXMTN\%.R \\
Coreia do Sul & Oxford Economics & Ticker DataStream: KOXMTN\%.R \\
\hline
\end{tabular}


Tabela 47 - PIB Nominal

Fonte Link

\begin{tabular}{lll}
\hline Brasil & FMI & Ticker DataStream: BRI99B..A \\
Bulgaria & FMI & Ticker DataStream: BLI99B..A \\
Chile & FMI & Ticker DataStream: CLI99B..A \\
China & FMI & Ticker DataStream: CHI99BP.A \\
Colombia & FMI & Ticker DataStream: CBI99B.CB \\
Republica Tcheca & FMI & Ticker DataStream: CZI99B..A \\
Hungria & FMI & Ticker DataStream: HNI99B..A \\
Malasia & FMI & Ticker DataStream: MYI99B..A \\
Mexico & FMI & Ticker DataStream: MXI99BACB \\
Polonia & FMI & Ticker DataStream: POI99B..A \\
Russia & FMI & Ticker DataStream: RSI99BP.A \\
Africa do Sul & FMI & Ticker DataStream: SAI99BACB \\
Coreia do Sul & FMI & Ticker DataStream: KOI99B..A \\
\hline
\end{tabular}


Tabela 48 - PIB Real

\begin{tabular}{lll} 
& Fonte & Link \\
\hline Brasil & FMI & Ticker DataStream: BRI99BJ4C \\
Bulgaria & FMI & Ticker DataStream: BLI99B10C,BLI99BGYC \\
Chile & FMI & Ticker DataStream: CLI99BH4C \\
China & Oxford Economics & Ticker DataStream: CHXGDPR.C \\
Colombia & FMI & Ticker DataStream: CBI99B.RD \\
Republica Tcheca & FMI & Ticker DataStream: CZI99B10C \\
Hungria & FMI & Ticker DataStream: HNI99BOPC \\
Malasia & FMI & Ticker DataStream: MYI99BZOC \\
Mexico & FMI & Ticker DataStream: MXI99A08D \\
Polonia & FMI & Ticker DataStream: POI99BZOC \\
Russia & FMI & Ticker DataStream: RSI99BZOC \\
Africa do Sul & FMI & Ticker DataStream: SAI99BSGD \\
Coreia do Sul & FMI & Ticker DataStream: KOI99B10C \\
\hline
\end{tabular}

Tabela 49 - Fatores Externos

Fonte

Taxa de Juros Tesouro Americano 10 anos

Taxa High Yield Bonds

Orçamento Governo Americano

Dívida Bruta Governo Americano

\section{Link}

berg

Barclay's

Bloomberg

Ticker Bloomberg: USGG10YR Index

Ticker Bloomberg: LF98YW Index

Ticker Bloomberg: EHBBUS Index 